Documents de travail du Département des Affaires économiques de l'OCDE No. 1602

\title{
Répondre aux défis du marché du travail en Belgique
}

\section{Müge Adalet McGowan,}

Alexander Hijzen,

$$
\text { David Law, }
$$

Andrea Salvatori, Patrizio Sicari, Stefan Thewissen 
DEPARTEMENT DES AFFAIRES ECONOMIQUES

\section{RÉPONDRE AUX DÉFIS DU MARCHÉ DU TRAVAIL EN BELGIQUE DÉPARTEMENT DES AFFAIRES ÉCONOMIQUES DOCUMENT DE TRAVAIL No. 1602}

Par Müge Adalet McGowan, Alexander Hijzen, David Law, Andrea Salvatori, Patrizio Sicari et Stefan Thewissen

Les documents de l'OCDE ne doivent pas être présentés comme exprimant les vues officielles de I'OCDE ou de ses pays membres. Les opinions exprimées et les arguments sont ceux des auteurs.

Accord pour la publication par Isabell Koske, Directeur adjoint, Branche Études par pays, Département des affaires économiques.

Les documents de travail du Département Économiques sont disponibles à www.oecd.org/eco/documentsdetravail

JT03458819 
Les documents de travail de l'OCDE ne doivent pas être présentés comme exprimant les vues officielles de l'OCDE ou de ses pays membres. Les opinions exprimées et les arguments employés sont ceux des auteurs.

Les documents de travail exposent des résultats préliminaires ou des travaux de recherche en cours menés par l'auteur/les auteurs et sont publiés pour stimuler le débat sur un large éventail de questions sur lesquelles l'OCDE travaille.

Les commentaires sur les documents de travail sont les bienvenus et peuvent être adressés au Département des Affaires économiques, OCDE, 2 rue André-Pascal, 75775 Paris Cedex 16, France ou à l'adresse mél. suivante : eco.contact@oecd.org.

Les Documents de travail du Département des Affaires économiques sont disponibles à www.oecd.org/eco/workingpapers.

Le contenu ainsi que les données et toute carte qui y figurent sont sans préjudice du statut de tout territoire, de la souveraineté s'exerçant sur ce dernier, du tracé des frontières et limites internationales, et du nom de tout territoire, toute ville ou toute région.

Les données statistiques concernant Israël sont fournies par et sous la responsabilité des autorités israéliennes compétentes. L'utilisation de ces données par l'OCDE est sans préjudice du statut des hauteurs du Golan, de Jérusalem Est et des colonies de peuplement israéliennes en Cisjordanie aux termes du droit international.

\section{(c) OCDE (2020)}

Vous êtes autorisés à copier, télécharger ou imprimer du contenu OCDE pour votre utilisation personnelle. Vous pouvez inclure des extraits des publications, des bases de données et produits multimédia de l'OCDE dans vos documents, présentations, blogs, sites Internet et matériel d'enseignement, sous réserve de faire mention de la source OCDE et du copyright. Les demandes pour usage commercial ou de traduction devront être adressées à rights@oecd.org. 


\section{Abstract/Résumé \\ Répondre aux défis du marché du travail en Belgique}

La création d'emplois a contribué à faire reculer le chômage, mais le marché du travail belge demeure confronté à de nombreux défis. Les taux d'emploi restent bas en raison d'obstacles tels que le faible niveau des compétences et le manque d'incitations au travail. En outre, les mutations du travail vont obliger les travailleurs à s'adapter plus vite. Ce chapitre présente une analyse détaillée des actions à mener en priorité pour relever ces défis, en s'appuyant notamment sur les constatations de la Stratégie de l'OCDE pour l'emploi. L'une des priorités sera de faire en sorte que chaque travailleur ait accès à la formation tout au long de la vie, en prévoyant des allocations complémentaires pour les travailleurs en situation de désavantage. Pour améliorer les transitions vers l'emploi, il convient de généraliser l'utilisation des outils de profilage des risques individuels. Une réforme des allocations de chômage et des prestations liées à l'exercice d'un emploi permettrait de combiner plus harmonieusement aide au revenu et incitations au travail. La réforme de certains aspects de la législation en matière de protection de l'emploi, tels que ceux liés aux licenciements collectifs, et du système de formation des salaires amènerait davantage de flexibilité. Bien que la Belgique ait accompli des progrès notables sur le plan de la fiscalité et des besoins d'aide sociale associés à l'emploi atypique, quelques écarts persistent vis-à-vis des travailleurs réguliers.

Ce Document de travail a trait à l'Étude économique de l'OCDE de la Belgique, 2020 (http://www.oecd.org/fr/economie/belgique-en-un-coup-d-oeil/)

Classification JEL : J20; J30; J50; J60

Mots clés : politiques du marché du travail, emploi, compétences, incitations au travail, assurance chômage.

\section{Addressing labour market challenges in Belgium}

Job creation has lowered unemployment, but the Belgian labour market still faces many challenges. Employment rates remain low, reflecting barriers to finding a job such as low levels of skills and weak work incentives. In addition, the changing nature of work will require faster adaptation of workers. In order to address these challenges, this chapter presents a detailed analysis of policy priorities, drawing notably on insights from the OECD Jobs Strategy. One priority should be that each worker has access to lifelong training, with additional allowances targeted to disadvantaged workers. To improve transitions into work, the use of tools for the profiling of individualised risks should be extended. A better combination of income support and incentives could be achieved through reforming both unemployment and in-work benefits. Reforming some aspects of employment protection legislation, such as those related to collective dismissals, and the wage formation system, would boost flexibility. Although Belgium has made good progress in addressing the social assistance needs and tax systems related to non-standard employment, some gaps remain vis-à-vis regular workers.

This Working Paper relates to the 2020 OECD Economic Survey of Belgium (http://www.oecd.org/economy/belgium-economic-snapshot/)

JEL classification: J20; J30; J50; J60

Keywords: Labour market policy, employment, skills, work incentives, unemployment insurance. 


\section{Table des matières}

Répondre aux défis du marché du travail en Belgique 6

Les principaux défis sur le marché du travail belge 10

La faiblesse du taux d'emploi reflète les obstacles à l'emploi qui existent au niveau des

travailleurs

Les disparités d'emploi entre catégories socio-économiques et entre régions sont importantes 12

II y a découplage entre la productivité du travail et les salaires 13

Les transitions sur le marché du travail sont relativement lentes $\quad 14$

L'évolution du type et de la nature du travail s'accompagnera de nouveaux défis $\quad 15$

Renforcer les compétences pour faire face à l'évolution des besoins du marché du travail et à la transformation numérique

Renforcer les compétences numériques $\quad 20$

Améliorer l'enseignement et la formation professionnels 23

Accroître l'attrait des études en STIM $\quad 26$

$\begin{array}{ll}\text { Instiller une nouvelle culture de la formation tout au long de la vie } & 27\end{array}$

Réformer le marché du travail pour stimuler l'emploi et la productivité 31

Des politiques d'activation mieux ciblées pour lutter contre les pertes d'emplois 31

Assouplir le marché du travail par une réglementation fiable 34

Coupler plus étroitement salaires et productivité au niveau de l'entreprise et au niveau du

salarié $\quad 36$

Pour une fiscalité et des prestations équitables et incitant à travailler $\quad 37$

$\begin{array}{ll}\text { Une protection sociale inclusive qui favorise le travail } & 37\end{array}$

Une fiscalité équitable et efficiente $\quad 47$

Références $\quad 51$

\section{Tableaux}

Tableau 1. Groupes définis selon différentes combinaisons d'obstacles à l'emploi 12

Tableau 2. Il existe des disparités régionales considérables sur les marchés du travail 13

Tableau 3. Recommandations sur les défis liés au marché du travail 50

\section{Graphiques}

Graphique 1. La situation du marché du travail s'est améliorée

Graphique 2. Plusieurs aspects de la dimension quantitative de l'emploi et de l'inclusivité du marché du travail pourraient être améliorés

Graphique 3. Les taux de vacance d'emploi restent relativement élevés 10

Graphique 4. Les obstacles à l'emploi au niveau des travailleurs sont multiples 11

Graphique 5. Les écarts d'emploi sont importants pour les groupes défavorisés 13

Graphique 6. Transitions sur le marché du travail $\quad 15$

Graphique 7. Part des formes de travail atypiques dans l'emploi total 17

Graphique.8. Tendances émergentes du travail atypique 18

Graphique 9. Le marché du travail est de plus en plus polarisé, mais la dispersion des salaires reste faible 19

Graphique 10. Face aux profonds changements que devraient connaître les emplois sous l'effet de

l'automatisation, un recyclage des compétences sera nécessaire

Graphique 11. La diffusion rapide des TIC a contribué aux pénuries de compétences en TIC 20

Graphique 12. Les compétences numériques sont faibles, en particulier dans certains groupes 22

Graphique 13. Les jeunes sont relativement mal lotis au regard de l'emploi 24

Graphique 14. L'enseignement professionnel pourrait être amélioré 25 
Graphique 15. La proportion de diplômés en STIM dans l'enseignement supérieur est faible 27 Graphique 16. Les politiques relatives à la formation tout au long de la vie pourraient être améliorées $\quad 28$ Graphique 17. Tout en étant disposés à suivre une formation, certains groupes défavorisés n'ont accès qu'à des possibilités de formation limitées

Graphique 18. Le chômage de longue durée a une incidence élevée

Graphique 19. Seule une part relativement faible des dépenses engagées au titre des PAMT est consacrée à

la formation

Graphique 20. La protection de l'emploi contre les licenciements collectifs est relativement forte

Graphique 21. Barème des allocations de chômage pendant la période de chômage 39

Graphique 22. La couverture des allocations de chômage est élevée 40

Graphique 23. Les taux de remplacement nets sont relativement élevés, en particulier pour 40

Graphique 24. Une aide au revenu importante pour les travailleurs à bas salaire est généralement associée à des taux d'imposition de l'activité élevés

Graphique 25. La durée de cotisation requise pour les retraites minimum pourrait être difficile à atteindre pour les travailleurs ayant une carrière en dents de scie

Graphique 26. Encours total des actifs des fonds de pension privés

Graphique 27. Les entrées dans les régimes d'indemnisation maladie et invalidité devraient être contrôlées

Graphique 28. La charge fiscale pesant sur les travailleurs belges est élevée

\section{Encadrés}

Encadré 1. La nouvelle Stratégie de l'OCDE pour l'emploi $\quad 7$

Encadré 2. Des interventions sur mesure pour remédier aux obstacles individuels à l'emploi 11

Encadré 3. Transitions sur le marché du travail : données empiriques tirées de l'EU-SILC 14

Encadré 4. Quelques initiatives destinées à renforcer les compétences numériques 22

Encadré 5. Le profilage statistique en Autriche $\quad 34$

Encadré 6. Le barème des allocations de chômage en Belgique

Encadré 7. Concentration des allocations de chômage en début de période : l'expérience de la Hongrie 43 


\title{
Répondre aux défis du marché du travail en Belgique
}

\author{
Par Müge Adalet McGowan, Alexander Hijzen, David Law, Andrea Salvatori, \\ Patrizio Sicari et Stefan Thewissen ${ }^{1}$
}

La Belgique a mené plusieurs réformes importantes récemment pour accroître les taux d'activité et d'emploi. Les impôts sur le travail ont été réduits, en particulier pour les bas salaires. Des réductions de cotisations sociales ont été accordées aux nouveaux employeurs qui embauchent leur premier salarié. Des subventions salariales ont été introduites en 2018 pour les entreprises de construction. Par ailleurs, la réforme des retraites, avec notamment le relèvement de l'âge légal de la retraite et le durcissement des conditions d'accès à la retraite anticipée, a favorisé l'augmentation des taux d'activité et d'emploi parmi les seniors.

Pour atténuer la rigidité des marchés du travail, les autorités ont assoupli la durée du travail dans certains secteurs et raccourci le délai de préavis pendant les premiers mois d'emploi. En outre, le champ d'application du dispositif Flexi-job, qui permet à un employeur d'embaucher un collaborateur - qui travaille à au moins $4 / 5 \mathrm{e}$ pour un autre employeur - selon un horaire variable (par exemple, pendant les périodes de pointe) et à des conditions avantageuses (allègements fiscaux et de contributions sociales par exemple), a été étendu. Dans un souci de compétitivité internationale au niveau des coûts, l'indexation des salaires a été momentanément suspendue pour réduire l'écart salarial qui ne cessait de se creuser entre la Belgique et les pays voisins. Pour éviter que de tels écarts ne se reforment, la définition de la norme salariale, qui détermine l'augmentation maximale des salaires dans les conventions collectives sectorielles, a été modifiée en 2017.

Conjuguées à une croissance économique modérée mais régulière, ces réformes ont contribué à améliorer la situation du marché du travail belge ces dernières années. Le taux d'emploi des 15-64 ans est passé de $61.8 \%$ en 2015 à $64.5 \%$ en 2018 , et le taux de chômage est tombé à un niveau historiquement bas, passant d'un pic de $8.5 \%$ en 2015 à $5.2 \%$ au troisième trimestre de 2019 (graphique 1).

1. Müge Adalet McGowan et Patrizio Sicari du Département des Affaires économiques, David Law (précédement au Département des Affaires économiques), Alexander Hijzen, Andrea Salvatori et Stefan Thewissen qui sont de la Direction de l'Emploi, du travail et des affaires sociales (ELS). Les auteurs tiennent à remercier Pierre Beynet, Isabell Koske, Cyrill Schwellnus (tous à ECO), Stéphane Carcillo et Oliver Denk (ELS) et Bert Brys (CTP) pour leurs commentaires. Le rapport a aussi bénéficié des commentaires des autorités belges. Sylvie Ricordeau en a assuré l'édition. 


\section{Graphique 1. La situation du marché du travail s'est améliorée}

15-64 ans

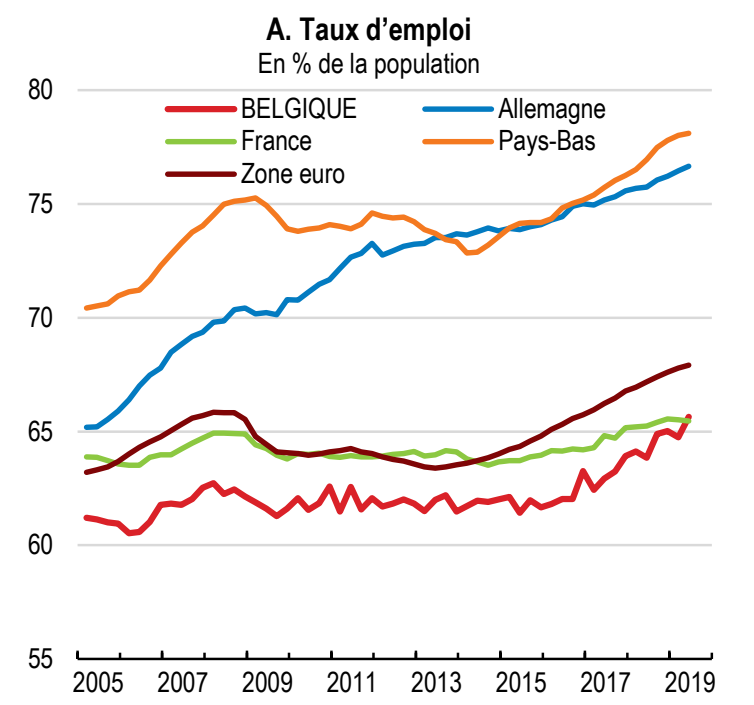

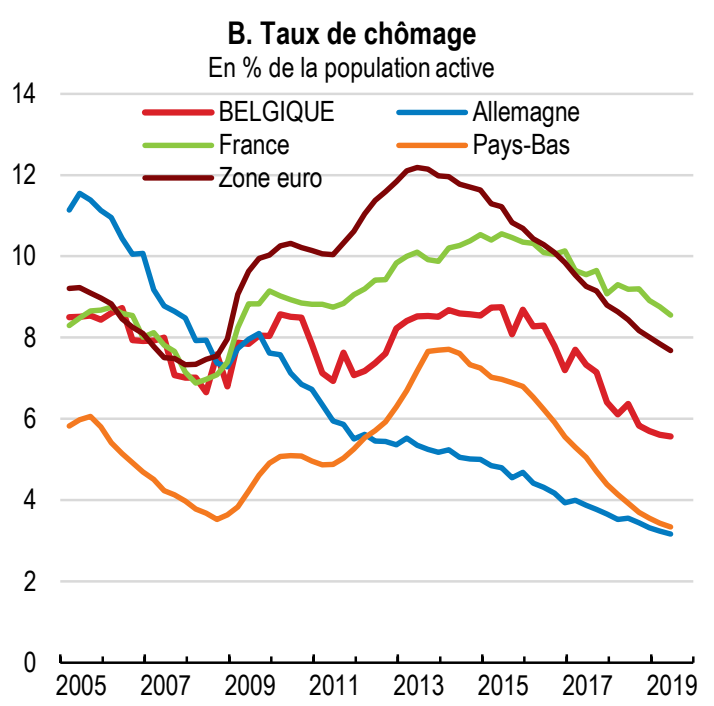

B. Taux de chômage

Source : OCDE (2019), Statistiques à court terme sur le marché de travail (base de données).

Ces progrès notables masquent néanmoins un certain nombre de défis. Selon les indicateurs de la nouvelle Stratégie de l'OCDE pour l'emploi, le faible niveau d'emploi, dû principalement à des taux d'inactivité élevés, et l'écart d'emploi important pour les groupes défavorisés sont deux faiblesses majeures des marchés du travail de la Belgique (encadré 1, graphique 2). La pénurie croissante de travailleurs hautement qualifiés freine la croissance de la productivité, qui est chroniquement faible. Le taux de rotation des emplois est bas, ce qui pourrait limiter la rapidité et l'efficacité de la réaffectation porteuse de gains d'efficience, et les écarts de salaires entre les entreprises et entre les individus ne reflètent peut-être pas suffisamment les écarts de productivité. De plus, les mutations du travail, motivées notamment par la transformation numérique, peuvent modifier sensiblement le contenu et l'organisation des tâches, les compétences dont les individus ont besoin tout au long de leur vie, et les risques auxquels ils sont confrontés sur le marché du travail.

\section{Encadré 1. La nouvelle Stratégie de l'OCDE pour l'emploi}

La révolution numérique, la mondialisation et le changement démographique sont en train de transformer les marchés du travail, alors que, simultanément, l'atonie de la croissance de la productivité limite la marge de manœuvre des pouvoirs publics. Ces transformations rapides et profondes soulèvent de nouveaux défis pour l'action publique. La nouvelle Stratégie de I'OCDE pour l'emploi lancée en décembre 2018 offre un cadre cohérent et des recommandations détaillées sur un large éventail de questions et domaines pour aider les pays à relever ces défis. La nouvelle Stratégie pour l'emploi, en particulier, va au-delà de la dimension quantitative de l'emploi pour considérer aussi la qualité des emplois et l'inclusivité comme des priorités de l'action publique, tout en soulignant que la résilience et la capacité d'adaptation sont essentielles à la bonne performance de l'économie et des marchés du travail dans un monde du travail en pleine transformation. Le message clé qu'il faut retenir est que les politiques visant à rendre les marchés de produits et les marchés du travail plus flexibles sont nécessaires mais pas suffisantes. Pour obtenir des résultats durablement satisfaisants, il faut également mener des politiques et établir des institutions qui protègent les travailleurs, 
favorisent l'inclusivité et permettent aux travailleurs et aux entreprises de tirer le meilleur parti des changements en cours.

L'OCDE aide activement les pays à mettre en œuvre sa Stratégie pour l'emploi en déterminant les priorités que doit poursuivre chacun d'eux et en formulant des recommandations s'y rapportant. Ces priorités et recommandations sont formulées dans les chapitres des Études économiques de l'OCDE ainsi que dans des documents analytiques consacrés à la mise en œuvre de la Stratégie de l'OCDE pour l'emploi dans les différents pays. Le processus s'achèvera par un rapport de synthèse qui tirera les leçons des examens nationaux et mettra en évidence les bonnes pratiques parmi l'ensemble des instruments d'action identifiés par la Stratégie pour l'emploi.

La Stratégie pour l'emploi utilise un tableau de bord pour évaluer les forces et les faiblesses des marchés du travail des diverses économies membres et non membres de l'OCDE. La Belgique est relativement bien classée pour ce qui est du chômage et de la qualité du revenu d'activité. Les principales faiblesses du marché du travail belge sont le faible niveau d'emploi, dû principalement à un niveau d'inactivité élevé, et l'écart d'emploi important pour les groupes défavorisés, en particulier les seniors et les travailleurs immigrés par rapport aux hommes d'âge très actif. La Belgique se place également sous la moyenne de l'OCDE pour la croissance de la productivité du travail (graphique 2).

Source : OCDE (2018a), Des emplois de qualité pour tous dans un monde du travail en mutation - La stratégie de l'OCDE pour l'emploi, Éditions OCDE, Paris.

Ce chapitre traite de la capacité de la Belgique à s'adapter aux défis nouveaux ou existants du marché du travail, en s'appuyant notamment sur les constatations de la nouvelle Stratégie de l'OCDE pour l'emploi. II appréhende d'abord la situation de la Belgique dans une perspective internationale, en analysant les principaux défis auxquels elle est confrontée, à commencer par les mutations du travail. II examine ensuite les politiques qui pourraient aider le pays à s'adapter à ces changements et à rendre le marché du travail plus inclusif. Ces politiques sont les suivantes : i) renforcer les compétences pour accroître le niveau d'emploi parmi les travailleurs peu qualifiés et aligner les compétences sur les besoins, en évolution, du marché du travail et sur les exigences de la transformation numérique (à travers les politiques de formation des adultes par exemple) ; ii) dynamiser les marchés du travail pour faciliter les transitions du chômage ou de l'inactivité vers l'emploi ou de l'emploi à l'emploi (via, par exemple, les politiques actives du marché du travail, les politiques salariales et la réglementation relative à l'emploi); et iii) ajuster le système d'imposition et de prestations sociales pour qu'il fournisse davantage d'incitations au travail (régimes d'indemnisation du chômage par exemple). 


\section{Graphique 2. Plusieurs aspects de la dimension quantitative de l'emploi et de l'inclusivité du marché du travail pourraient être améliorés}

Tableau de bord du marché du travail suivant la nouvelle Stratégie pour l'emploi de l'OCDE'1

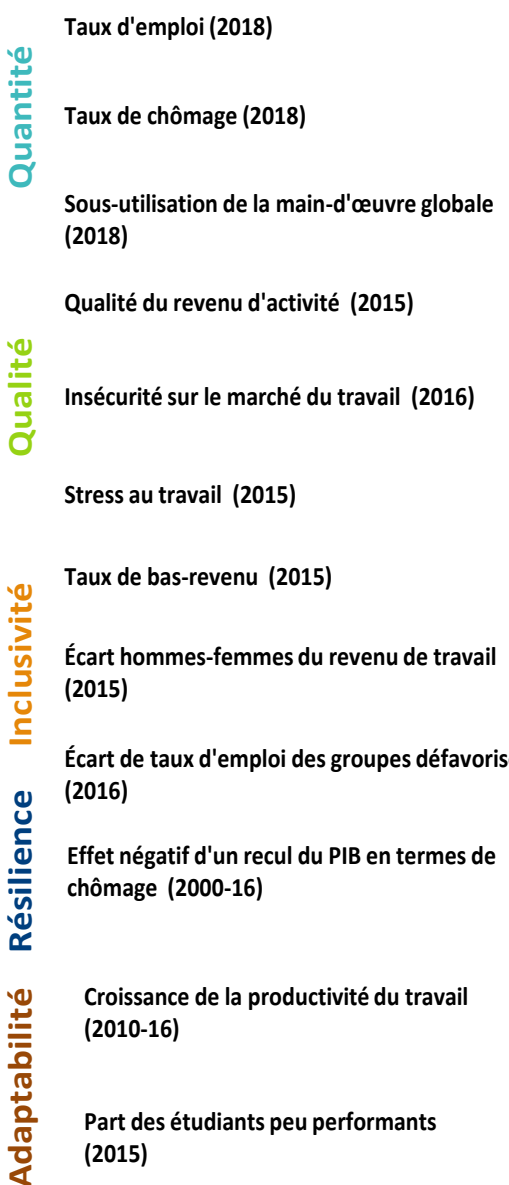

Performance la plus faible de l'OCDE

Performance la plus élevée de l'OCDE

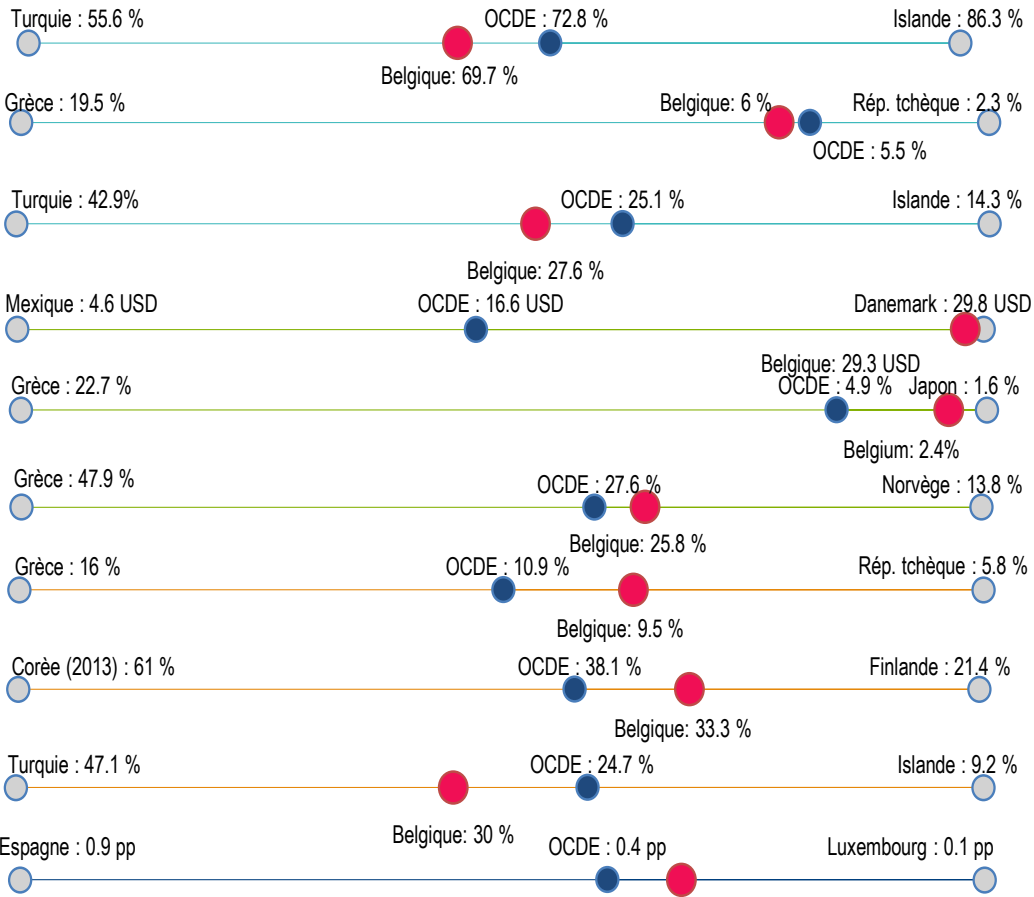

Belgique: $0.3 \mathrm{ppt}$

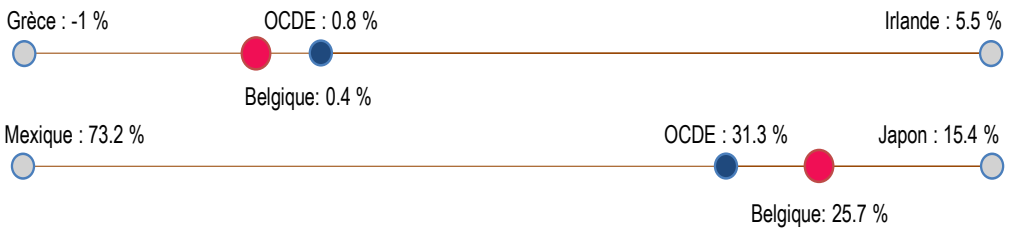

1. Taux d'emploi : pourcentage de la population d'âge actif (20-64 ans) occupant un emploi (\%). Sous-emploi global : pourcentage des inactifs, des chômeurs ou des travailleurs à temps partiel subi (15-64 ans) dans la population, à l'exception des jeunes (15-29 ans) qui suivent une formation et n'occupent pas d'emploi. Qualité du revenu d'activité : salaire horaire brut en USD corrigés des inégalités. Insécurité sur le marché du travail : perte monétaire attendue en cas de chômage et de maintien au chômage en pourcentage du salaire antérieur. Situation de tension au travail : pourcentage des travailleurs qui occupent des emplois caractérisés par des exigences professionnelles généralement élevées et des ressources insuffisantes pour les satisfaire. Taux de bas revenus : pourcentage des personnes d'âge actif vivant avec moins de $50 \%$ du revenu disponible équivalent médian des ménages. Écart hommes-femmes du revenu du travail : différence entre le revenu d'activité annuel moyen des hommes et celui des femmes, rapportée au revenu d'activité moyen des hommes (\%). Écart d'emploi des groupes défavorisés : écart moyen de taux d'emploi entre les travailleurs de sexe masculin d'âge très actif et cinq groupes défavorisés (femmes avec enfants, jeunes qui ne sont pas scolarisés ou qui ne suivent pas une formation à plein temps, travailleurs âgés entre 55 et 64 ans, personnes nées à l'étranger et personnes handicapées), en pourcentage du taux d'emploi des travailleurs de sexe masculin d'âge très actif. Résilience : augmentation moyenne du taux de chômage sur trois ans suite à un choc négatif de PIB de $1 \%(2000$ 16). Croissance de la productivité du travail : croissance annuelle moyenne de la productivité du travail par travailleur (2010-16). Proportion d'élèves peu performants : pourcentage de jeunes de 15 ans qui ne fréquentent pas l'enseignement secondaire ou qui se situent sous le niveau 2 du PISA (\%) (2015).

Source : Calculs de l'OCDE à partir des données 2018 ou de la dernière année disponible et de sources diverses ; OCDE (2018), Des emplois de qualité pour tous dans un monde du travail en mutation - La stratégie de l'OCDE pour l'emploi, Éditions OCDE, Paris. 


\section{Les principaux défis sur le marché du travail belge}

\section{La faiblesse du taux d'emploi reflète les obstacles à l'emploi qui existent au niveau des travailleurs}

Si elle s'accompagne de conditions d'emploi décentes, l'augmentation du nombre de personnes exerçant un emploi réduit le risque de pauvreté et améliore l'inclusion sociale. Or, à $64.5 \%$, le taux d'emploi (des 15-64 ans) en Belgique est inférieur à la moyenne OCDE de 68.6\%. Ce faible taux d'emploi pourrait s'expliquer en partie par l'existence d'obstacles à l'emploi importants au niveau des travailleurs, davantage que par le manque de possibilités d'emploi.

Le taux de vacance d'emploi en Belgique a fortement augmenté depuis 2015 pour atteindre $3.4 \%$, un niveau bien supérieur à la moyenne de l'UE de $2.4 \%$ (graphique 3). Cette situation pourrait traduire, outre un faible taux d'activité économique, une certaine pénurie de compétences, les compétences recherchées par les entreprises n'étant pas nécessairement celles dont disposent les demandeurs d'emploi. De fait, d'après la base de données de la Stratégie de l'OCDE pour l'emploi, la part des professions hautement qualifiées dans les pénuries de compétences totales est plus élevée en Belgique (67\%) que dans l'OCDE en moyenne (54\%) (OCDE, 2019a). Les conditions de travail insuffisamment attrayantes et le manque d'incitations financières, dû en partie à la conception des systèmes d'imposition et de protection sociale - en particulier dans le cas des bas salaires, pourraient aussi contribuer aux pénuries de main-d'œuvre.

\section{Graphique 3. Les taux de vacance d'emploi restent relativement élevés}

\section{En pourcentage}

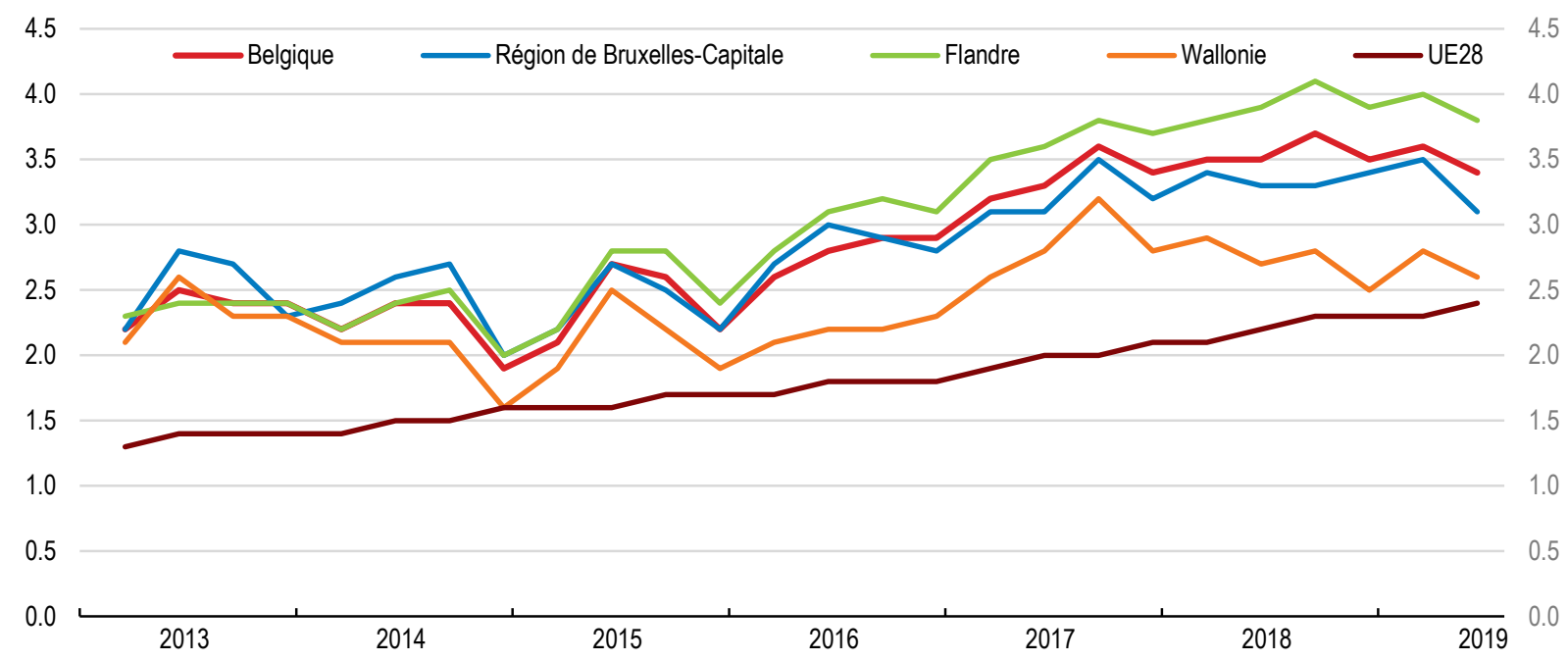

Note : Le taux de vacance d'emploi est le rapport entre le nombre d'emplois vacants et la somme des emplois vacants et des emplois occupés. Emplois dans l'industrie, la construction et les services, sauf les activités des ménages en tant qu'employeurs et les activités d'institutions extraterritoriales.

Source : Eurostat (2019), Statistiques sur les vacances d'emploi, base de données Eurostat.

Des données empiriques récentes de l'OCDE fondées sur les microdonnées de la Belgique recensent trois types d'obstacles à l'emploi : préparation à l'emploi (niveau d'instruction et compétences faibles, expérience nulle ou réduite), disponibilité pour l'emploi (problèmes de santé ou obligations familiales) et incitations au travail (revenu du conjoint ou revenus hors travail élevés, ou soutien généreux au revenu). La faiblesse des compétences, à la fois en termes de niveau d'instruction et d'expérience professionnelle, et les problèmes de santé sont les obstacles à l'emploi les plus fréquents en Belgique 
(Hijzen et al., 2020 ; graphique 4). En outre, plus de $50 \%$ des personnes âgées entre 18 et 64 ans qui déclarent être en situation de chômage de longue durée, être inactives ou avoir des liens ténus avec le marché du travail sont confrontées à plusieurs de ces obstacles simultanément, d'où l'importance de concevoir des interventions sur mesure (encadré 2). Dans ce contexte, les outils de profilage peuvent être utiles pour identifier la combinaison précise d'obstacles rencontrée par chaque personne sans emploi.

\section{Graphique 4. Les obstacles à l'emploi au niveau des travailleurs sont multiples}

Pourcentage de la population confronté à chaque obstacle à l'emploi identifié

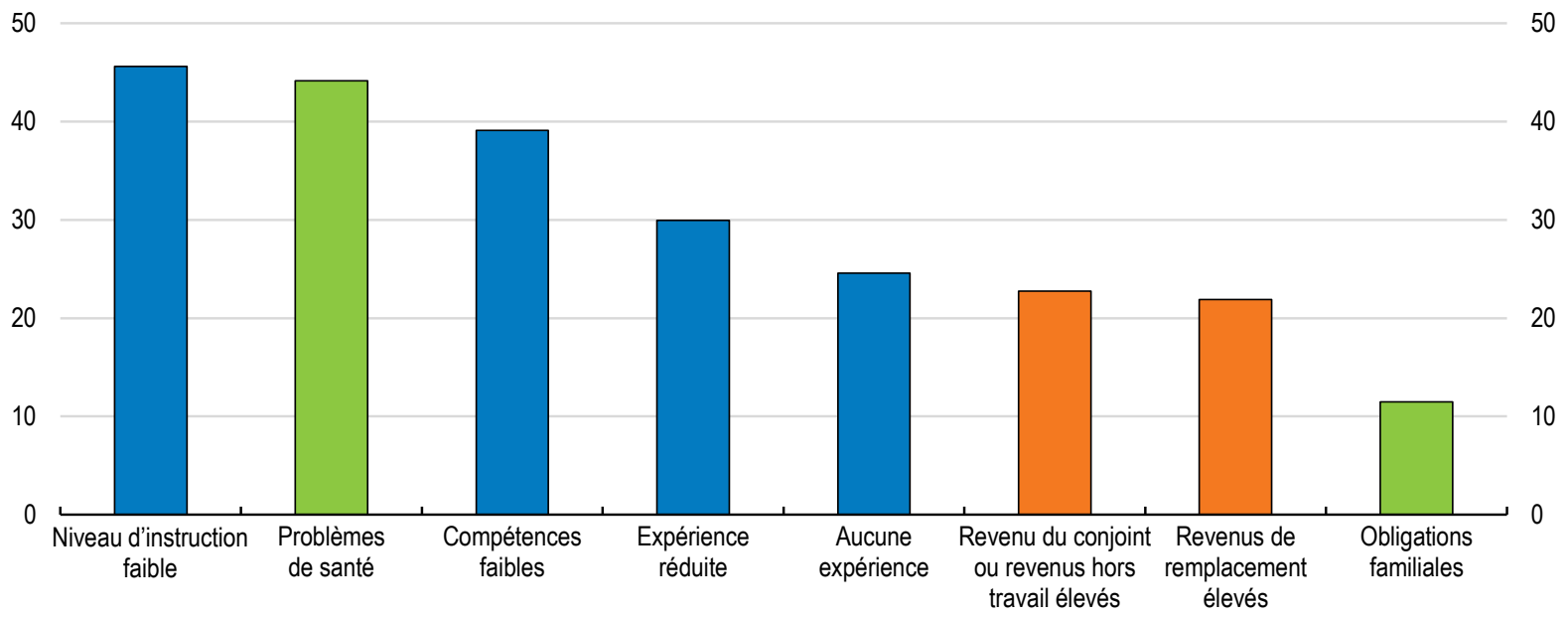

Note : La population qui éprouve des difficultés d'emploi importantes est définie comme l'ensemble des personnes âgées entre 18 et 64 ans qui déclarent être en situation de chômage de longue durée, être inactives ou avoir des liens ténus avec le marché du travail (emploi instable, nombre d'heures de travail restreint ou revenus d'activité presque nuls), à l'exclusion des étudiants à plein temps et des personnes qui effectuent leur service militaire obligatoire. Les barres bleues désignent des obstacles qui relèvent de la préparation à l'emploi, les barres vertes des obstacles liés à la disponibilité pour l'emploi et les barres orange des obstacles en termes d'incitations au travail. Le graphique indique le pourcentage de la population confronté à chaque type d'obstacle identifié. Une personne pouvant être confrontée à plusieurs obstacles simultanément, la somme des barres n'est pas égale à 100. Voir (Fernandez et al., 2016) pour de plus amples précisions. Source : Hijzen et al. (2020), « Lowering employment barriers in Belgium and Norway », Documents de travail de l'OCDE sur les affaires sociales, l'emploi et les migrations. Calculs fondés sur l'EU-SILC 2017.

\section{Encadré 2. Des interventions sur mesure pour remédier aux obstacles individuels à l'emploi}

La population des personnes en situation de chômage de longue durée, inactives ou ayant des liens ténus avec le marché du travail en Belgique peut être divisée en dix groupes, confrontés chacun à une combinaison spécifique d'obstacles à l'emploi parmi ceux recensés dans le graphique 4 . Le tableau 1 décrit la mesure dans laquelle les dix groupes sont confrontés à des obstacles relevant de la préparation à l'emploi, de la disponibilité pour l'emploi et des incitations au travail.

Une personne pouvant être confrontée à plusieurs obstacles simultanément, il est crucial d'identifier les besoins de chaque travailleur individuel pour concevoir des solutions sur mesure. Par exemple, le groupe 1 (chômeurs plutôt instruits) a essentiellement besoin de services d'aide à la recherche et à la demande d'emploi et de services de placement, tandis que le groupe 5 (pré-retraités peu incités à travailler) requiert des mesures de formation tout au long de la vie (voir ci-après). Pour deux groupes composés essentiellement de femmes dont le conjoint exerce un emploi (groupes 3 et 4), il est possible 
de renforcer les incitations au travail en modifiant le régime d'imposition du second revenu, tandis que les membres du groupe 6 (femmes qui s'occupent de jeunes enfants) tireraient profit d'une amélioration des services d'accueil des jeunes enfants.

\section{Tableau 1. Groupes définis selon différentes combinaisons d'obstacles à l'emploi}

\begin{tabular}{|c|c|c|c|c|}
\hline Groupe & Définition & $\begin{array}{l}\text { Préparation à } \\
\text { l'emploi }\end{array}$ & $\begin{array}{l}\text { Disponibilité pour } \\
\text { l'emploi }\end{array}$ & $\begin{array}{l}\text { Incitations au } \\
\text { travail }\end{array}$ \\
\hline 1 & Chômeurs plutôt instruits & Mieux préparés & Plus disponibles & $\begin{array}{l}\text { Incitations plus } \\
\text { fortes }\end{array}$ \\
\hline 2 & $\begin{array}{l}\text { Travailleurs à temps partiel jeunes et peu } \\
\text { instruits }\end{array}$ & Mieux & Plus & Plus fortes \\
\hline 3 & $\begin{array}{l}\text { Femmes travaillant à temps partiel dont le } \\
\text { conjoint exerce un emploi }\end{array}$ & Mieux & Plus & Plus faibles \\
\hline 4 & $\begin{array}{l}\text { Femmes inactives ayant des revenus hors } \\
\text { travail élevés }\end{array}$ & Mieux & Moyennement & Plus faibles \\
\hline 5 & Pré-retraités peu incités à travailler & Mieux & Moyennement & Plus faibles \\
\hline 6 & Femmes qui s'occupent de jeunes enfants & Mieux & Moins & Plus fortes \\
\hline 7 & $\begin{array}{l}\text { Personnes inactives sans expérience et peu } \\
\text { instruites }\end{array}$ & Moins & Moyennement & Plus fortes \\
\hline 8 & $\begin{array}{l}\text { Personnes handicapées, peu instruites, et } \\
\text { percevant un revenu de remplacement élevé }\end{array}$ & Mieux & Moins & Moyennement \\
\hline 9 & $\begin{array}{l}\text { Femmes qui s'occupent de jeunes enfants et } \\
\text { sont sans expérience }\end{array}$ & Moins & Moins & Plus fortes \\
\hline 10 & $\begin{array}{l}\text { Faible niveau d'instruction et problèmes de } \\
\text { santé }\end{array}$ & Moyennement & Moyennement & Plus fortes \\
\hline
\end{tabular}

Note : Les colonnes indiquent la mesure dans laquelle les différents groupes sont confrontés à des obstacles en termes de préparation à l'emploi (problèmes de santé ; obligations familiales), de disponibilité pour l'emploi (faible niveau d'instruction ; faibles compétences professionnelles ; aucune expérience) et d'incitations au travail (revenus hors travail élevés, revenus de remplacement élevés). Cette mesure est calculée sous la forme d'une moyenne des différents obstacles individuels et exprimée en termes relatifs (le fait que le groupe soit confronté à des obstacles plus élevés ou moins élevés que les autres groupes).

Source : Hijzen et al. (2020), "Lowering employment barriers in Belgium and Norway », Documents de travail de l'OCDE sur les affaires sociales, l'emploi et les migrations. Calculs fondés sur l'EU-SILC 2017.

\section{Les disparités d'emploi entre catégories socio-économiques et entre régions sont importantes}

Les disparités d'emploi sont considérables, et ce facteur milite lui aussi en faveur d'interventions conçues sur mesure. Ainsi, les écarts d'emploi pour les groupes défavorisés (par exemple, les seniors, les personnes handicapées et les immigrés) par rapport aux hommes d'âge très actif sont particulièrement marqués en comparaison de la moyenne OCDE (graphique 5). Les immigrés venant de pays non membres de l'UE sont parmi les plus désavantagés, puisqu'en comparaison de leurs homologues ressortissants de pays de l'UE, leur situation sur le marché du travail est beaucoup plus précaire. En outre, seule une petite partie de l'écart d'emploi entre les personnes nées dans le pays et celles nées dans un pays extérieur à l'UE est due aux caractéristiques individuelles telles que l'âge, le sexe, le niveau d'instruction ou la région de résidence (CSE, 2018).

Les performances du marché du travail diffèrent également d'une région à une autre, pour des raisons variables (tableau 2). Par exemple, le taux d'emploi relativement élevé observé en Flandre s'explique par des taux de chômage et d'inactivité inférieurs à la moyenne nationale. En Wallonie et dans la Région de Bruxelles-Capitale, le taux d'emploi relativement faible traduit des taux d'inactivité et de chômage supérieurs à la moyenne nationale, même s'il est vrai que dans la Région de Bruxelles-Capitale, les changements démographiques ont entraîné une forte augmentation de la population d'âge actif. La mobilité régionale limitée entre la Flandre et la Wallonie, due aux longs temps de transport, à certaines 
carences de transport en commun et aux barrières linguistiques, est l'un des facteurs qui explique les disparités régionales du marché du travail. Néanmoins, les différences des structures industrielles, qui contribuent aux différences régionales de productivité, ainsi que les disparités de niveaux d'instruction et de compétences pourraient également jouer un rôle.

\section{Graphique 5. Les écarts d'emploi sont importants pour les groupes défavorisés}

Écart d'emploi', en pourcentage, 2016

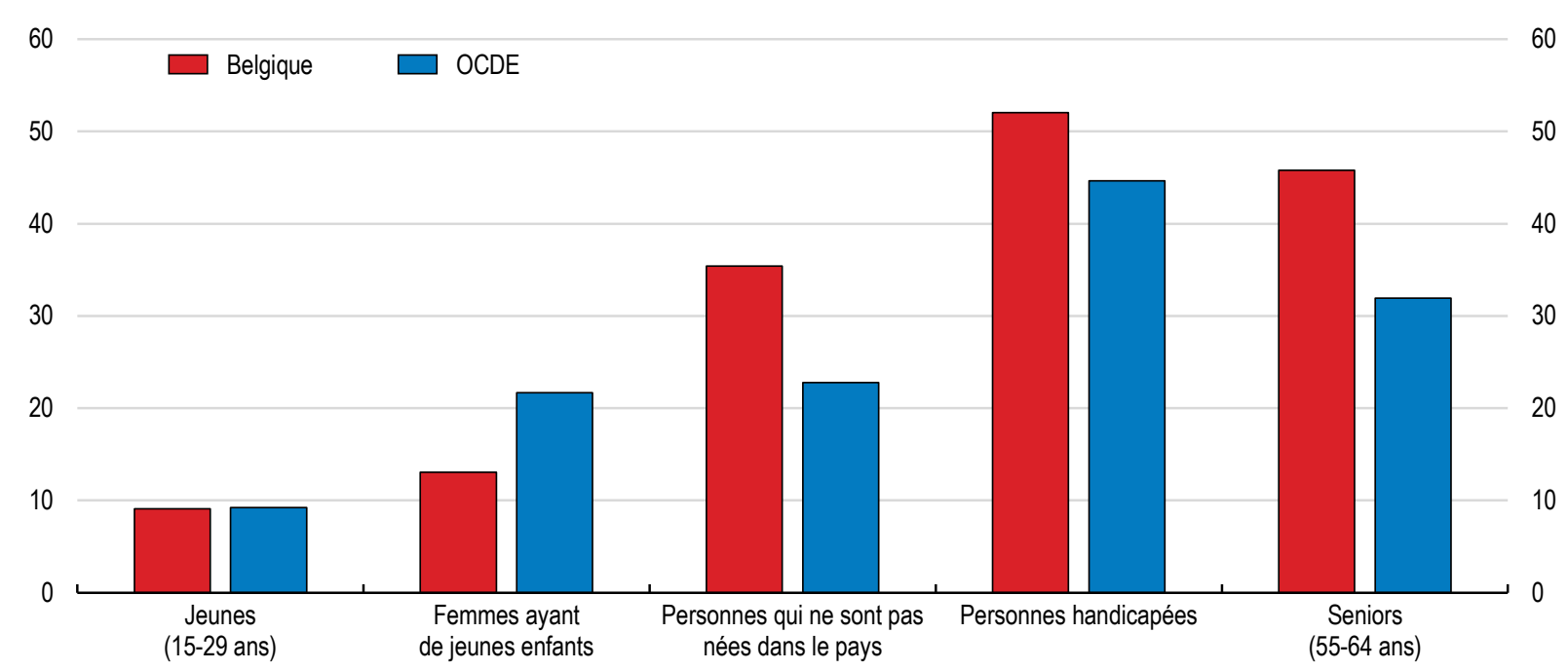

1. L'écart d'emploi est défini comme la différence entre le taux d'emploi des hommes d'âge très actif (25-54 ans) et celui du groupe considéré, exprimée en pourcentage du taux d'emploi des hommes d'âge très actif. Jeunes à l'exclusion de ceux qui suivent des études ou une formation à plein temps. Les femmes ayant de jeunes enfants sont les femmes d'âge actif qui ont au moins un enfant âgé de 0 à 14 ans. Les personnes qui ne sont pas nées dans le pays désignent l'ensemble des personnes nées à l'étranger, sans distinction de nationalité. Source : OCDE (2018a), Des emplois de qualité pour tous dans un monde du travail en mutation - La stratégie de l'OCDE pour l'emploi, Éditions OCDE, Paris.

Tableau 2. II existe des disparités régionales considérables sur les marchés du travail 2018

\begin{tabular}{l|c|c|c|c|c}
\hline & Belgique & $\begin{array}{c}\text { Bruxelles- } \\
\text { Capitale }\end{array}$ & Flandre & Wallonie & UE28 \\
\hline Taux de chômage1 & 6.0 & 13.2 & 3.4 & 8.5 & 6.9 \\
\hline Chômage de longue durée $^{2}$ & 2.9 & 7.5 & 1.2 & 4.8 & 3.0 \\
\hline Chômage des jeunes $^{3}$ & 15.8 & 30.6 & 10.9 & 22.5 & 15.2 \\
\hline Taux d'emploi $^{4}$ & 64.5 & 56.8 & 69.4 & 58.4 & 68.6 \\
\hline Inactivité4 $^{4}$ & 31.4 & 34.5 & 28.2 & 36.2 & 26.3 \\
\hline
\end{tabular}

1. 15-74 ans. 2. En \% de la population active. 3. 15-24 ans. 4. 15-64 ans.

Source : Eurostat.

\section{II y a découplage entre la productivité du travail et les salaires}

Comme de nombreux autres pays de l'OCDE, la Belgique a enregistré une diminution de la part du travail dans le revenu des facteurs au cours des dernières décennies, quoique le déclin ait été plus limité qu'ailleurs dans I'UE. Les salaires ont progressé un peu plus lentement que la productivité depuis 1995, mais la tendance s'est inversée au cours de la sous-période 2007-17 (Schwellnus et al., 2018). Depuis dix ans, la faible croissance de la productivité et des salaires réels a évité à la Belgique une 


\section{4}

ECO/WKP(2020)10

dégradation significative de sa compétitivité extérieure. Néanmoins, cette faible croissance de la productivité, conjuguée à un système de formation des salaires qui prend en compte l'évolution des prix et des salaires mais pas celle de la productivité - ni en Belgique, ni dans les pays voisins -, peut créer des points de fragilité.

Selon la publication In-Depth Productivity Review of Belgium de l'OCDE, le manque de réactivité des salaires aux différences de productivité entre entreprises est l'un des facteurs qui pourrait expliquer la croissance atone de la productivité. Ainsi, les entreprises belges dont la productivité est supérieure de $10 \%$ à celle des autres entreprises du même secteur versent des salaires supérieurs de $2.7 \%$ en moyenne, alors que le différentiel salarial moyen correspondant dans les autres pays de l'OCDE est de $5.4 \%$ (OCDE, 2019a). Cette faible association entre la productivité et les salaires à l'échelon des entreprises risque d'empêcher la répartition efficace des travailleurs entre les entreprises, les entreprises les plus productives éprouvant une relative difficulté à attirer des travailleurs qualifiés (OCDE, 2018b).

\section{Les transitions sur le marché du travail sont relativement lentes}

Le manque de dynamisme des carrières professionnelles individuelles peut brider la croissance de la productivité et amoindrir l'efficacité de l'affectation de la main-d'œuvre. Par exemple, les taux de transition de l'inactivité et du chômage vers l'emploi sont faibles en Belgique (encadré 3), de même que les taux de transition d'emploi à emploi (OCDE, à paraître). Ces observations peuvent être reliées à certaines caractéristiques du marché du travail, telles que l'association entre rémunération et ancienneté, aux règles strictes qui encadrent les licenciements collectifs, à la conception des régimes de protection sociale et à l'efficacité des politiques actives du marché du travail.

\section{Encadré 3. Transitions sur le marché du travail : données empiriques tirées de l'EU-SILC}

Les caractéristiques et les déterminants de divers types de transitions professionnelles ont été analysés dans de nouveaux travaux qui utilisent les données longitudinales des statistiques de l'Union européenne sur le revenu et les conditions de vie (EU-SILC) pour la période 2005-2015, suivant la méthodologie exposée dans Garda (2016) .

Le graphique 6 illustre les différences entre pays des flux d'entrée et de sortie du chômage et de l'inactivité. Si les taux de transitions de l'emploi vers l'inactivité et de l'emploi vers le chômage sont de niveaux proches en Belgique, le premier est supérieur et le second inférieur à la moyenne de l'UE (parties A et B). Quant à la probabilité de passer du non-emploi (inactivité économique ou chômage) à l'emploi pour une personne qui était sans emploi à la fin de l'année précédente, elle est relativement faible (parties $C$ et $D$ ). 


\section{Graphique 6. Transitions sur le marché du travail}

En pourcentage ${ }^{1}$

A. Transition : de l'emploi vers l'inactivité

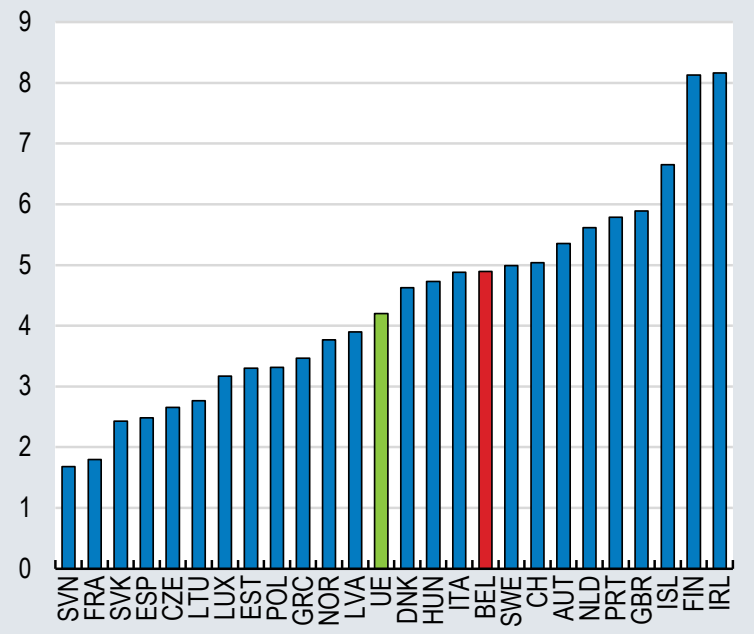

C. Transition : de l'inactivité vers l'emploi

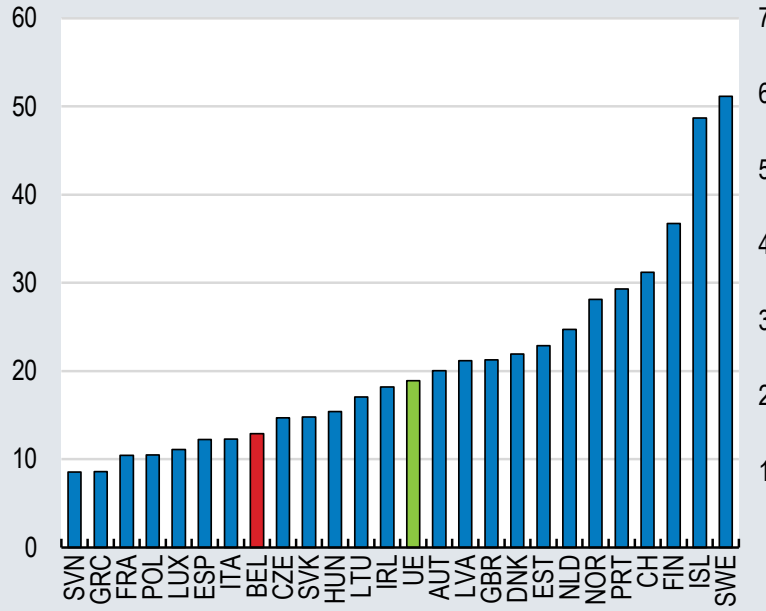

B. Transition : de l'emploi vers le chômage

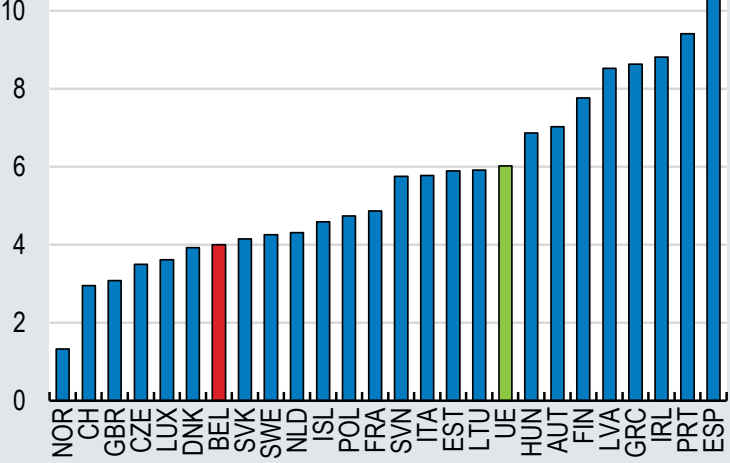

D. Transition : du chômage vers l'emploi

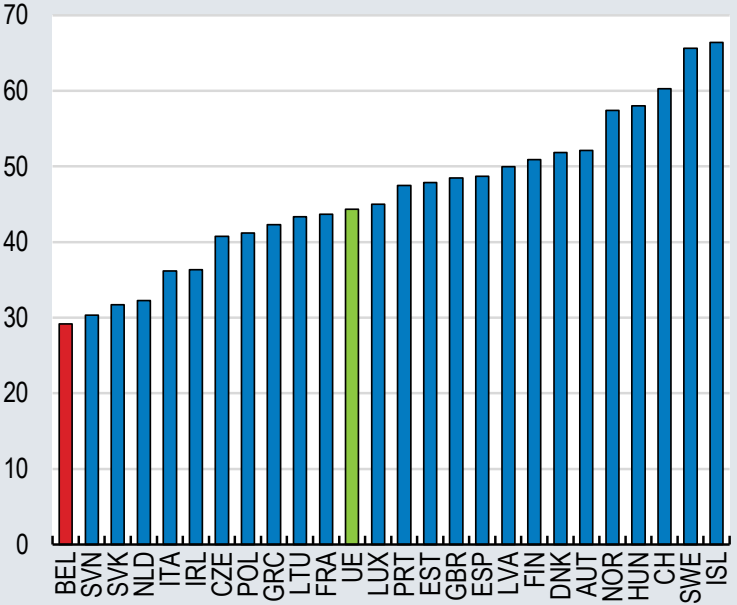

1. Probabilité de changer de statut au regard de l'emploi au cours d'une année t pour une personne qui avait le statut antérieur à la fin de l'année t-1. Moyennes d'un échantillon pondéré pour la période 2005-2015. "UE » est la moyenne simple des 22 pays inclus dans l'échantillon (tous les pays de l'UE qui sont aussi membres de l'OCDE, sauf l'Allemagne, pour laquelle les données ne sont pas disponibles). Les calculs sont basés sur les réponses auto-évaluées fournies par les répondants de l'enquête.

Source : Calculs effectués par le Secrétariat de l'OCDE à partir des données EU-SILC d'Eurostat.

\section{L'évolution du type et de la nature du travail s'accompagnera de nouveaux défis}

\section{Importance du travail atypique}

Le travail atypique désigne l'ensemble des formes de travail qui ne sont pas exercées à plein temps et de manière permanente ; il comprend notamment le travail temporaire et sur plateforme, le travail à temps partiel et le travail indépendant. Ces modalités de travail peuvent procurer une souplesse accrue aux travailleurs et aux entreprises, facilitent l'émergence de nouveaux modèles économiques et peuvent servir de tremplin vers l'emploi traditionnel pour certains, notamment les jeunes et les personnes peu qualifiées. Elles suscitent néanmoins un certain nombre d'interrogations concernant la qualité des 
emplois et le risque de creusement des disparités et pourraient de ce fait nécessiter une importante refonte des politiques du marché du travail, des politiques de compétence et des politiques sociales (OCDE, 2019b). Si une compensation des risques économiques accrus auxquels sont exposés les travailleurs atypiques est nécessaire, le traitement différencié qui leur est appliqué en matière fiscale et de retraite (impôts et cotisations obligatoires de retraite réduits) peut engendrer de nouvelles distorsions, comme on le verra plus loin. L'incidence du travail atypique peut également avoir d'importantes retombées sur la productivité, dans la mesure où les travailleurs indépendants, en particulier les travailleurs à compte propre, sont généralement beaucoup moins productifs que les salariés par exemple.

Les parts de l'emploi temporaire et de l'emploi à temps partiel en Belgique sont à peu près conformes aux moyennes de OCDE (graphique 7, parties A et B). L'emploi indépendant compte pour environ $15 \%$ de l'emploi total, soit plus que dans un certain nombre de pays pairs comme l'Allemagne, le Danemark et la France (graphique 7, partie $\mathrm{C}$ ). Les travailleurs à compte propre sont prépondérants dans cette catégorie (9.4\% de l'emploi total en 2016), quoique leur part décline depuis deux décennies. D'un autre côté, la part des travailleurs à compte propre qui n'ont en général pas plus d'un client a augmenté entre 2010 et 2015. Cela pourrait traduire une augmentation du faux travail indépendant (OCDE, 2018a) et signifier que certaines personnes ne bénéficient pas entièrement des droits et de la protection accordés aux salariés.

Le recours aux formes de travail atypiques pourrait croître à l'avenir à mesure de la poursuite de la mondialisation et des changements technologiques, ainsi que sous l'effet de la réorientation des politiques. Ainsi, en vertu de réformes récentes, les retraités (personnes ayant 65 ans révolus ou ayant travaillé pendant au moins 45 ans) peuvent combiner pension de retraite et revenus tirés d'une activité indépendante ou salariée. Cette mesure pourrait introduire davantage de flexibilité et accroître les niveaux d'activité et d'emploi parmi les seniors, y compris en favorisant le travail indépendant. L'emploi indépendant progresse régulièrement parmi les personnes de 50 ans et plus moyennement à hautement qualifiées (graphique 8, partie A). La part élevée de travailleurs moyennement à hautement qualifiés parmi l'ensemble des travailleurs indépendants en Belgique est liée au poids des professions libérales dans l'emploi indépendant (Nautet et Piton, 2019).

L'incidence de l'emploi temporaire et la probabilité qu'une personne sous contrat à durée déterminée soit titulaire d'un contrat à durée indéterminée trois ans plus tard sont à peu près identiques aux moyennes de l'OCDE (OCDE, 2018a). Les contrats temporaires apportent de la flexibilité non seulement aux entreprises mais aussi, potentiellement, aux travailleurs, en particulier au début de leur carrière ; ils offrent des possibilités d'emploi à des personnes qui, sinon, auraient été contraintes au chômage, et peuvent constituer un tremplin important vers l'emploi permanent. Entre 2016 et 2017, 40 \% environ des personnes titulaires d'un contrat temporaire ont évolué vers un contrat permanent en Belgique (Nautet et Piton, 2019). 
Graphique 7. Part des formes de travail atypiques dans l'emploi total

En pourcentage de l'emploi total

\section{A. Emploi temporaire}

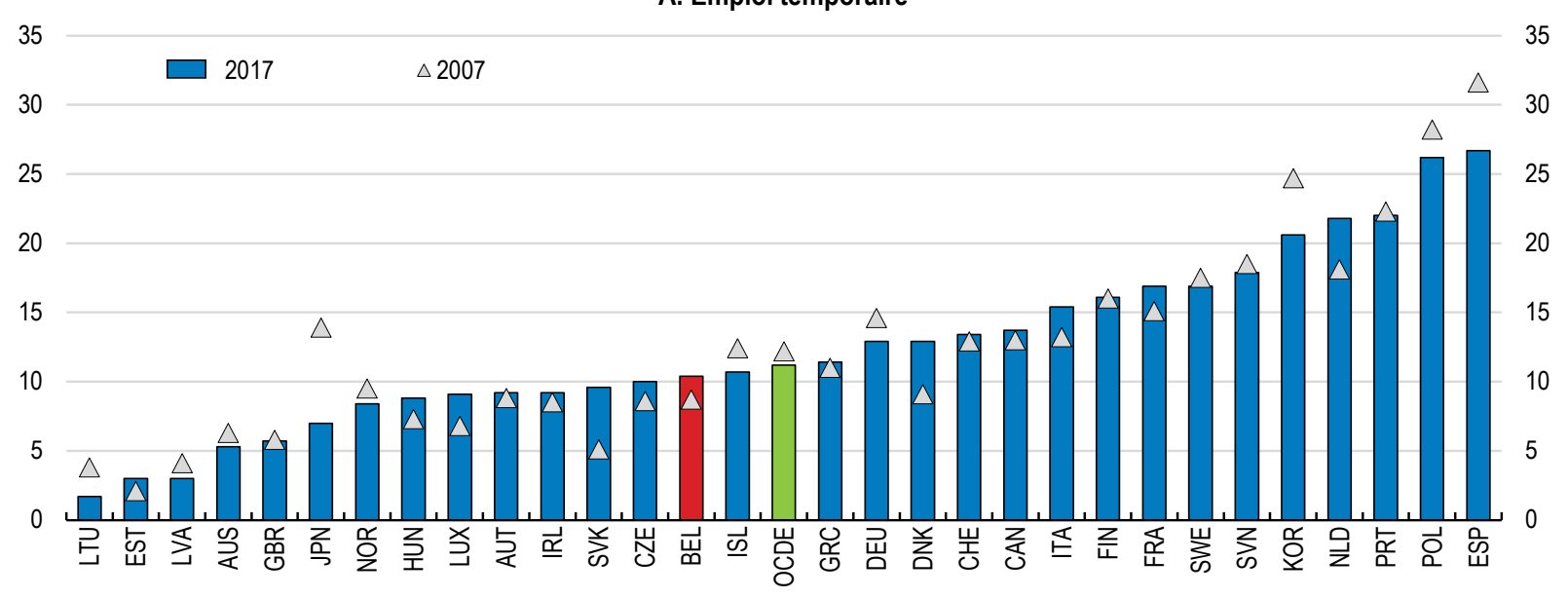

B. Emploi à temps partiel

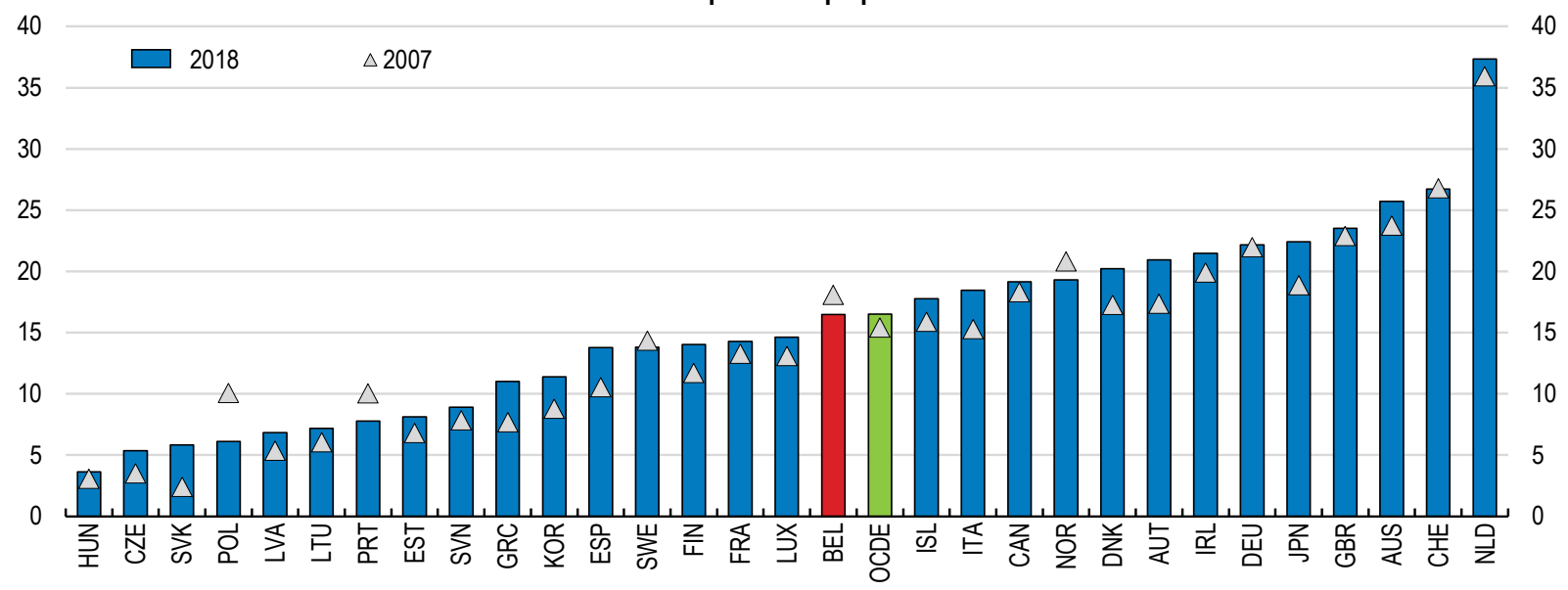

\section{Emploi indépendant}

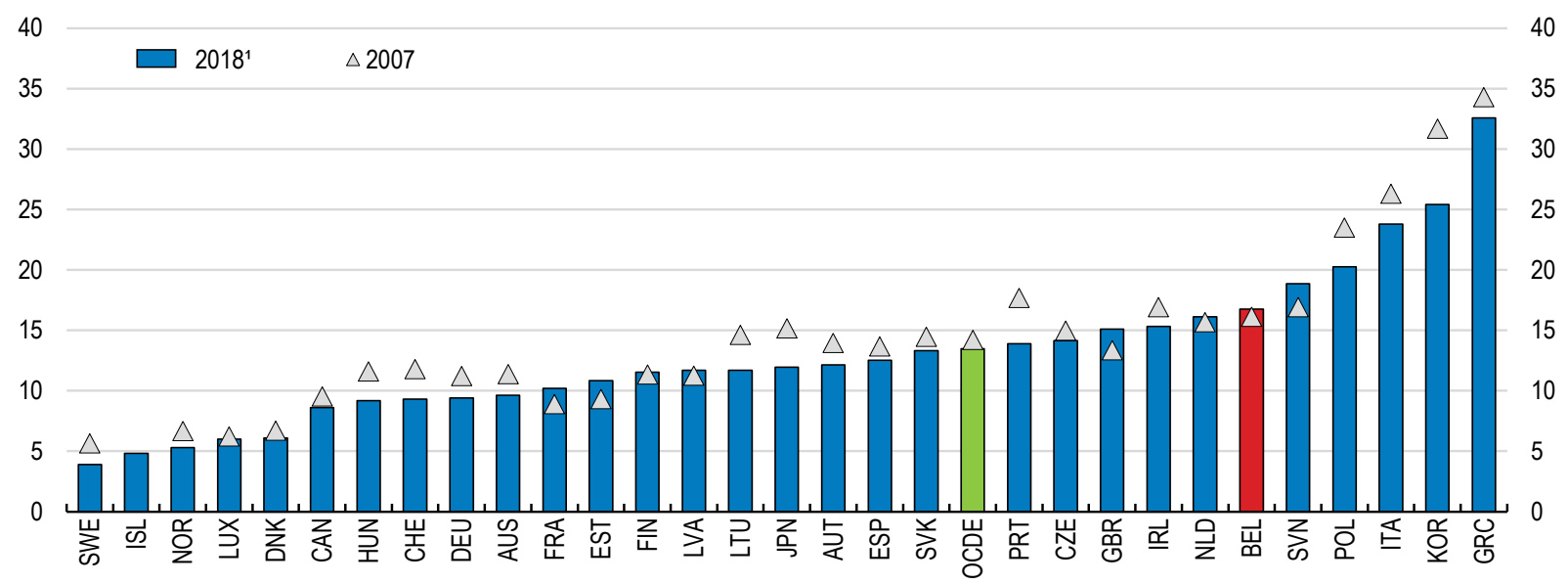

1. Ou dernière année disponible.

Source : OCDE (2019), Statistiques de la population active de l'OCDE et Statistiques de l'OCDE sur les comptes nationaux (bases de données). 


\section{Graphique.8. Tendances émergentes du travail atypique}
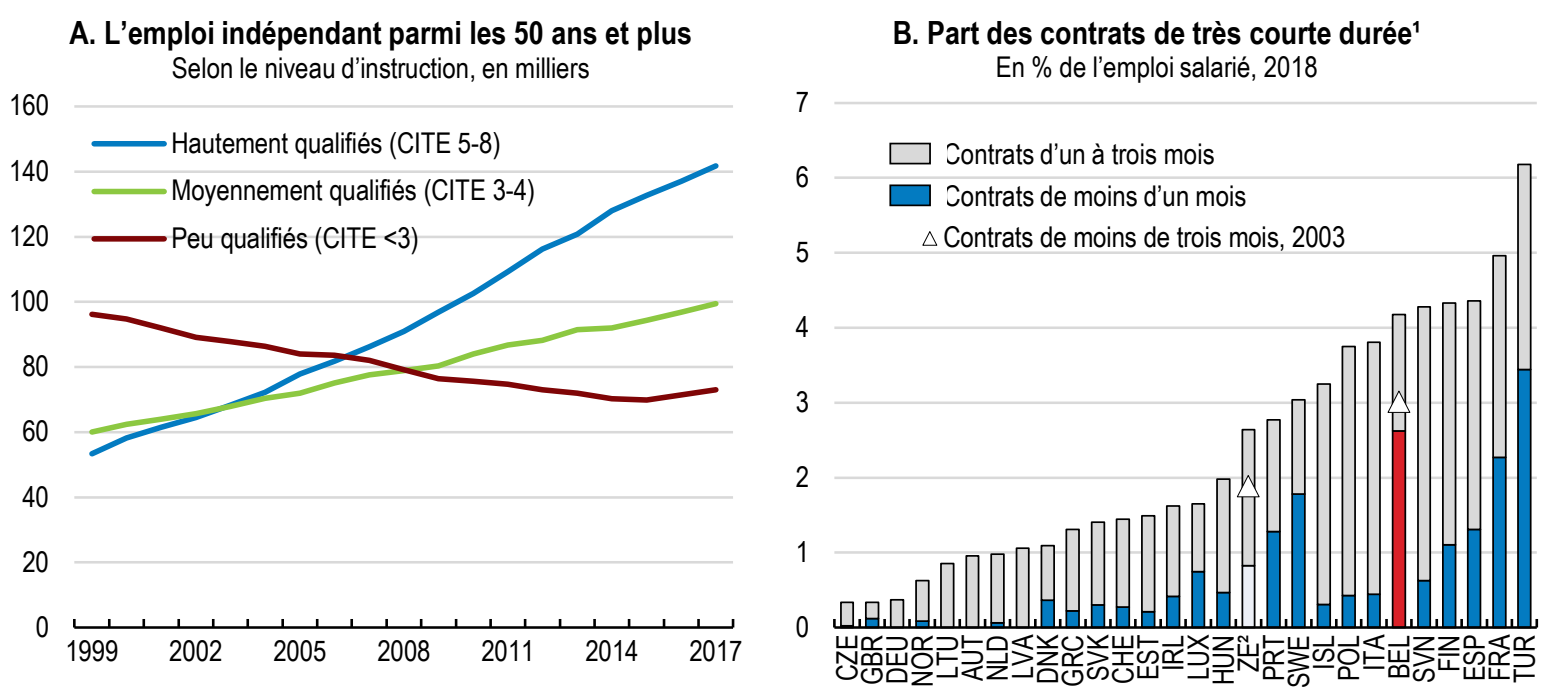

1. Part des contrats de très courte durée dans les contrats à durée déterminée.

2. Zone euro, 19 pays.

Source : Estimations du Bureau fédéral du Plan fondées sur les données EU KLEMS ; Eurostat (2019), Résultats annuels détaillés de l'Enquête européenne sur les forces de travail, base de données Eurostat.

Néanmoins, sur vingt personnes titulaires d'un contrat temporaire, sept ne l'ont pas choisi, et la part des contrats de très courte durée (moins d'un mois) est élevée (graphique 8, partie B). Bien que les contrats courts puissent être renouvelés plusieurs fois par l'employeur, cette pratique peut affecter l'accès des travailleurs à la formation et leur bien-être (OCDE, 2018a), et induit un coût pour les finances publiques par le biais des indemnités de chômage. En outre, certains groupes sont surreprésentés dans l'emploi temporaire : c'est le cas des travailleurs originaires de pays extérieurs à l'UE, qui sont environ trois fois plus susceptibles d'être embauchés avec un contrat temporaire que les Belges.

\section{Transformation numérique et automatisation}

Les changements structurels, y compris la transformation numérique, devraient aussi fortement peser sur l'évolution de la nature du travail. Comme dans d'autres pays, le marché du travail de la Belgique s'est progressivement polarisé au cours des dernières décennies (Autor, Katz et Kearney, 2006 ; Goos et Manning, 2007 ; Goos, Manning et Salomons, 2009 ; OCDE, 2017a). Autrement dit, la part des emplois hautement qualifiés et, dans une moindre mesure, la part des emplois peu qualifiés dans l'emploi total ont augmenté, tandis que celle des emplois moyennement qualifiés a régressé (graphique 9, partie A ; De Sloover et Saks, 2018). Malgré ces changements, la dispersion des salaires est restée faible et stable (graphique 9, partie B). 
Graphique 9. Le marché du travail est de plus en plus polarisé, mais la dispersion des salaires reste faible

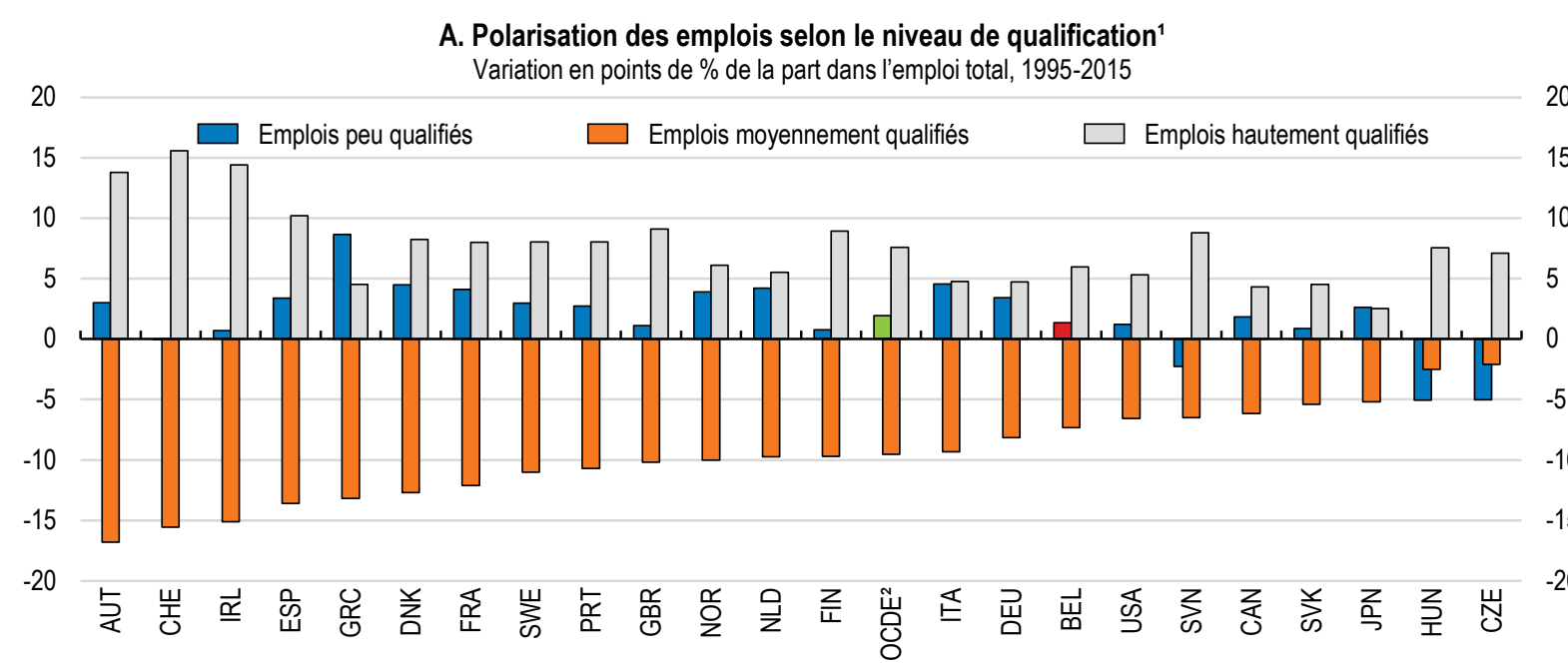

\section{B. Dispersion entre hauts et bas salaires}

5 Ratio, $2018^{3}$

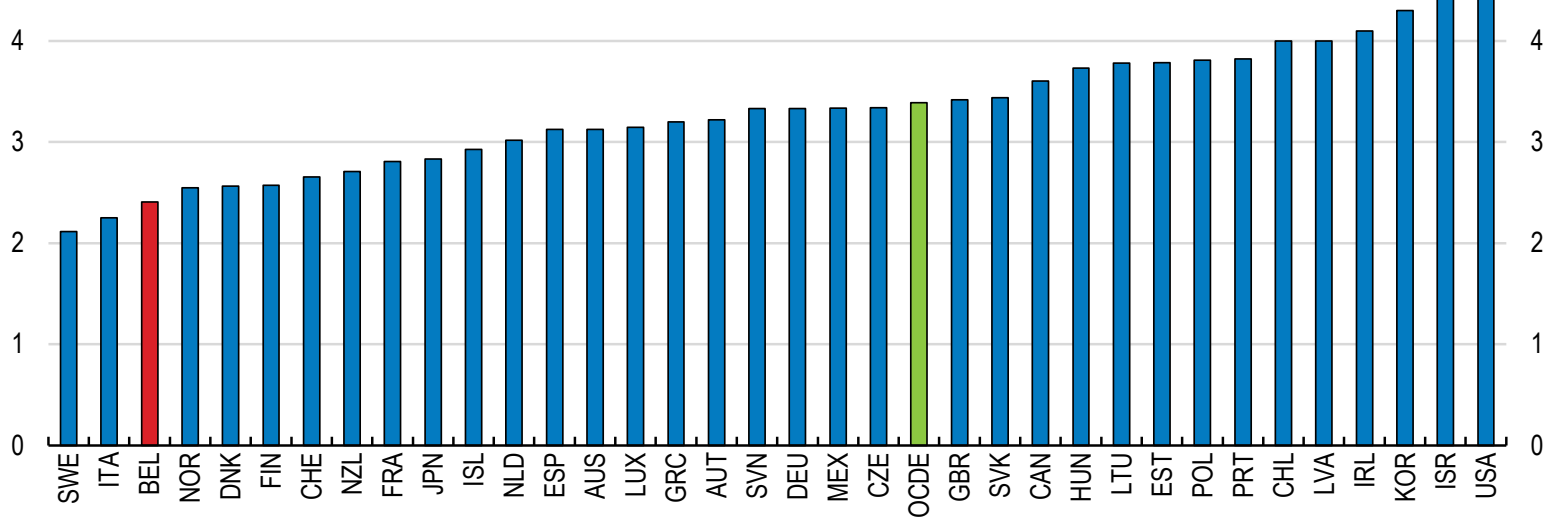

1. Les emplois hautement qualifiés sont définis comme étant ceux classés dans les grands groupes 1,2 et 3 de la CITP-88. Les emplois moyennement qualifiés sont ceux qui sont classés dans les grands groupes 4, 7 et 8 . Les emplois peu qualifiés sont ceux qui sont classés dans le grand groupe 5 . Voir OCDE (2017a) pour plus de détails.

2. Moyenne simple des 23 pays pour lesquels on dispose de données.

3. Ratio entre les neuvième et premier déciles des salaires, revenus d'activité bruts des salariés à plein temps ; 2018 ou dernière année pour laquelle des données sont disponibles.

Source : OCDE (2017), Perspectives de l'emploi de l'OCDE 2017, Éditions OCDE, Paris ; OCDE (2019), Statistiques de l'OCDE sur les rémunérations (base de données).

La transformation numérique pourrait avoir de profondes répercussions sur le marché du travail car elle permet aux entreprises de remplacer les travailleurs par des machines pour effectuer un certain nombre de tâches. En contrepartie, elle peut aussi aider les individus à accomplir leurs tâches, améliorer les conditions de travail et accroître la productivité et l'efficience. Selon des estimations du Conseil supérieur de l'emploi, $39 \%$ de l'emploi en Belgique serait susceptible d'une numérisation complète (CSE, 2016). Et il ressort des estimations de l'OCDE que $42 \%$ des emplois en Belgique sont exposés à un risque tangible de changement ou un risque élevé d'automatisation (graphique 10, partie A). Bien que ce problème soit moins aigu que dans d'autres pays de l'OCDE, la proportion significative de travailleurs qui ont une probabilité élevée de perdre leur emploi et le changement profond des 
compétences qui seront requises dans les emplois subsistants nécessiteront d'améliorer les politiques de formation tout au long de la vie. Or, le taux de participation des travailleurs dont l'emploi est exposé à un risque élevé d'automatisation aux mesures de formation tout au long de la vie est faible en Belgique, à $34.8 \%$ (graphique 10, partie B).

\section{Graphique 10. Face aux profonds changements que devraient connaître les emplois sous l'effet de l'automatisation, un recyclage des compétences sera nécessaire}
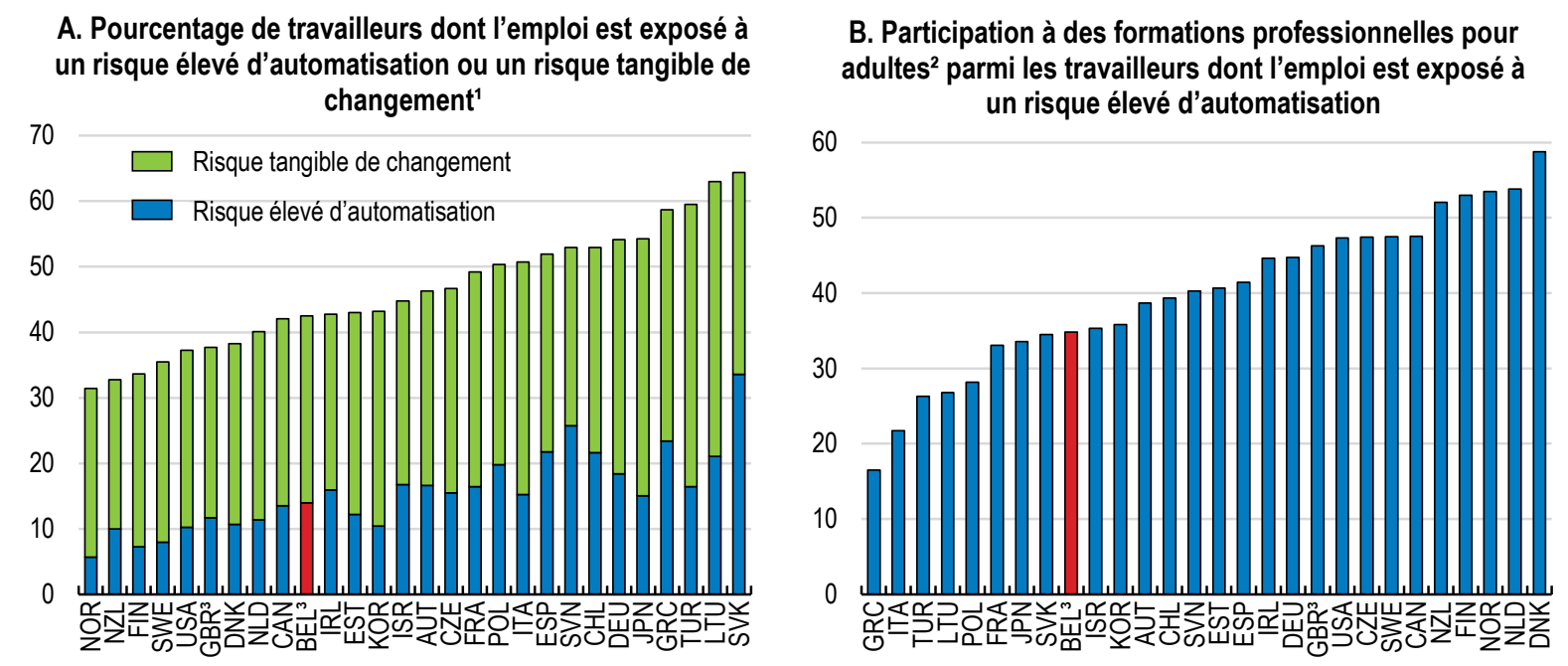

1. Un risque tangible de changement et un risque élevé d'automatisation correspondent à une probabilité d'automatisation comprise entre 50 et $70 \%$ et supérieure à $70 \%$ respectivement.

2. Pourcentage de travailleurs ayant suivi une formation pour adultes au cours des 12 mois précédant l'enquête.

3. Les données pour la Belgique portent uniquement sur la Flandre et les données pour le Royaume-Uni uniquement sur l'Angleterre et I'Irlande du Nord.

Source : Nedelkoska, L. et G. Quintini (2018), « Automation, Skills Use and Training », Documents de travail de l'OCDE sur les affaires sociales, l'emploi et les migrations, $n^{\circ} 202$, Éditions OCDE, Paris.

\section{Renforcer les compétences pour faire face à l'évolution des besoins du marché du travail et à la transformation numérique}

\section{Renforcer les compétences numériques}

Les technologies numériques offrent des possibilités considérables d'améliorer la productivité, un abondant corpus d'études ayant observé des liens positifs entre l'adoption des technologies numériques et la productivité à l'échelon de l'entreprise (Draca et al., 2009 ; Syverson, 2011). Par exemple, les estimations de l'OCDE indiquent que dans les pays de l'UE, une hausse de l'utilisation de l'internet haut débit ("cloud computing ") à l'échelon sectoriel est associée à une hausse de la productivité multifactorielle de l'entreprise moyenne du secteur. Cependant, en présence de pénuries de compétences, les gains de productivité sont plus faibles (Gal et al., 2019), résultat qui pourrait s'expliquer par les complémentarités existant entre les technologies numériques et d'autres formes de capital (telles que les compétences, l'organisation ou les actifs incorporels) (OCDE, 2019c). De fait, les travailleurs hautement qualifiés sont généralement mieux placés pour exploiter ces complémentarités, bénéficiant à la fois d'un taux d'activité plus élevé et de meilleurs salaires (OCDE, 2015a).

La diffusion des technologies de l'information et des communications (TIC) dans les entreprises a été relativement rapide en Belgique - plus que dans les pays voisins. Entre 1995 et 2014, les services du 
capital des TIC par heure travaillée ont augmenté de plus de $450 \%$, ce qui a probablement contribué aux pénuries importantes de compétences en TIC (graphique 11). D'après les résultats de l'enquête d'Eurostat sur les compétences numériques, $57 \%$ des Belges d'âge actif avaient des compétences numériques « de base ou inférieures au niveau de base » en 2017. La proportion correspondante chez les jeunes de 16--24 ans est également élevée en comparaison des autres pays européens (graphique 12). Le niveau de compétences numériques diminue parallèlement au niveau d'instruction et de revenu. Par conséquent, pour qu'entreprises et travailleurs profitent pleinement de la transformation numérique, il y a lieu d'améliorer à la fois le niveau général des compétences numériques et leur répartition.

\section{Graphique 11. La diffusion rapide des TIC a contribué aux pénuries de compétences en TIC}

A. Les TIC dans l'entreprise

Services du capital des TIC par heure travaillée' ${ }^{1}$, indice $1995=100$

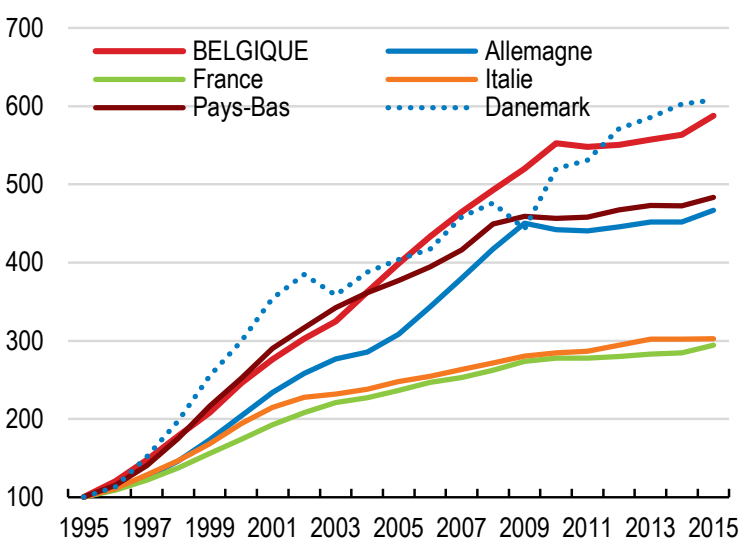

B. Entreprises faisant état de difficultés à pourvoir des postes de spécialistes des TIC

En pourcentage de l'ensemble des entreprises, $2018^{2}$

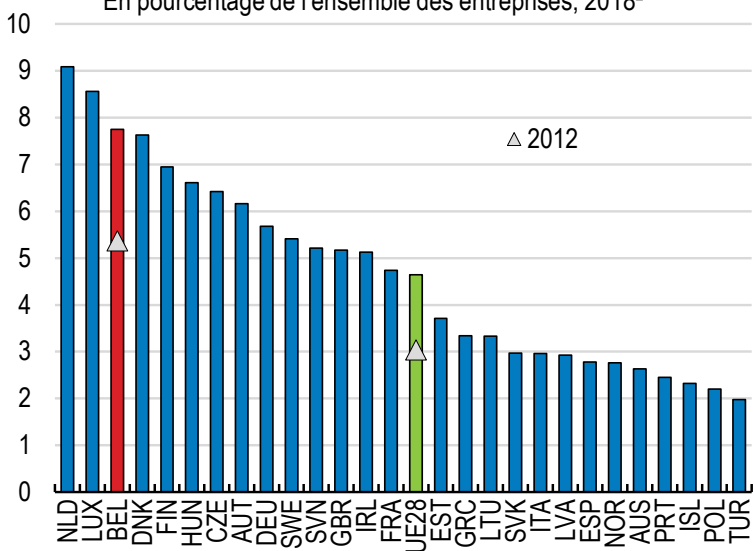

1. L'intensité en capital des technologies de l'information et des communications par heure travaillée correspond à la variable CAPIT_QPH dans la base de données EU KLEMS. Pour étendre les séries de données, on a utilisé la croissance du numérateur et du dénominateur du ratio d'intensité en TIC, en se référant à plusieurs éditions de la base de données EU KLEMS (2009, 2013 et 2017). Les valeurs pour le Danemark ont été corrigées pour tenir compte de l'augmentation anormalement élevée de l'intensité en TIC dans les industries extractives. 2. Les données portent sur l'exercice budgétaire 2015/16 pour l'Australie, et sur 2017 pour l'Islande.

Source : OCDE (2019), Perspectives de l'emploi de l'OCDE 2019, Éditions OCDE, Paris ; calculs fondés sur les données des Comptes de la croissance et de la productivité du projet EU KLEMS ; OCDE (2019), Measuring the Digital Transformation, Éditions OCDE, Paris.

Plusieurs initiatives individuelles ont déjà été mises en place pour élever le niveau des compétences numériques : par exemple, octroi de subventions à divers projets numériques, organisation de « foires aux compétences numériques », établissement d'un "Digital Hub » et formations aux technologies numériques pour les enseignants (encadré 4). Ces initiatives devraient être évaluées et, le cas échéant, rationalisées. Un ciblage plus resserré des formations numériques sur les personnes peu qualifiées et à faible revenu permettrait de corriger le déficit de compétences numériques précédemment décrit et élèverait le niveau général de ces compétences. Par exemple, dans la Région de Bruxelles-Capitale, l'organisme public Bruxelles Formation organise des formations numériques à l'attention des détenus faiblement qualifiés. II serait également souhaitable d'accroître le nombre de diplômés en STIM (voir ciaprès), et la généralisation des TIC en tant que discipline secondaire accessible à tout étudiant du cycle supérieur, recommandée dans l'Étude économique 2017 de la Belgique, permettrait de renforcer les compétences intermédiaires en TIC. 


\section{Graphique 12. Les compétences numériques sont faibles, en particulier dans certains groupes}

Pourcentage de déclarants indiquant avoir des compétences numériques de base ou inférieures au niveau de base $^{1}, 2017$

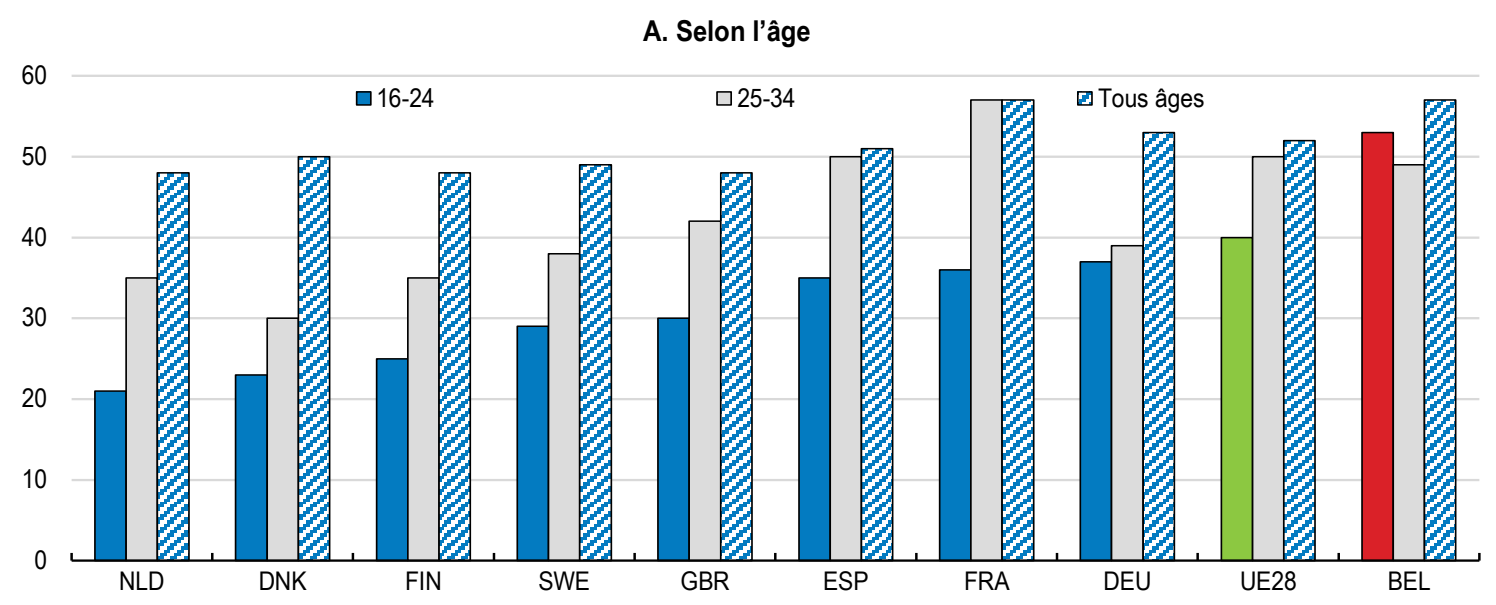

B. Selon le niveau d'instruction

Différence en pts de \% entre les personnes à niveau d'instruction formelle faible et les personnes à niveau

\section{Selon le revenu}

Différence en pts de \% entre les personnes à revenu faible et les personnes à revenu élevé ${ }^{3}$
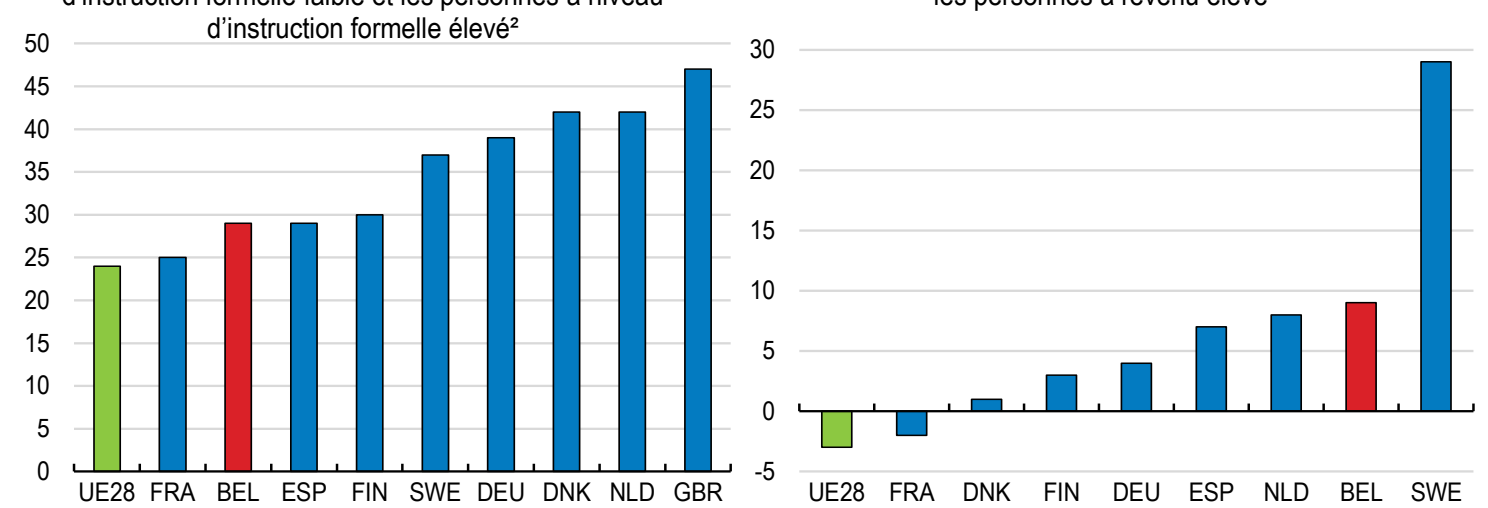

1. Sauf les personnes qui ont déclaré ne pas avoir utilisé l'internet au cours des trois mois précédant l'enquête et qui n'ont pas été interrogées sur leurs compétences numériques.

2. Personnes âgées entre 25 et 54 ans.

3. Les personnes à revenu élevé sont celles qui vivent dans un ménage dont le revenu est situé dans le quatrième quartile, et les personnes à revenu faible celles qui vivent dans un ménage dont le revenu est situé dans le premier quartile.

Source : Eurostat (2019), « Statistiques sur les aptitudes perçues », base de données Eurostat.

\section{Encadré 4. Quelques initiatives destinées à renforcer les compétences numériques}

Digital Belgium Skills Fund : ce fonds établi en avril 2017 finance des projets qui améliorent les compétences numériques des enfants et des jeunes adultes socialement vulnérables. Les projets sélectionnés sont admissibles à un soutien financier compris entre 50000 et 500000 EUR, et 37 projets en ont bénéficié en 2018.

DigitalChampions.be : la coalition belge en faveur des compétences numériques (« Belgium National Coalition for Digital Skills and Jobs ») réunit des parties prenantes du gouvernement, du secteur éducatif et du secteur privé. Elle mène des activités diverses telles que formations, ateliers et certifications pour permettre aux citoyens de tous âges et de tous milieux de renforcer leurs compétences numériques. En outre, DigitalChampions a organisé en mai 2017 sa première Foire aux compétences numériques, suivie d'une deuxième édition en 2018. 
BeCentral: Un campus numérique a été établi à Bruxelles en 2017 par les partenaires de la Coalition nationale et plus de 40 entrepreneurs. II a pour objectif de doter au moins 10000 personnes de compétences numériques et accueille plus de 30 initiatives en lien avec le numérique, dont des écoles de codage et des programmes de cybersécurité.

WallCode.be: Digital Wallonia s'est donné pour objectif de développer les compétences numériques des jeunes au travers du projet \#WallCode, qui met l'accent sur le codage, la logique algorithmique et les langages de programmation. Ses actions comprennent des animations sur la programmation pour les élèves, des formations aux technologies numériques pour les enseignants et l'organisation de " semaines du code ».

CoderDojo: CoderDojo organise des ateliers de programmation gratuits pour les 7-18 ans. L'initiative bénéficie du soutien de la Région flamande, de même que d'autres initiatives telles CodeFever (programme de formation plus formel) et CodeSchools (en milieu scolaire).

FabLab Mobile : financé par l'institut d'encouragement de l'innovation de la Région de BruxellesCapitale (Innoviris), le FabLab Mobile est un atelier itinérant installé dans un camion qui permet à des jeunes (10-18 ans) de participer à des projets liés aux technologies numériques et à la programmation.

En outre, les diverses réformes récentes ou en cours dans l'enseignement obligatoire devraient améliorer des compétences numériques des élèves. La Communauté française a établi une Stratégie numérique pour l'éducation en 2018 et adopté en février 2019 un décret sur la formation initiale des enseignants qui introduit de nouveaux contenus relatifs aux TIC, prépare les enseignants à la mise en œuvre de dispositifs d'enseignement intégrant les outils numériques, et prépare l'accès aux épreuves du master de spécialisation en techno-pédagogie. De même, en 2018, la Flandre a adopté une réforme des programmes devant être déployée progressivement à partir de septembre 2019, qui fixe de nouveaux acquis d'apprentissage et résultats à atteindre dans le domaine des TIC pour le premier cycle du secondaire.

On peut également renforcer les compétences numériques en encourageant la participation à la formation des adultes, qui est faible en Belgique (voir ci-après). II serait sans doute possible d'améliorer l'efficacité des dispositifs de formation des salariés et d'accroître la transférabilité des compétences acquises entre les entreprises et entre les secteurs. Plus particulièrement, une bonne partie de la formation des salariés est organisée à l'échelon sectoriel en Belgique, et $51 \%$ des salariés travaillent dans un secteur qui a pris des mesures concrètes pour promouvoir la formation au niveau sectoriel. Parmi eux, $58 \%$ ont bénéficié de deux jours de formation en moyenne par an, et $14 \%$ de cinq jours de formation en moyenne par an (Service Public Fédéral Emploi, Travail et Concertation Sociale, 2017). Les partenaires sociaux gagneraient à coopérer davantage et à mieux coordonner les formations sur les compétences numériques, par exemple en établissant un fonds central pour la formation.

\section{Améliorer l'enseignement et la formation professionnels}

Le chômage des jeunes et la proportion de jeunes qui ne sont ni en emploi, ni scolarisés, ni en formation (NEET) sont relativement élevés en Belgique (graphique 13). L'enseignement et la formation professionnels (EFP) ont un rôle important à jouer pour préparer les jeunes au monde du travail, développer leurs compétences et répondre aux besoins du marché du travail. On s'accorde largement à reconnaître que les programmes qui comportent un élément de formation en milieu professionnel sont efficaces pour développer les compétences générales et les compétences spécifiques à l'emploi, en combinant formation et travail (OCDE, 2010). Les aptitudes relationnelles, qui revêtent une importance grandissante (Deming et Kahn, 2018), s'acquièrent en général plus facilement sur le lieu de travail que 
dans la salle de classe (OCDE, 2010). Des données indiquent de surcroît que la formation en milieu de travail, dans le cadre d'un apprentissage par exemple, peut avoir retombées positives sur la situation professionnelle, tant en termes de durée de la recherche du premier emploi que de temps passé par les jeunes dans leur premier emploi (Bratberg et Nilsen, 1998). La formation en milieu de travail est également utile aux employeurs car elle comporte un volet travail adapté aux besoins de l'entreprise et facilite le recrutement (Mühlemann, 2017 ; Kuczera, 2017).

\section{Graphique 13. Les jeunes sont relativement mal lotis au regard de l'emploi}
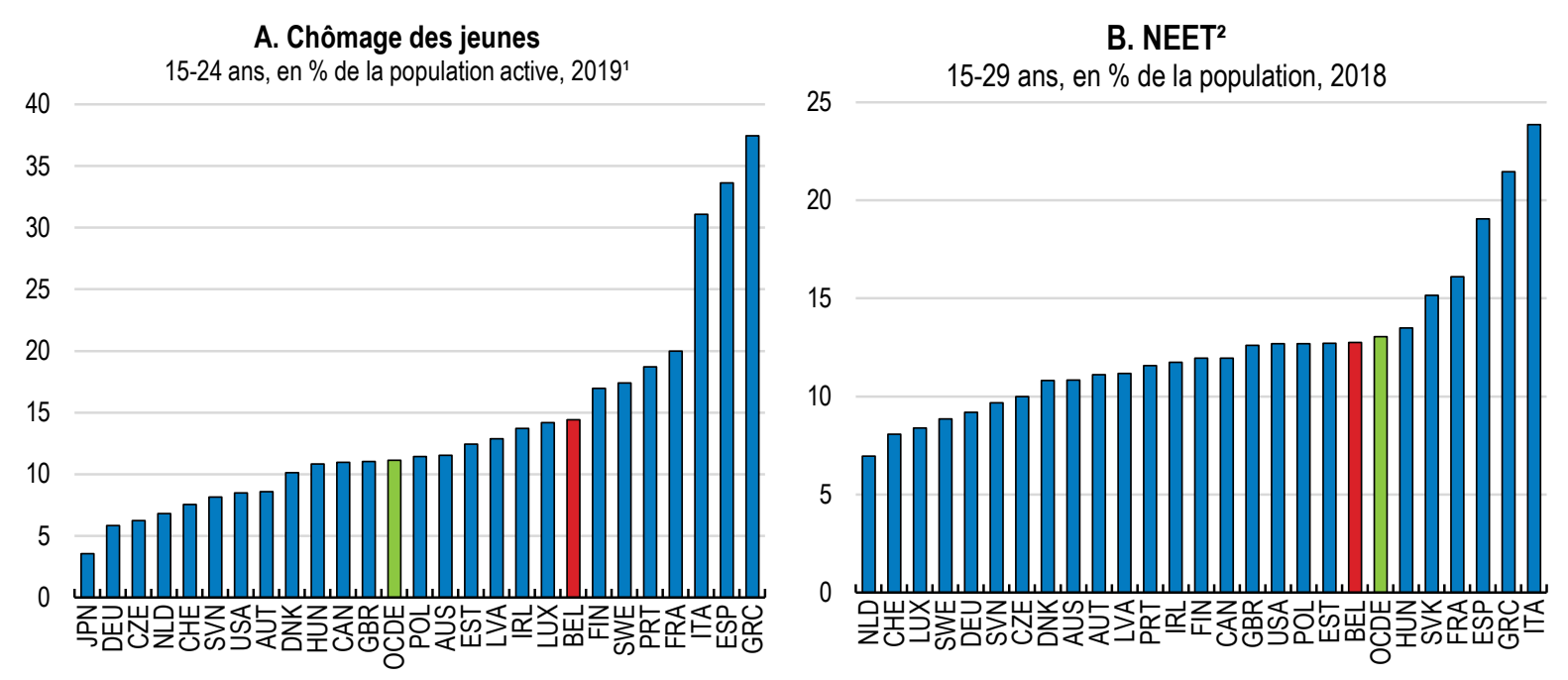

1. Moyenne des quatre derniers trimestres.

2. Jeunes ni en emploi, ni scolarisés, ni en formation.

Source : OCDE (2019), Statistiques de la population active de l'OCDE et Statistiques de l'OCDE sur l'éducation (bases de données).

La part des élèves du deuxième cycle du secondaire inscrits dans une filière professionnelle est élevée en Belgique : $59 \%$, contre $44 \%$ en moyenne dans la zone OCDE. Cependant, la proportion d'élèves inscrits dans un programme d'EFP par alternance associant formation scolaire et formation en milieu professionnel est de seulement $3 \%$, soit beaucoup moins que la moyenne OCDE de $11 \%$ (graphique 14, partie A). La faible proportion d'élèves qui suivent un programme d'EFP par alternance se double d'une proportion relativement élevée de diplômés de l'EFP qui ne sont ni en emploi, ni scolarisés, ni en formation (NEET) - environ $24 \%$ (graphique 14, partie B).

Plusieurs initiatives récentes visent à améliorer la composante formation en milieu professionnel de I'EFP. La Communauté flamande a approuvé un nouveau décret sur la formation par alternance qui entrera en vigueur en septembre 2019 avec 87 programmes d'étude. L'une des composantes importantes du nouveau modèle est l'outil en ligne werkplek duaal, qui permet aux entreprises de faire accréditer leurs places d'apprentissage (Syntra Vlaanderen, 2017). La Communauté française a conçu un projet pilote de stages d'immersion en entreprise axé sur les secteurs ou disciplines confrontés à des pénuries de main-d'œuvre. Le Plan Formation 2020 de la Région de Bruxelles-Capitale, adopté en décembre 2016, comporte un certain nombre de mesures telles que la création du label « entreprise formatrice », qui garantit que l'entreprise labélisée offre une formation de qualité.

Dans les pays de l'OCDE, le risque de devenir « NEET » est souvent plus élevé parmi les diplômés de l'EFP que parmi ceux de l'enseignement général, en raison notamment d'une moindre probabilité de poursuivre des études dans le cycle supérieur. La proportion de diplômés de l'EFP post-secondaire qui effectuent des études supérieures est de $2.4 \%$ en Belgique, ce qui est faible à l'échelon international (graphique 14, partie C). Des mesures récentes pourraient renforcer les liens entre l'EFP et l'enseignement supérieur. À partir de septembre 2019, dans la Communauté flamande, les 
responsabilités en matière d'EFP post-secondaire seront transférées des centres de formation des adultes aux établissements d'enseignement supérieur (OCDE, 2018c). De même, en 2016, la Communauté française a approuvé un décret qui permet aux étudiants d'obtenir un diplôme délivré par un établissement d'enseignement supérieur en combinant formation en entreprise et formation dans l'établissement en question (OCDE, 2018c).

\section{Graphique 14. L'enseignement professionnel pourrait être amélioré}

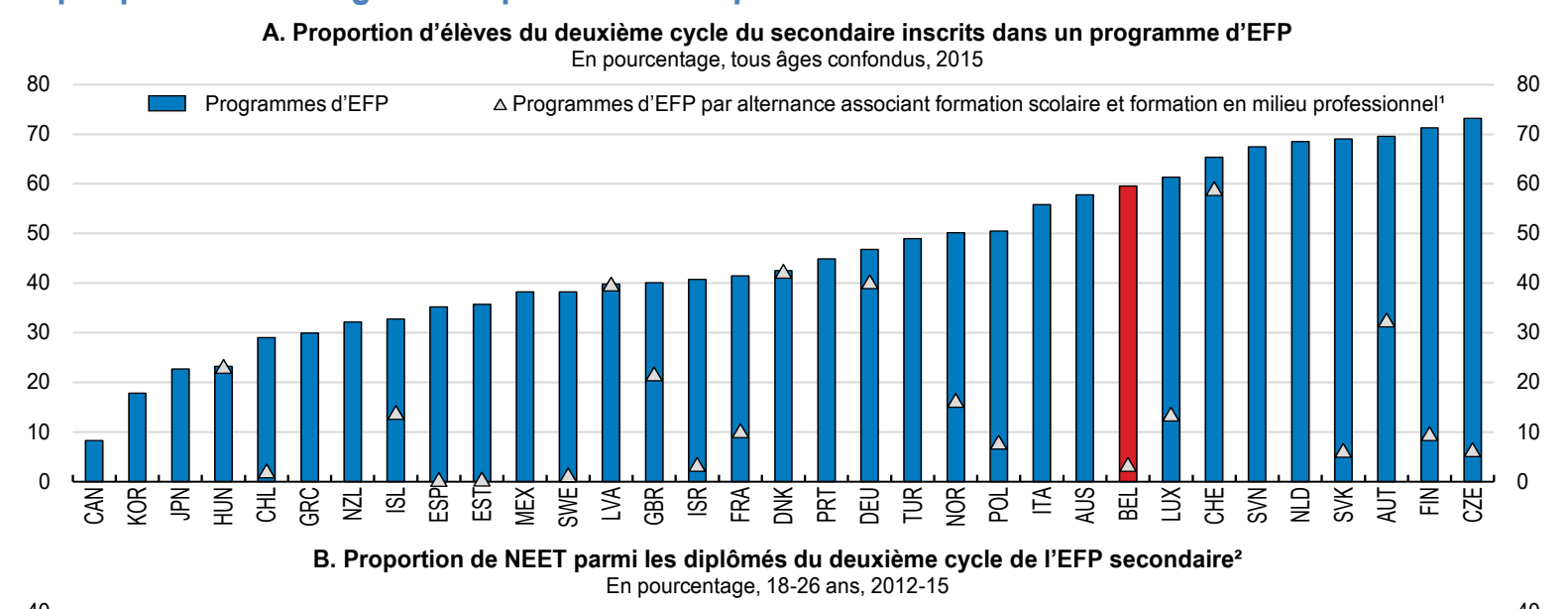
En pourcentage, $18-26$ ans, 2012-15

$35 \longrightarrow 35$
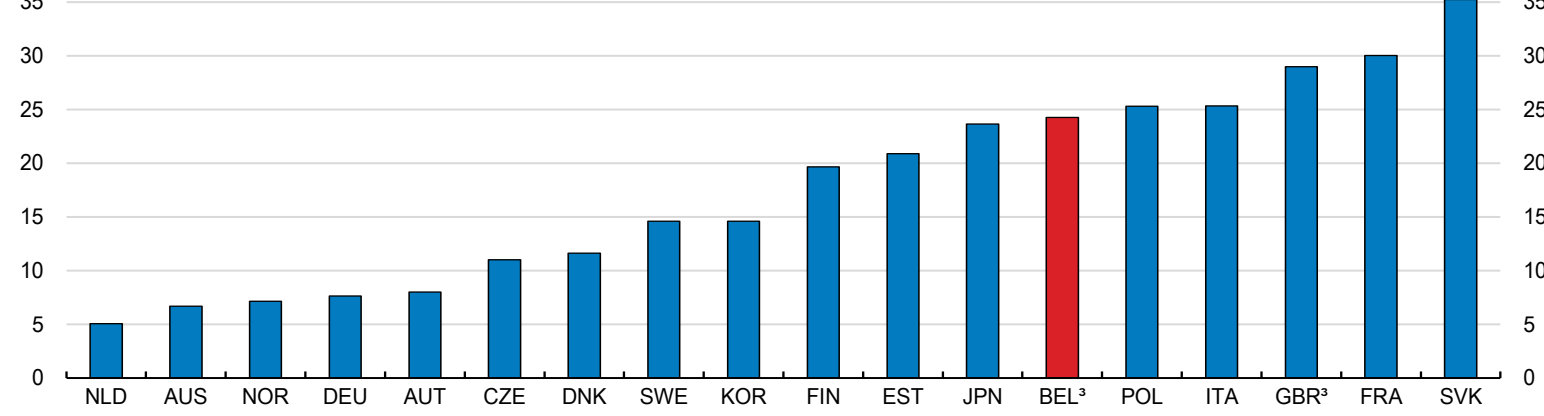

C. Proportion de diplômés de l'EFP post-secondaire suivant des études supérieures En pourcentage, diplômés des niveaux CITE 5A ou 5B âgés entre 18 et 26 ans, 2012-15

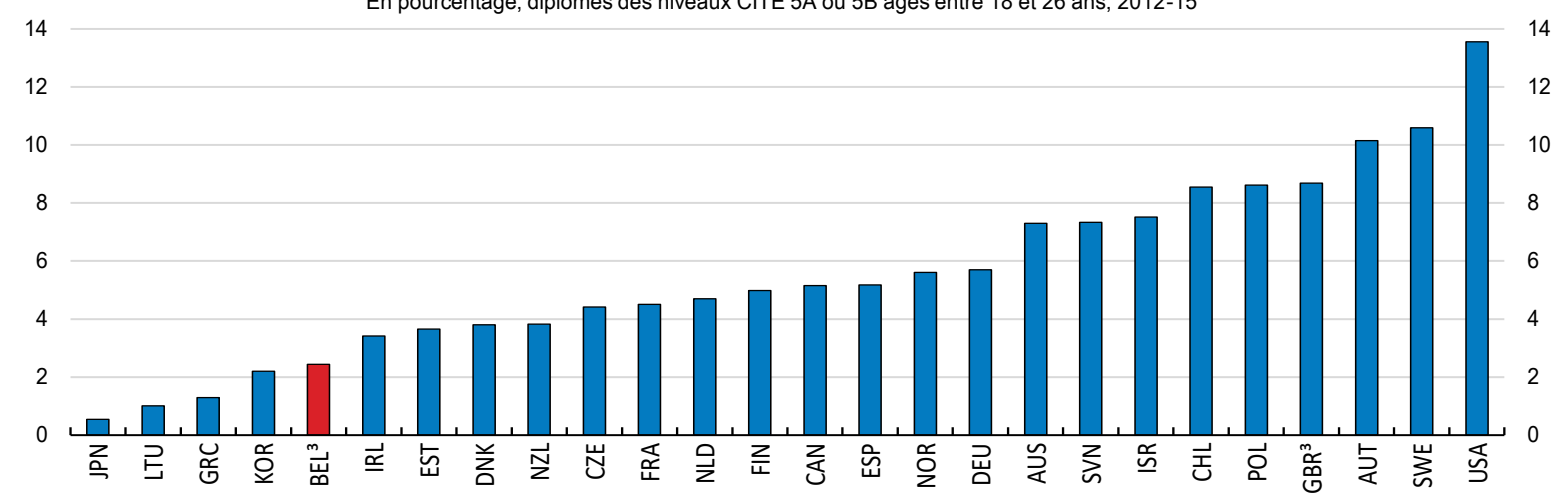

1. Les programmes d'EFP par alternance associant formation scolaire et formation en milieu professionnel sont ceux dans lesquels entre $25 \%$ et $90 \%$ de la formation sont assurés en milieu professionnel. Pour l'Australie, le Canada, la Corée, la Grèce, l'Italie, le Japon, le Mexique, la Nouvelle-Zélande, les Pays-Bas, le Portugal, la Slovénie et la Turquie, les informations sur les programmes par alternance ne sont pas disponibles ou cette catégorie n'est pas pertinente.

2. Ni en emploi, ni scolarisés, ni en formation. Le deuxième cycle de l'EFP secondaire recouvre les programmes classés dans les niveaux $3 \mathrm{C}$ long, $3 \mathrm{~B}$ et $3 \mathrm{~A}$ de la $\mathrm{CITE}$ et considérés par les pays comme ayant une orientation professionnelle.

3. Les données relatives à la Belgique et au Royaume-Uni portent uniquement sur la Flandre et l'Angleterre respectivement.

Source : OCDE (2017), Regards sur l'éducation 2017, Éditions OCDE, Paris ; calculs effectués par l'OCDE à partir de l'Évaluation des compétences des adultes (PIAAC) de l'OCDE (bases de données 2012-2015). 
Les petites entreprises étant relativement nombreuses en Belgique, les coûts fixes induits par la formation et l'apprentissage en milieu professionnel - coûts d'administration, de supervision et de formation des superviseurs - peuvent être prohibitifs pour beaucoup d'employeurs. Les formateurs en entreprise pourraient utiliser davantage les outils de formation en ligne, et les alliances de formation pourraient être encouragées pour aider les entreprises qui n'ont pas la possibilité de former leurs apprentis à l'ensemble des compétences requises pour une profession particulière. Par exemple, certains Länder d'Autriche soutiennent les alliances de formation en diffusant des informations et en orientant les entreprises vers des partenaires potentiels - autres entreprises ou établissements d'enseignement - ainsi qu'en coordonnant différentes activités de formation (ministère fédéral autrichien des Sciences, de la Recherche et de l'Économie, 2014).

En outre, le nouveau modèle d'EFP par alternance et les divers projets pilotes devraient être évalués du point de vue des élèves et des entreprises. Par exemple, les régions octroient différents types de subventions directes. Des études portant sur la Suisse suggèrent que les subventions directes sont plus efficaces pour les firmes qui ne sont pas encore impliquées dans les formations en entreprises par rapport à celles qui offrent déjà ce type de formation (OCDE, 2015b). Dans d'autres pays de l'OCDE, les apprentis reçoivent une compensation financière pour rendre l'apprentissage plus attractif à la fois pour les étudiants et les employeurs. En Australie et en Norvège, des institutions dédiées ont pour but de faciliter les appariements entre employeurs et futurs apprentis, et aussi de favoriser la coopération entre PMEs pour remplir les tâches administratives liées à l'apprentissages. II faudrait également évaluer et, le cas échéant, étendre et renforcer les dispositifs de soutien financier existants à la formation en alternance, comme les subventions directes, tant pour les entreprises que pour les élèves. Ces mesures pourraient s'accompagner d'une obligation pour les entreprises d'être accréditées et de renouveler leur accréditation, pour garantir le maintien de la qualité.

\section{Accroître l'attrait des études en STIM}

En Belgique, la proportion d'étudiants de l'enseignement supérieur diplômés en sciences, technologie, ingénierie ou mathématiques (STIM) est tombée de $22.4 \%$ en 2005 à seulement $18.2 \%$ en 2017 , une proportion nettement inférieure à la moyenne OCDE de $27 \%$ (graphique 15). De même, en 2015, seulement $25 \%$ des diplômés du deuxième cycle de l'EFP secondaire avaient un diplôme en « ingénierie, fabrication et construction », contre $34 \%$ à l'échelle de l'OCDE. D'après la base de données des compétences pour l'emploi de l'OCDE, les activités professionnelles, scientifiques et techniques, ainsi que l'information et la communication, font partie des secteurs confrontés à des pénuries de main-d'œuvre en Belgique (OCDE, 2018d).

Un grand nombre d'initiatives ont été lancées pour accroître le nombre de diplômés dans les disciplines des STIM. Deux des cinq objectifs clés du Plan d'action 2012-2020 sur les STIM de la Flandre, qui vise à augmenter le nombre de diplômés en STIM, sont d'ores et déjà atteints (par exemple, entre 2010 et 2017, le pourcentage de nouveaux entrants dans les formations de bachelier optant pour une filière STIM a grimpé de $23.8 \%$ à $26.6 \%$ ). Ce plan prévoyait d'améliorer la promotion et la communication autour des filières STIM, de renforcer la formation des enseignants des disciplines STIM, d'améliorer les processus qui guident les choix d'études et de carrière et d'attirer davantage de filles dans les formations et les professions liées aux STIM. La Communauté française n'a pas de plan d'action particulier en faveur des STIM mais a pris diverses initiatives pour encourager les étudiants à suivre une formation dans ces disciplines. Une diffusion plus large des données relatives aux avantages de salaire par domaine d'études, en complément des données par niveau d'études, pourrait inciter davantage d'étudiants à opter pour les STIM (OCDE, 2017a).

Autre facteur susceptible d'avoir une incidence sur le nombre de diplômés en STIM, les salaires relatifs des diplômés dans ces disciplines en comparaison des diplômés issus d'autres cursus. Si, en Belgique, les diplômés en STIM perçoivent en moyenne des salaires plus élevés que les diplômés dans des 
domaines autres que les STIM, des données indiquent que cet avantage salarial est faible en comparaison de la situation d'autres pays de l'UE (Goos et al., 2013), quoique l'avantage en termes de salaire dépende du niveau de qualification STIM (secondaire, licence ou master). Par conséquent, peutêtre faudra-t-il que les employeurs améliorent la rémunération des spécialistes des STIM pour attirer davantage d'étudiants dans ces filières.

\section{Graphique 15. La proportion de diplômés en STIM dans l'enseignement supérieur est faible}

Titulaires d'un diplôme de l'enseignement supérieur en sciences naturelles, ingénierie ou TIC, en \% de l'ensemble des diplômés de l'enseignement supérieur', 2017

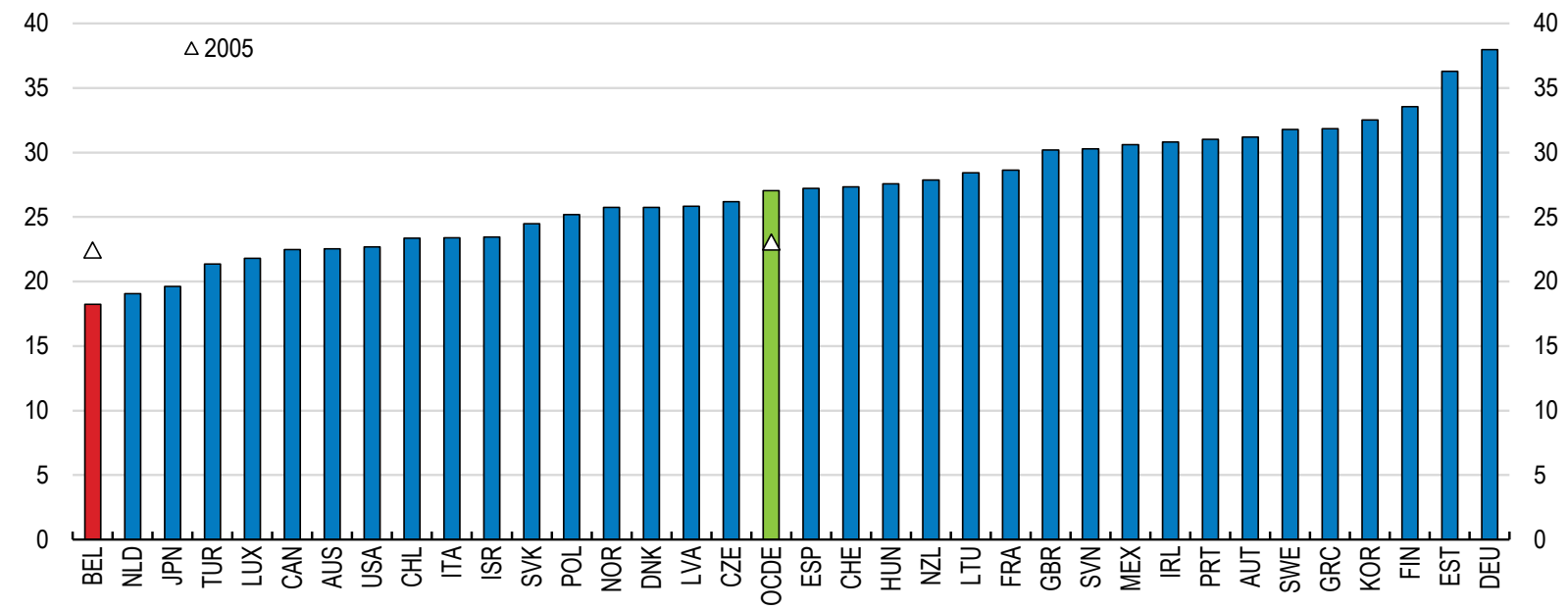

1. Les diplômés de l'enseignement supérieur sont ceux dont le niveau d'études est compris entre les niveaux 5 et 8 de la CITE. Les diplômés en TIC sont classés dans d'autres domaines au Japon, et les données relatives aux Pays-Bas ne comprennent pas les titulaires d'un doctorat. Source : OCDE (2019), Statistiques de l'OCDE sur l'éducation - Diplômés par domaine (base de données).

\section{Instiller une nouvelle culture de la formation tout au long de la vie}

La formation tout au long de la vie est un moyen d'éviter la dépréciation ou l'obsolescence des compétences et facilite la transition des emplois et secteurs en déclin vers les professions émergentes dans le contexte d'un changement technologique rapide. Elle est d'autant plus importante que, du fait du vieillissement démographique, les individus sont obligés d'entretenir et d'actualiser leurs compétences sur des carrières professionnelles de plus en plus longues (OCDE, 2019b). Cet aspect revêt une importance particulière en Belgique, où le succès de la réforme récente des retraites - notamment le durcissement des conditions de départ en retraite anticipé et le relèvement de l'âge légal de la retraite - sera subordonné à la capacité de maintenir les seniors sur le marché du travail.

À $8.5 \%$ en 2018, le taux de participation à la formation tout au long de la vie en Belgique est inférieur à la moyenne de l'UE de $11.1 \%$ et à l'objectif d'un taux moyen de $15 \%$ dans l'UE fixé par le cadre Éducation et formation 2020 (graphique 16, partie A). Par ailleurs, la participation est très variable selon les régions : elle est presque deux fois plus élevée à Bruxelles (12.6\%) qu'en Wallonie (6.7\%). Les obstacles à la participation des adultes les plus fréquemment cités en Flandre sont le manque de temps à cause du travail, la difficulté de concilier formation et obligations familiales, et les horaires et lieux peu pratiques des formations pour adultes, ces contraintes étant toutes plus répandues que dans l'OCDE en moyenne. Si le coût est aussi considéré comme un obstacle important par certains, c'est un facteur moins problématique en Flandre que dans d'autres pays de l'OCDE (graphique 16, partie B). 
Graphique 16. Les politiques relatives à la formation tout au long de la vie pourraient être améliorées

\section{5-64 ans}

A. Participation à la formation tout au long de la vie En pourcentage de la population ${ }^{1}, 2018$

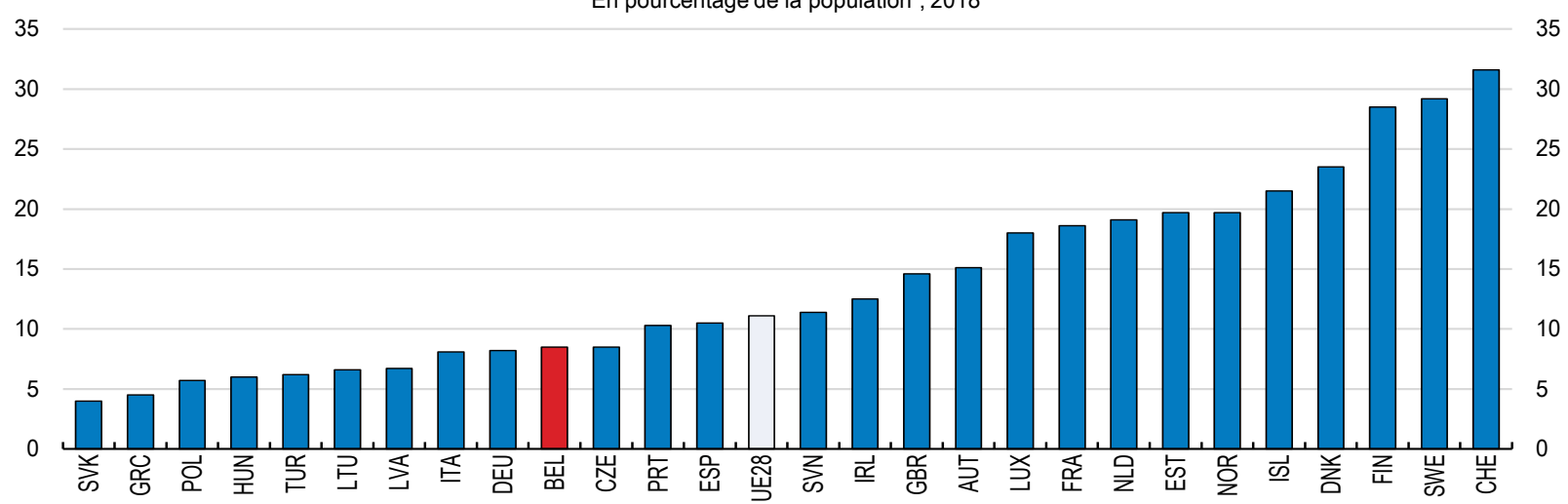

B. Obstacles à la participation à la formation tout au long de la vie En \% du total, 2012-15

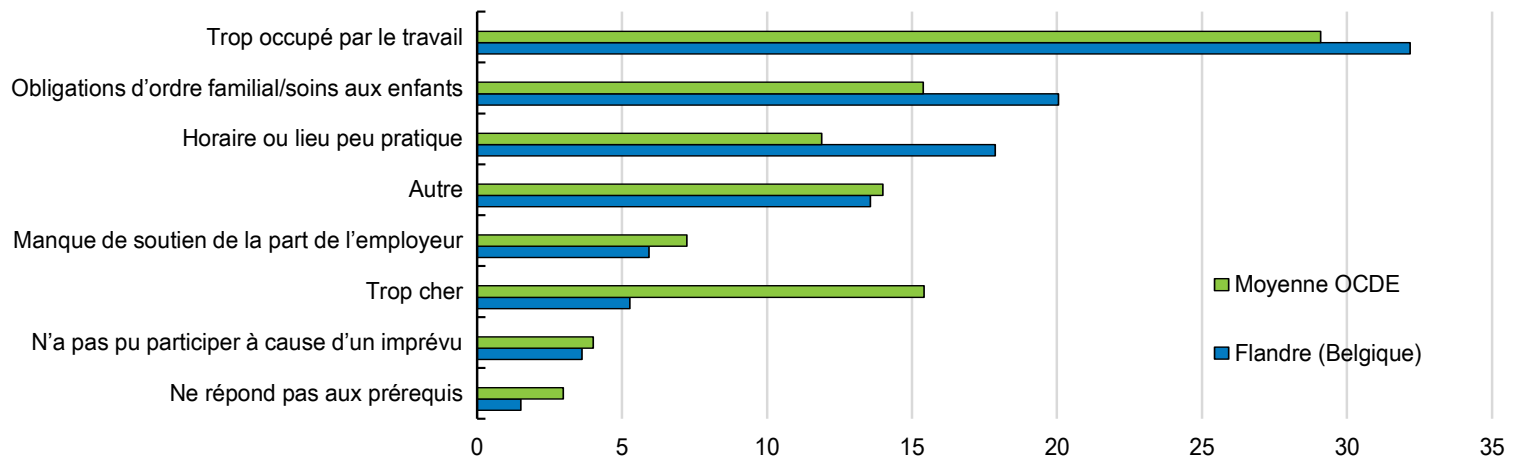

C. Impact perçu de la formation tout au long de la vie ${ }^{3}$

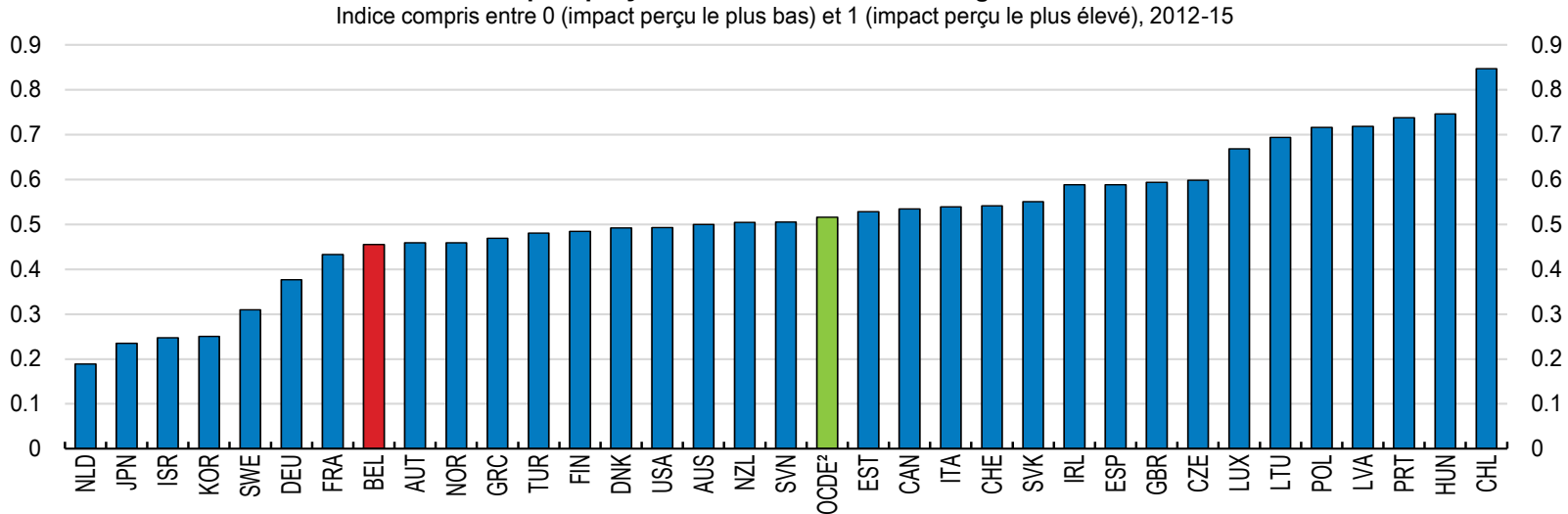

1. Adultes ayant suivi une formation au cours des quatre semaines précédant l'enquête.

2. Moyenne non pondérée de 34 pays.

3. L'indicateur mesure l'impact perçu sur quatre dimensions ressenties : utilité de la formation, utilisation des compétences acquises, situation au regard du marché du travail et rendement de la formation en termes de salaire.

Source : Eurostat (2019), "Statistiques de la formation des adultes », base de données Eurostat; OCDE (2019), OECD Skills Strategy Flanders, Éditions OCDE, Paris ; OCDE (2019), Getting Skills Right: Future-Ready Adult Learning Systems, Getting Skills Right, Éditions OCDE, Paris. 
La participation à la formation des adultes peut avoir un impact sur un grand nombre d'aspects, dont certains ne sont pas faciles à mesurer. L'OCDE a conçu un nouvel indicateur d'impact de la formation des adultes qui met l'accent sur quatre dimensions clés: satisfaction ressentie, utilisation des compétences, situation au regard du marché du travail et rendement de la formation en termes de salaire. Les résultats indiquent que l'impact perçu de la formation des adultes est relativement faible en Belgique (graphique 16, partie C ; OCDE, 2019d).

On constate également des écarts de participation importants selon les caractéristiques individuelles. Le taux de participation à la formation tout au long de la vie des adultes peu qualifiés est inférieur d'environ 38 points au taux de participation des adultes hautement qualifiés (graphique 17, partie A). Les obstacles les plus fréquemment cités diffèrent entre ces groupes: les personnes peu qualifiées invoquent le manque de temps dû aux obligations familiales, et les plus qualifiées le manque de temps dû aux obligations professionnelles. Par conséquent, les interventions devront cibler différents obstacles selon les groupes auxquels elles sont destinées (OCDE, 2019e). La participation des seniors aux formations est inférieure de 30 points à la participation des travailleurs plus jeunes (graphique 17, partie B). Enfin, bien qu'ils soient plus disposés à suivre une formation, les travailleurs temporaires affichent un taux de participation inférieur de plus de 15 points à celui des travailleurs permanents à plein temps, soit l'un des écarts relatifs les plus élevés parmi les pays de l'OCDE (graphique 17, partie C).

Un certain nombre de mesures ont été adoptées récemment pour accroître la participation à la formation tout au long de la vie. En 2018, par exemple, la Flandre a adopté une réforme du congé-éducation payé qui permettra à tous les travailleurs du secteur privé de bénéficier de 125 heures de formation annuelles avec maintien du salaire, et approuvé un nouveau décret qui améliore la reconnaissance des acquis d'apprentissage (OCDE, 2019e). En 2017, la Communauté française a adopté un décret visant à harmoniser les pratiques d'évaluation dans les établissements d'enseignement et à favoriser la reconnaissance des acquis d'apprentissage, de manière à accroître la participation des adultes à la formation tout au long de la vie. Les réformes engagées dans la Région de Bruxelles-Capitale ont amélioré la validation des compétences acquises hors des parcours de formation classiques.

II reste néanmoins une marge considérable d'amélioration de la participation à la formation tout au long de la vie. À l'échelon fédéral, le système de formation a été modifié en 2017 : les entreprises doivent désormais offrir à leurs salariés au moins cinq jours de formation en moyenne par an, alors qu'auparavant, les employeurs devaient consacrer, ensemble, $1.9 \%$ de la masse salariale totale aux programmes de formation continue. À court terme, il faudra veiller en priorité à ce que cette législation soit correctement mise en œuvre et appliquée, comme le recommande l'Étude économique de 2017 sur la Belgique. Toutefois, ces nouvelles dispositions ne garantissent pas que les travailleurs qui ont le plus besoin de formation y auront effectivement accès, car les obligations sont fixées à l'échelon de l'entreprise et non à l'échelon individuel. II serait donc souhaitable, lors d'une première étape, de faire en sorte que le droit à la formation soit appliqué à chaque travailleur individuel et non à la moyenne de l'ensemble des salariés.

À plus long terme, il pourra être envisagé d'apporter d'autres modifications au système pour s'assurer que les travailleurs aient accès des formations adéquates leur permettant d'acquérir les compétences recherchées sur le marché du travail. Premièrement, il est essentiel de recueillir des informations de qualité concernant l'évaluation et l'anticipation des besoins en compétences afin de déterminer les besoins en compétences actuels et futurs. Deuxièmement, ces informations pourront être utilisées pour orienter les travailleurs et les employeurs, établir des incitations ciblées et mettre en place des formations adaptées aux besoins en compétences (OCDE, 2019d). Enfin, pour que l'ensemble des travailleurs aient accès à des formations pertinentes et conservent la trace de toutes les formations suivies et qualifications acquises - un aspect utile en cas de changement d'emploi - des allocations de formation individualisées pourraient être créées. 
Graphique 17. Tout en étant disposés à suivre une formation, certains groupes défavorisés n'ont accès qu'à des possibilités de formation limitées

\section{2-2015}

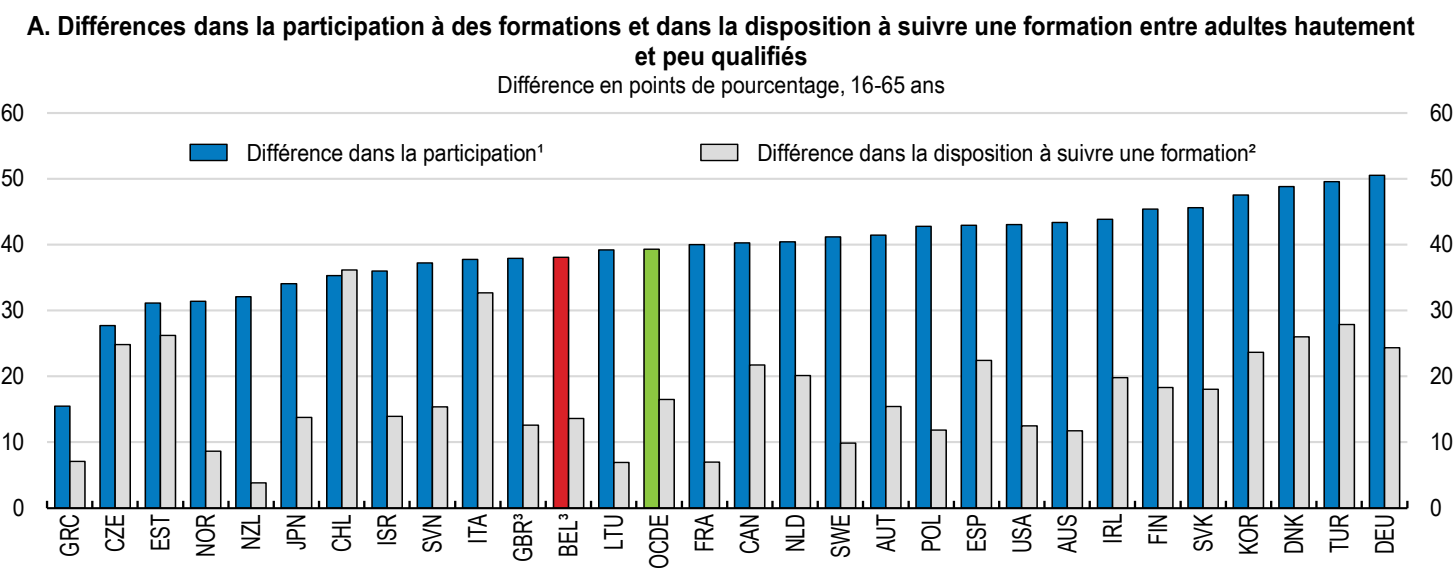

B. Différences dans la participation à des formations et dans la disposition à suivre une formation entre jeunes adultes et seniors

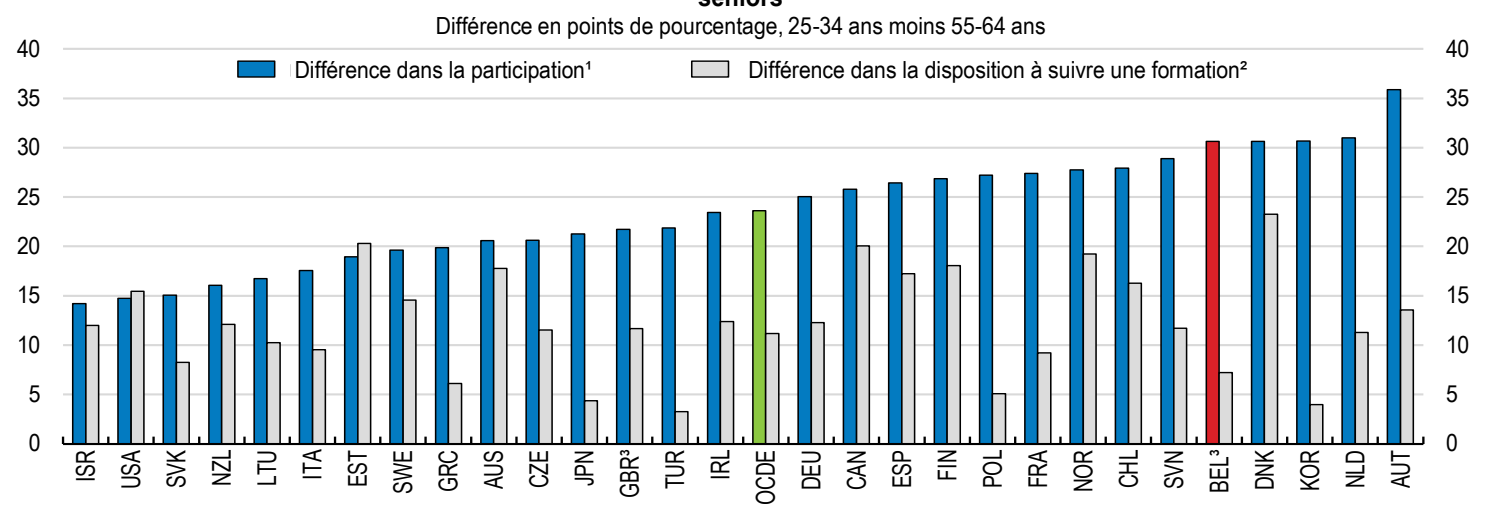

C. Différences dans la participation à des formations et dans la disposition à suivre une formation entre travailleurs permanents à plein temps et travailleurs temporaires Différence en points de pourcentage, 16-65 ans

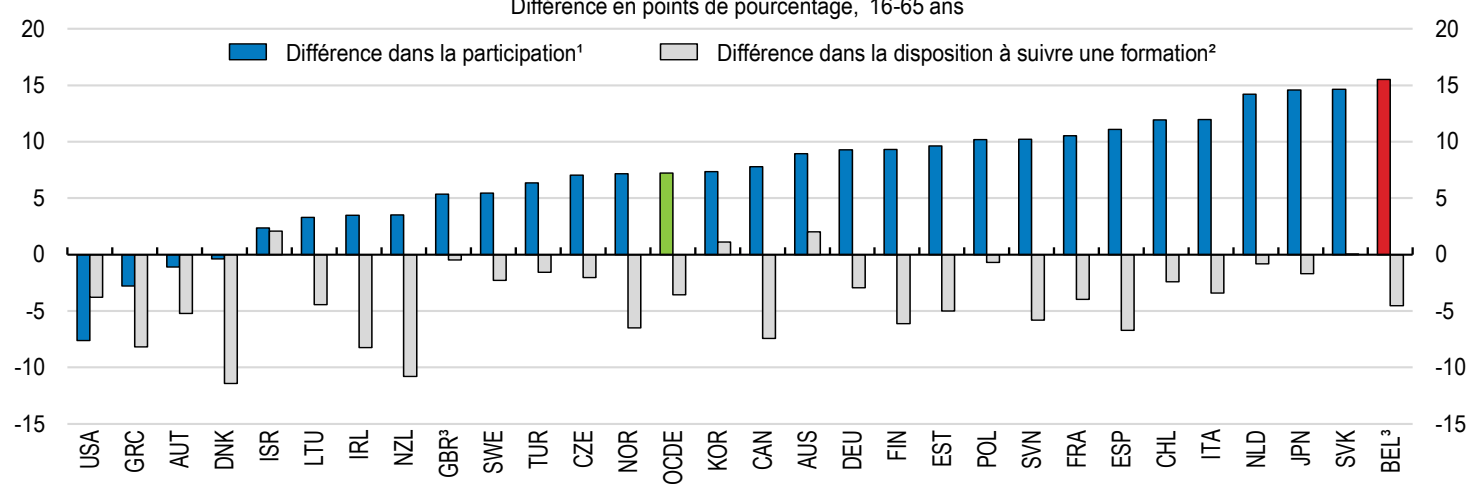

1. La différence dans la participation correspond à la différence en points dans la part d'adultes ayant suivi une formation au cours des 12 mois précédents. Une valeur positive indique que cette part est plus élevée pour les adultes hautement qualifiés que pour les adultes peu qualifiés (partie A), pour les jeunes adultes que pour les seniors (partie B) et pour les salariés permanents à plein temps que pour les salariés temporaires (partie C).

2. La différence dans la disposition à suivre une formation correspond à la différence, en points de pourcentage, dans la part des adultes qui n'ont pas suivi de formation mais qui auraient souhaité le faire, selon les réponses fournies au questionnaire du PIAAC.

3. Les données pour la Belgique portent sur la Flandre et les données pour le Royaume-Uni sur l'Angleterre et l'Irlande du Nord. Source : OCDE (2019b), Perspectives de l'emploi de l'OCDE 2019 : L'Avenir du travail, Éditions OCDE, Paris. 
La mise en place de ces allocations de formation individualisées devra s'accompagner d'une offre de formations de qualité dans les domaines de compétence recherchés par les employeurs et, plus important encore, de conseils personnalisés sur le choix des programmes de formation. Pour s'assurer que ces allocations de formation seront réellement affectées à des formations qui améliorent les compétences des travailleurs, il pourrait être judicieux de définir les allocations individuelles en termes monétaires et non en nombre d'heures, comme l'a fait la France en 2018. Le coût des formations étant plus bas pour les travailleurs peu qualifiés, une allocation monétaire leur donnerait accès à un volume de formations plus important (OCDE, 2019f). Enfin, ces mesures pourraient être complétées par un soutien ciblé pour les travailleurs défavorisés - temps de formation plus long et/ou obligations de financement plus élevées par exemple - comme c'est déjà le cas en Flandre dans certains dispositifs de formation.

En complément d'un accès amélioré aux formations, qui peut être rendu possible par les mesures d'individualisation précédemment évoquées, et pour développer la culture de l'apprentissage parmi les adultes en Belgique, les autorités pourraient intensifier les campagnes de sensibilisation du public. Force est de reconnaître, néanmoins, que dans les nombreux pays de l'OCDE qui ont organisé des campagnes de ce type, celles-ci sont souvent restées sans effet sur les personnes peu qualifiées (Commission européenne/EACEA/Eurydice, 2015 ; OCDE, 2019g). Pour relever ce défi, plusieurs pays commencent à mener des initiatives plus volontaristes à l'attention des personnes peu qualifiées, en intervenant dans les lieux qu'elles sont susceptibles de fréquenter régulièrement - entreprises, jardins d'enfants, écoles, espaces publics et autres (OCDE, 2019g). Par exemple, en 2017, la ville de Bruxelles a créé un centre d'information itinérant (le Formtruck) pour promouvoir la formation des adultes auprès des demandeurs d'emploi jeunes et peu qualifiés (OCDE, 2018a).

\section{Réformer le marché du travail pour stimuler l'emploi et la productivité}

\section{Des politiques d'activation mieux ciblées pour lutter contre les pertes d'emplois}

La proportion de chômeurs de longue durée parmi l'ensemble des personnes sans emploi est élevée, s'élevant à $50 \%$ environ (Graphique 18). On mesure à cette aune combien les politiques actives du marché du travail (PAMT), par les conseils, l'aide à la formation et les autres aides au retour à l'emploi apportés, pourraient faciliter l'adaptation des demandeurs d'emploi aux attentes de ce marché. Des observations internationales ont donné la preuve que des mesures d'activation bien conçues et ciblées peuvent accroître l'employabilité des demandeurs d'emploi de manière efficace au regard de leur coût (OCDE, 2015c). Ces mesures sont appelées à prendre une importance grandissante avec l'évolution de la nature du travail et alors que la transformation numérique de l'économie se poursuit. À cela s'ajoute que les réformes visant à assouplir le marché du travail et favoriser le retour à l'emploi des chômeurs ou des inactifs (voir ci-après) devraient rendre d'autant plus nécessaire la mise en place de PAMT efficaces. 


\section{Graphique 18. Le chômage de longue durée a une incidence élevée}

Personnes au chômage depuis plus d'un an en pourcentage de l'ensemble des chômeurs, 2018

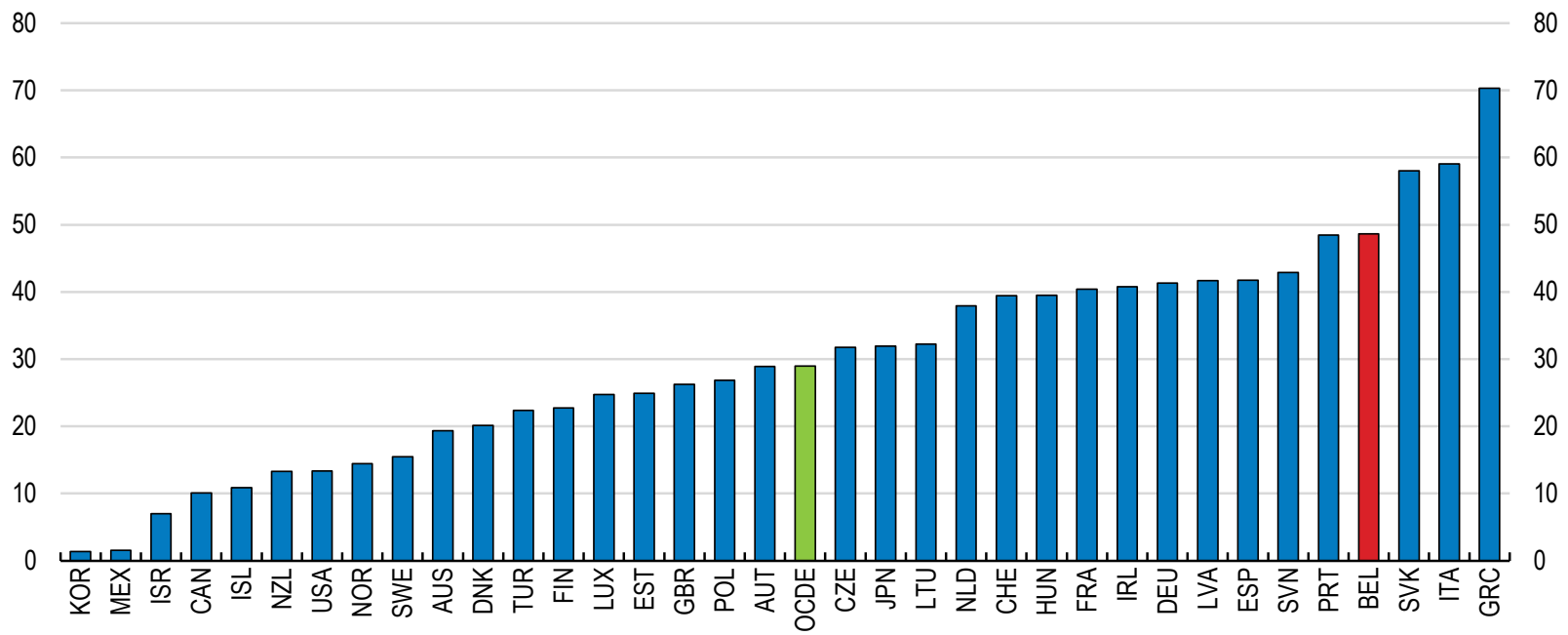

Source : OCDE (2019), Statistiques de la population active (base de données).

Les dépenses par demandeur d'emploi au titre des PAMT, exprimées en pourcentage du PIB par habitant, s'élèvent à $25 \%$ en Belgique, soit plus que la moyenne OCDE qui est d'environ $16 \%$ (Graphique 19, Partie A). Depuis 2011 et la sixième réforme de l'État, les PAMT relèvent dans une large mesure de la responsabilité des régions. Outre l'allègement des cotisations de sécurité sociale dues par l'employeur qui a été décidé au niveau fédéral pour donner un coup de pouce à l'emploi au bas de l'échelle des salaires, des dispositifs sont prévus dans chaque région au bénéfice de certains groupes de demandeurs d'emploi, dispositifs qui prennent la forme de diminutions des cotisations patronales de sécurité sociale et d'allocations de travail. Les demandeurs d'emploi peuvent d'autre part recevoir des conseils ou un accompagnement personnalisés. II n'en reste pas moins que le niveau des dépenses d'activation demeure inférieur à ce qu'il est au Danemark et en Allemagne.

Les pouvoirs publics pourraient augmenter les dépenses consacrées à la formation, dont le niveau $0.15 \%$ du PIB en 2016 - se situe aux environs de la moyenne OCDE mais nettement en-deçà de celui observé dans les pays voisins. Au surplus, ces dépenses sont relativement faibles, en Belgique, par rapport à l'ensemble des dépenses allouées aux PAMT, puisqu'elles n'en représentent que $15 \%$ environ quand la moyenne OCDE s'établit à $23 \%$ (Graphique 19, Partie B). De nombreuses données internationales démontrent que les moyens consacrés à la formation permettent d'améliorer tant l'employabilité des individus que la qualité des emplois occupés à moyen et long termes (Card et al., 2018; Wulfgramm et Fervers, 2013). Le bénéfice d'un tel investissement serait sans doute considérable en Belgique, où le manque de compétences constitue un obstacle majeur à l'emploi (Hijzen et al., 2020). Il conviendrait toutefois que l'éventuelle augmentation des dépenses publiques de formation vise en premier lieu à renforcer les compétences des individus dont le niveau d'instruction est le plus faible et s'accompagne de mesures destinées à ancrer fermement la formation tout au long de la vie dans la culture belge, comme il a en été question plus haut. 
Graphique 19. Seule une part relativement faible des dépenses engagées au titre des PAMT est consacrée à la formation
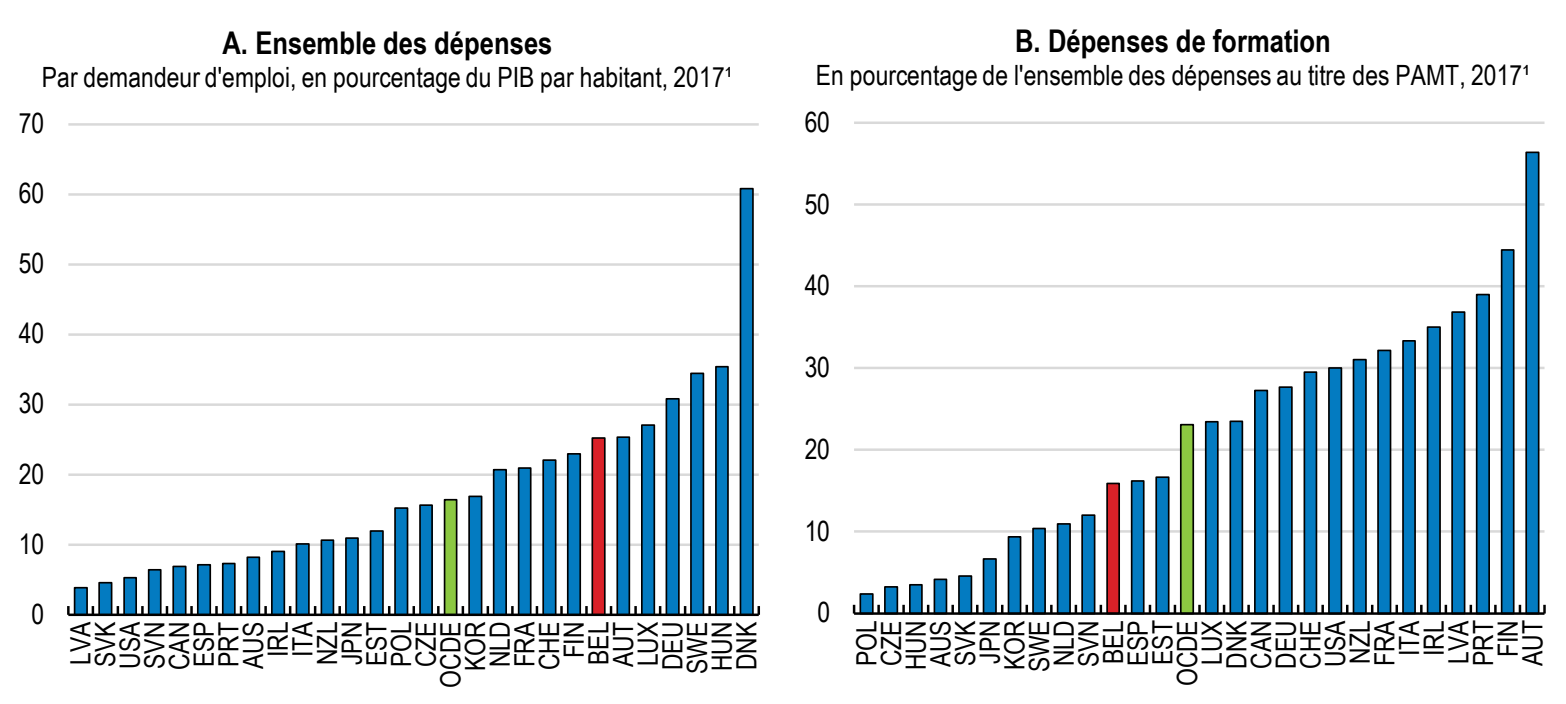

1. 2015 pour l'Italie et 2016 pour la Nouvelle-Zélande.

Source : OCDE (2019), Statistiques sur les programmes du marché du travail (base de données).

Compte tenu de la forte disparité des résultats sur le marché du travail en Belgique, les retombées qu'apporterait une utilisation plus effective, par les services publics de l'emploi (SPE), des outils de profilage statistique seraient sans doute importantes. Ces outils permettent en effet de mieux cibler les services les plus coûteux et les plus exigeants, destinés aux demandeurs d'emploi que le chômage de longue durée guète plus particulièrement, d'intervenir plus tôt et d'offrir à chacun un accompagnement qui corresponde plus précisément à ses besoins. Ils reposent sur un modèle statistique permettant d'anticiper les situations de désavantage sur le marché du travail, à la différence des systèmes de profilage où la classification des demandeurs d'emploi entre différentes catégories se fait sur la base de critères d'admissibilité ou en fonction de l'appréciation des conseillers. Le volume de données disponibles en temps réel ayant augmenté, tout comme la puissance de calcul nécessaire, l'utilisation des outils de profilage statistique tend à se généraliser dans les pays de l'OCDE (Desiere, Langenbucher et Struyven, 2019 ; Encadré 5).

Les outils de profilage statistique ne sont pas largement utilisés en Belgique. Cela étant, dans le cadre d'une nouvelle stratégie de contact appliquée depuis octobre 2018, le service public de l'emploi de la Communauté flamande (VDAB) a développé un modèle de profilage statistique, baptisé « Next Steps ", servant à déterminer selon quelle probabilité un individu donné risquera de connaître le chômage plus de six mois durant. Ce modèle repose sur un algorithme d'apprentissage automatique et exploite des renseignements issus de diverses sources: caractéristiques socioéconomiques, antécédents professionnels et données de navigation du demandeur d'emploi sur le site web du VDAB, qui permettent de prendre en compte son attitude et sa motivation à l'égard de la recherche d'emploi. L'objectif de la stratégie est que les nouveaux demandeurs d'emploi soient recontactés et leur dossier étudié dans un délai de six semaines à compter de leur inscription auprès du VDAB. Les conseilleurs élaborent des programmes de retour au travail personnalisés pour ceux ayant été désignés comme les plus vulnérables par le modèle de profilage (Desiere, Langenbucher et Struyven, 2019). 


\section{Encadré 5. Le profilage statistique en Autriche}

L'outil de profilage statistique utilisé par les services publics de l'emploi en Autriche (AMAS) possède deux fonctions et sert à calculer, de manière extrêmement fiable, la probabilité de retour à l'emploi d'un individu à court et moyen termes. La fonction de court terme permet d'apprécier les chances d'occuper un emploi non subventionné pendant un minimum de trois mois au cours des sept premiers mois de chômage.

La fonction de long terme donne la probabilité d'occuper un emploi non subventionné pendant six mois au minimum sur une période de 24 mois. Les demandeurs d'emploi sont ensuite répartis en trois groupes selon que leurs chances de réinsertion sont élevées, moyennes ou faibles. Le modèle repose exclusivement sur des sources de données administratives. II fait appel à des variables socioéconomiques (sexe, âge, nationalité), ainsi qu'à des renseignements sur l'employabilité de la personne (niveau d'instruction, problèmes de santé, responsabilités familiales) et sur l'offre d'emplois (situation du marché du travail dans la région). L'une de ses principales caractéristiques consiste en l'utilisation d'informations détaillées sur le parcours de chaque demandeur d'emploi, comme l'expérience professionnelle (nature et niveau), la fréquence et la durée des périodes de chômage et les éventuels programmes d'activation auxquels il a déjà pris part.

Source: Desiere, S., K. Langenbucher et L. Struyven (2019), " Statistical profiling in public employment services: An international comparison ", Documents de travail de l'OCDE sur les questions sociales, l'emploi et les migrations, n 224, Éditions OCDE, Paris.

II serait souhaitable que les outils de profilage statistique visant à repérer les personnes risquant le plus de basculer dans le chômage de longue durée, comme " Next Steps ", voient leur usage se généraliser dans toutes les régions de Belgique. Synerjob, organisme de coordination des services publics de l'emploi des différentes régions, serait un excellent relais pour faire connaître les résultats obtenus, en Flandre, avec « Next Steps ». Cet outil de profilage novateur pourrait d'autre part être perfectionné, par exemple en intégrant à son modèle davantage de renseignements d'ordre comportemental recueillis au moyen d'un questionnaire succinct en ligne servant à mieux apprécier la motivation des demandeurs d'emploi et leur confiance en eux.

\section{Assouplir le marché du travail par une réglementation fiable}

Le marché du travail belge semble présenter des rigidités car peu de salariés quittent leur entreprise pour une autre et la durée d'occupation des emplois est élevée. D'un côté, les garanties offertes par la législation sur la protection de l'emploi incitent les salariés à s'investir dans l'acquisition des savoir-faire propres à leur entreprise et les employeurs à investir dans le perfectionnement professionnel de leur personnel, ce qui est bon pour l'innovation (Belloc, 2019 ; Kleinknecht et al., 2014). D'un autre côté, une répartition de la main-d'œuvre plus conforme à l'efficience pourrait stimuler la croissance de la productivité et profiter à l'innovation du fait qu'il encouragerait les entreprises à prendre davantage de risques (Bartelsman, Gautier et De Wind, 2016) et serait propice à la diffusion de technologies et d'idées nouvelles par la voie des recrutements. Par ailleurs, plus la mobilité de la main-d'œuvre est importante, plus il y a d'ordinaire d'entrées et de sorties parmi le groupe des chômeurs, et plus faible est la durée moyenne du chômage (Cournede, Denk et Garda, 2016).

La protection contre les licenciements individuels assurée aux salariés au bénéfice d'un contrat de durée indéterminée est, en Belgique, d'un niveau de rigueur comparable à la moyenne OCDE (Graphique 20, Partie A). Deux raisons principales expliquent que cet indicateur OCDE ne soit pas plus faible en l'occurrence. D'abord, l'employeur a le choix entre donner un préavis à son salarié ou lui verser une indemnité de rupture, ce qui amoindrit la protection des travailleurs sous contrat à durée indéterminée. 
Néanmoins, tant la durée du préavis que le montant de l'indemnité sont élevés : trois mois et demi pour la première et 3.5 fois le salaire mensuel pour le second, après 4 années d'emploi. À titre de comparaison, en France, par exemple, la durée du préavis, pour la même durée d'exercice professionnel, est supérieure au montant de l'indemnité de rupture, puisqu'elle est de deux mois quand l'indemnité représente un mois de salaire. Ensuite, il n'y a pas de période probatoire pour les salariés sous contrat à durée indéterminée (OCDE, 2019a), même si cette absence est compensée, dans une certaine mesure, par l'observation d'un délai de préavis plus court si le licenciement concerne une personne recrutée depuis peu (le préavis est d'une semaine tant que le salarié n'a pas passé trois mois dans l'entreprise).

En ce qui concerne la protection des travailleurs contre les licenciements collectifs sous contrat à durée indéterminée, la Belgique se classe deuxième parmi les pays de l'OCDE pour la rigueur de sa législation (Graphique 20, Partie B). Celle-ci s'applique aux entreprises de plus de 20 salariés qui se séparent de 10 à 30 personnes, en fonction de leur taille, sur une période de deux mois, et se distingue nettement, quant à sa sévérité, de la législation relative aux licenciements individuels.

La rigueur du cadre régissant les licenciements collectifs tient à plusieurs éléments. D'abord, tout licenciement collectif doit faire l'objet d'une double notification. La première est adressée aux représentants du personnel et à l'administration compétente et sera obligatoirement suivie de l'ouverture d'un processus de consultation. Celui-ci est long et particulièrement incertain sur le plan juridique car, la loi ne fixant pas un terme précis aux consultations, les salariés peuvent facilement en remettre en cause la validité. L'entreprise ne pourra adresser aux autorités la seconde notification, précisant le plan de licenciement envisagé, qu'une fois la phase de consultation achevée, et aucun licenciement ne sera possible dans les 30 à 60 jours suivant son envoi. Ensuite, l'employeur doit étudier en amont à d'autres solutions pour démontrer que le licenciement collectif ne peut être évité. Enfin, à la différence des licenciements individuels, où l'employeur a le choix entre observer un délai de préavis ou verser une indemnité de rupture, les licenciements collectifs comportent et préavis et compensation financière pour les salariés qui en font l'objet.

Afin de de donner davantage de souplesse au marché du travail, la protection des salariés contre les licenciements collectifs pourrait être allégée de diverses manières, conformément aux recommandations formulées dans le rapport 2019 OECD In-Depth Productivity Review of Belgium. L'introduction d'un critère explicite dans la loi ou l'intervention d'une tierce partie, qui pourrait être un médiateur social, aideraient à expliciter le terme de la procédure de consultation. Une autre solution consisterait à simplifier la procédure de notification en deux temps de sorte qu'elle se rapproche de celles prévues en Allemagne et aux Pays-Bas, qui ne comportent qu'une seule notification. Le recours à de nouvelles formes de ruptures collectives dans le cadre d'un accord entre l'entreprise et les salariés concernés, sur le modèle par exemple de la « rupture conventionnelle collective » introduite en France en 2017, pourrait également être envisagé (OCDE, 2019a). 


\section{Graphique 20. La protection de l'emploi contre les licenciements collectifs est relativement forte} Indicateurs de la législation sur la protection de l'emploi des travailleurs sous contrat à durée indéterminée ${ }^{1}$

\section{A. Licenciements individuels}

5

4

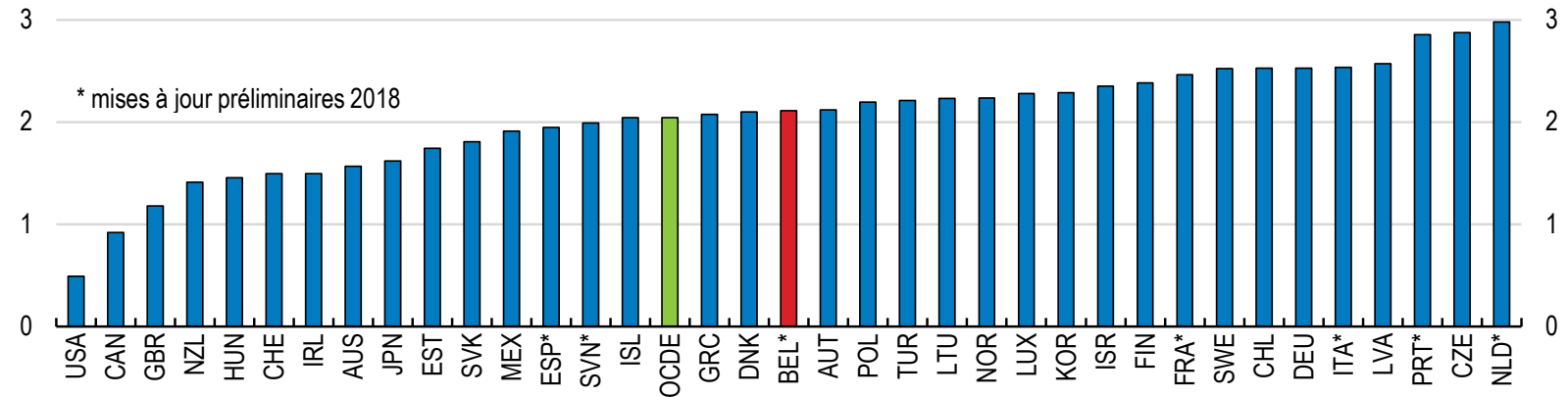

B. Licenciements collectifs

5

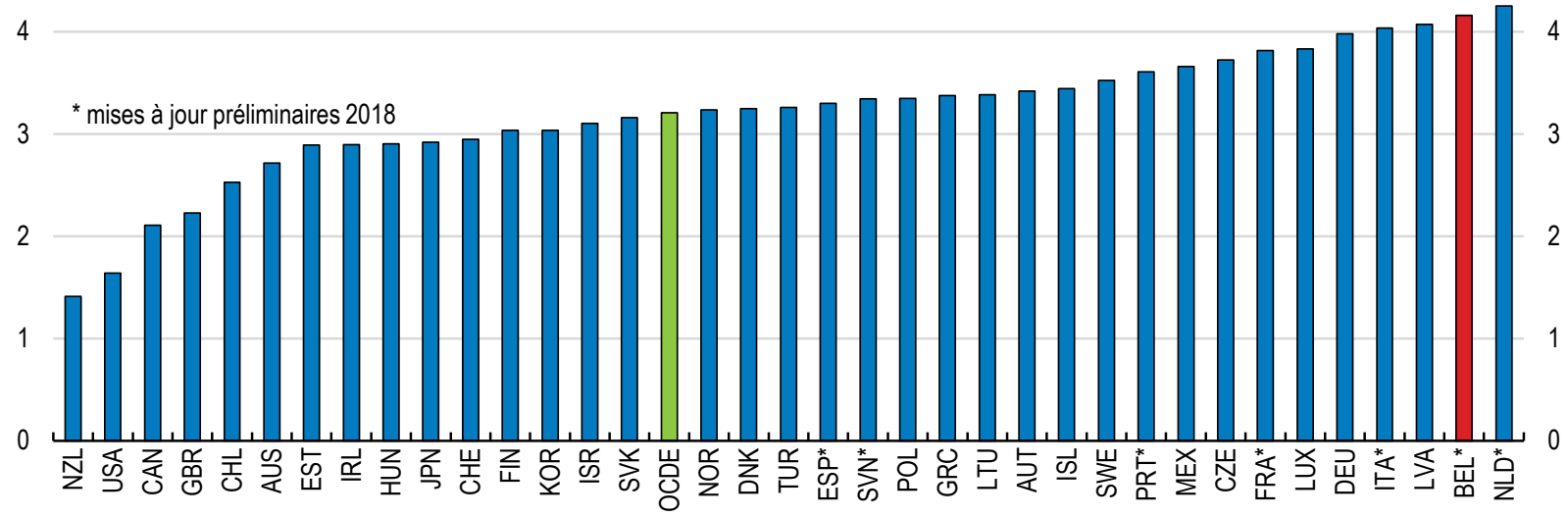

1. Données de 2013 pour la plupart des pays, dernière année disponible dans la base de données. Données de 2014 pour le Royaume-Uni et de 2015 pour la Lituanie. Les données concernant la Belgique, l'Espagne, la France, l'Italie, les Pays-Bas, le Portugal et la Slovénie sont issues de mises à jour préliminaires pour l'année 2018. Pour calculer l'indicateur relatif aux licenciements collectifs, il a été pris pour hypothèse que la fourchette de valeurs correspondant aux règles spécifiques applicables à ces licenciements est supérieure de $40 \%$ à celle de l'indicateur relatif aux licenciements individuels, de manière à ce qu'il y ait concordance avec l'indicateur actuel qui couvre à la fois les licenciements individuels et les licenciements collectifs. Cette fourchette de valeurs s'étend de 0 à 6 dans le cas des licenciements individuels et de 0 à 8.4 dans celui des licenciements collectifs. La moyenne OCDE correspond à la moyenne non pondérée de ses 36 pays membres. Voir OCDE (2019a), In-Depth Productivity Review of Belgium pour plus de précisions.

Source : Estimations de l'OCDE établies à partir de la base de données sur la législation sur la protection de l'emploi.

\section{Coupler plus étroitement salaires et productivité au niveau de l'entreprise et au niveau du salarié}

Plusieurs des caractéristiques du cadre institutionnel tel qu'il est conçu sont susceptibles de fausser les mesures d'incitation adressées aux travailleurs et aux entreprises, ce qui a des conséquences sur la redistribution de la main-d'œuvre et sur la productivité. Parmi ces sources possibles d'interférences, le système de négociation collective et la rémunération à l'ancienneté ont d'ores et déjà été signalés, dans 
l'Étude économique 2017 de la Belgique ainsi que dans le rapport 2019 In-Depth Productivity Review of Belgium, comme deux éléments qu'il faudrait envisager de réformer.

Les salaires des employés de bureau qui ont le plus d'ancienneté sont relativement élevés, en Belgique, par rapport à ceux des plus jeunes, ce qui peut constituer un frein à l'employabilité et à la mobilité professionnelle des travailleurs âgés. Le maintien de ceux-ci sur le marché du travail sera déterminant pour le succès de la réforme des retraites. Si d'autres facteurs, comme la formation tout au long de la vie, entreront aussi en ligne de compte, il peut être utile également de faire en sorte que la rémunération progresse moins fortement avec l'ancienneté en s'appuyant pour cela sur le processus tripartite de négociation des salaires. À cet égard, le rapport que le Conseil central de l'économie doit rendre prochainement sur le sujet arrive à point nommé.

La négociation salariale se caractérise, en Belgique, par sa forte centralisation à l'échelle des entreprises et son étroite coordination entre les secteurs. De tels systèmes vont de pair avec des taux d'emploi relativement élevés et des inégalités salariales relativement faibles, d'une part, ainsi qu'avec une croissance de la productivité plus limitée, d'autre part (OCDE, 2018b). La coordination des salaires devrait, en principe, permettre de mieux ajuster la rémunération à la conjoncture macroéconomique, et favoriser ainsi la résilience et l'adaptabilité. II sera important d'évaluer dans quelle mesure la réforme du système de fixation des salaires, à laquelle elle a procédé en 2017, a permis à la Belgique de gagner en compétitivité sur la scène internationale, conformément à la recommandation formulée dans l'Étude économique de 2017.

II pourrait être nécessaire d'assouplir encore le mécanisme de fixation des salaires au niveau microéconomique, tout en préservant la négociation sectorielle. On peut à cet effet ménager, dans l'accord-cadre sectoriel, une certaine marge de manœuvre aux entreprises, comme c'est le cas en Allemagne, en Autriche, au Danemark, en Norvège, aux Pays-Bas et en Suède, pays dont les systèmes de négociation collective sont considérés comme des systèmes décentralisés organisés et coordonnés (OCDE, 2018a ; 2019a). À titre d'exemple, les accords sectoriels conclus en Allemagne et en Autriche offrent la possibilité d'invoquer des clauses de non-participation, chose rare en Belgique. Compte tenu des niveaux de syndicalisation relativement élevés et du rôle clé joué par les partenaires sociaux dans le processus de fixation des salaires, la Belgique pourrait adopter une démarche similaire à celle suivie dans les pays nordiques. Au Danemark et en Suède, l'application du principe de faveur, qui permet de déroger aux dispositions de la réglementation dès lors que celles prévues dans le contrat de travail du salarié sont plus favorables, est laissée à l'appréciation des partenaires sociaux, ce qui a pour effet d'accroître la flexibilité du système et d'établir une corrélation plus étroite entre les salaires et les résultats de l'entreprise.

\section{Pour une fiscalité et des prestations équitables et incitant à travailler}

\section{Une protection sociale inclusive qui favorise le travail}

\section{Les allocations de chômage}

La structure optimale des allocations versées pendant le chômage a fait l'objet d'un vif débat en Belgique, conduisant en 2012 à une réforme importante qui a étendu la diminution des allocations de chômage à un plus grand nombre de travailleurs et accéléré cette réduction (encadré 6 ). Un système d'allocations de chômage bien conçu doit trouver le bon équilibre entre l'assurance d'une protection efficace contre les pertes de revenu et le maintien d'incitations à travailler pendant toute la période de chômage. Tout dépend ainsi de la couverture du système, du niveau et du financement des allocations pendant la période de chômage et de ses interactions avec les autres mesures relatives à l'impôt et aux prestations. 
Selon les recommandations de la Stratégie de l'OCDE pour l'emploi, un niveau élevé de la couverture chômage et d'autres prestations hors emploi, sous réserve d'une application rigoureuse des obligations mutuelles, est un facteur déterminant de la réussite des stratégies d'activation (OCDE, 2018a). La couverture des allocations de chômage est importante en Belgique, plus de $60 \%$ des chômeurs étant ainsi couverts en 2017, soit plus du double de la moyenne dans l'UE (graphique 22, partie A). De plus, la couverture est élevée pour toutes les durées de chômage, notamment le chômage de longue durée, qui représente environ $55 \%$ de l'ensemble des allocataires. Cette proportion est proche de celle observée en Allemagne (47\%), et nettement supérieure à la moyenne dans l'UE, soit $26 \%$ (graphique 22, partie B). Dans une certaine mesure, cela tient au fait que la Belgique offre un accès aux allocations illimité dans le temps (en lien avec une recherche d'emploi active), alors que bien d'autres pays prévoient un basculement des chômeurs arrivés en fin de droit vers des aides sociales soumises à conditions de ressources.

\section{Encadré 6. Le barème des allocations de chômage en Belgique}

Une réforme mise en œuvre en 2012, dans le but d'accroître les incitations à travailler pour les chômeurs de longue durée, a étendu la diminution des allocations de chômage à un plus grand nombre de travailleurs et accéléré cette réduction. Pour de nombreux travailleurs, cet objectif a été atteint en relevant le taux de remplacement pendant les tout premiers mois (de $60 \%$ à $65 \%$ des revenus d'activité récents) et en abaissant les taux de remplacement effectifs par la suite. Cette réforme a permis de décorréler le niveau à long terme des allocations de chômage des revenus d'activité antérieurs pour tous les chômeurs (avant la réforme, c'était déjà le cas pour les personnes cohabitantes de longue durée), évoluant ainsi vers un système visant à assurer un revenu minimum à long terme, plutôt que de lisser les variations de revenus en elles-mêmes.

Le graphique 21 illustre les principales implications de la réforme à l'aide d'un exemple particulier (un couple à revenu unique avec deux enfants) appliqué à des travailleurs dont les durées de cotisation diffèrent (6 et 21 ans). Avant la réforme, les allocations de chômage se stabilisaient à leur niveau de long terme au bout de 12 mois pour ces deux travailleurs. Après la réforme, l'un et l'autre perçoivent des allocations plus élevées à court terme, mais subissent aussi des variations plus fréquentes (à 3 , 6 et 12 mois). Au final, pour les deux carrières, les allocations convergent vers le même taux de remplacement, mais cette convergence est plus rapide pour la personne qui a travaillé moins longtemps. 


\section{Graphique 21. Barème des allocations de chômage pendant la période de chômage \\ $\%$ du salaire antérieur pour un travailleur faiblement rémunéré appartenant à un couple à revenu unique avec deux enfants ${ }^{1}$}

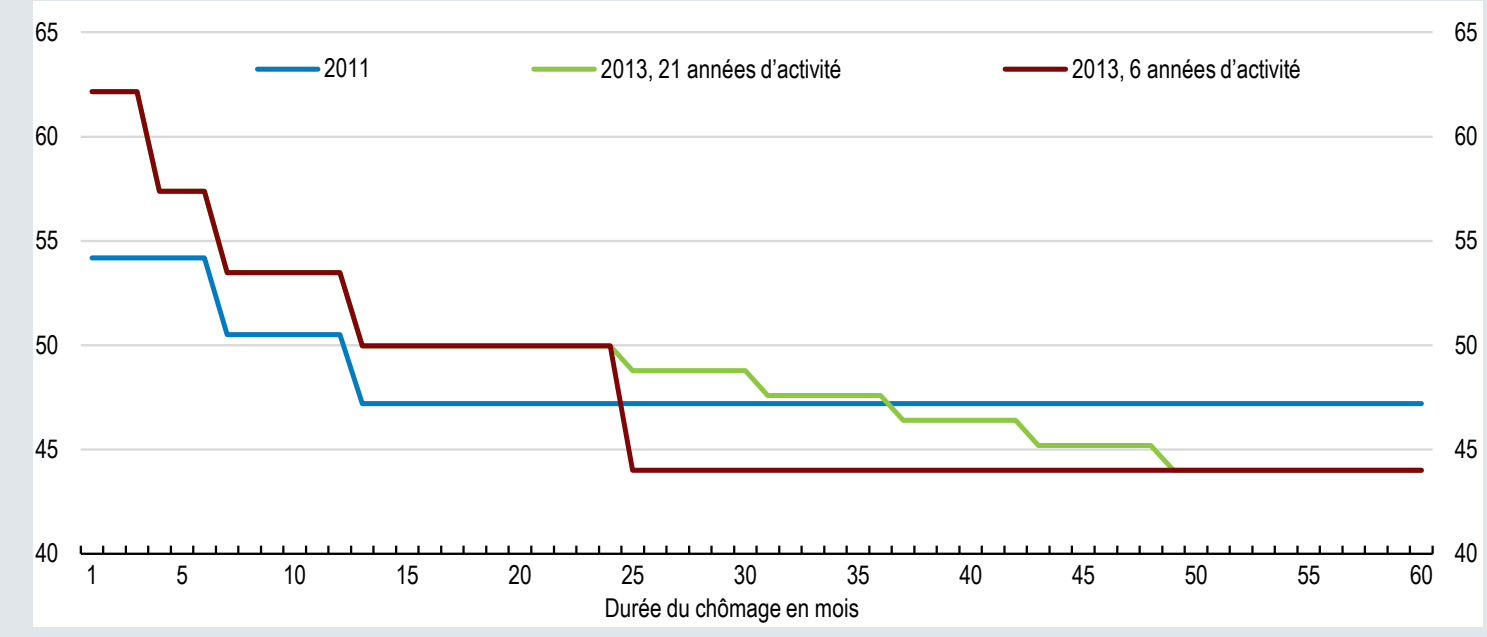

1. Le graphique montre l'évolution des allocations de chômage nettes sur 60 mois (avant et après la réforme) pour un travailleur faiblement rémunéré ( $67 \%$ du salaire moyen pour une année donnée) qui est le seul apporteur de revenu d'un couple avec deux enfants. Deux profils professionnels sont étudiés ici, le premier travailleur ayant cotisé pendant 21 ans, le deuxième pendant 6 ans. Par souci de comparabilité dans le temps, le niveau des allocations de chômage est présenté en proportion du salaire antérieur. Source : Hijzen et Salvatori (2020), calculs de l'OCDE basés sur le modèle impôts-prestations de l'OCDE.

La Belgique se caractérise aussi par une couverture élevée des allocations de chômage parmi les salariés et les travailleurs inactifs. Parmi les salariés, cela correspond dans une grande mesure aux travailleurs à temps partiel qui peuvent, dans certains cas, cumuler des allocations de chômage partielles (Allocation de garantie de revenus, AGR, ou Inkomensgarantieuitkering, IGU) et un emploi. Ces allocations garantissent aux personnes travaillant à temps partiel un revenu net égal ou supérieur aux allocations de chômage à taux plein. Parmi les allocataires inactifs, plus de $70 \%$ ne sont pas immédiatement disponibles pour travailler, les $30 \%$ restants étant des travailleurs " découragés » qui sont disponibles pour travailler mais ne cherchent pas activement un emploi (Hijzen et Salvatori, 2020). Ces deux catégories d'allocataires inactifs ont généralement besoin d'une aide sur mesure pour surmonter les obstacles à l'emploi, afin d'accroître leur disponibilité pour travailler (services de garde d'enfants, par exemple), leur aptitude au travail (formation, notamment) et l'efficacité de leur recherche d'emploi (aide à la recherche d'emploi, par exemple) (Hijzen et al., 2020), sujets qui sont abordés dans d'autres parties de l'étude.

Pour les travailleurs faiblement rémunérés, les taux de remplacement nets sont plus élevés en Belgique que dans les pays de l'OCDE en moyenne, l'écart se creusant au cours de la première année de chômage (graphique 23), en raison notamment du caractère illimité dans le temps de l'accès aux allocations de chômage. Toutefois, comparé à ceux des pays voisins qui versent des allocations de chômage sur une longue durée, le système belge n'apparaît pas comme étant particulièrement généreux, même si cela dépend du type de famille concerné. 


\section{Graphique 22. La couverture des allocations de chômage est élevée}
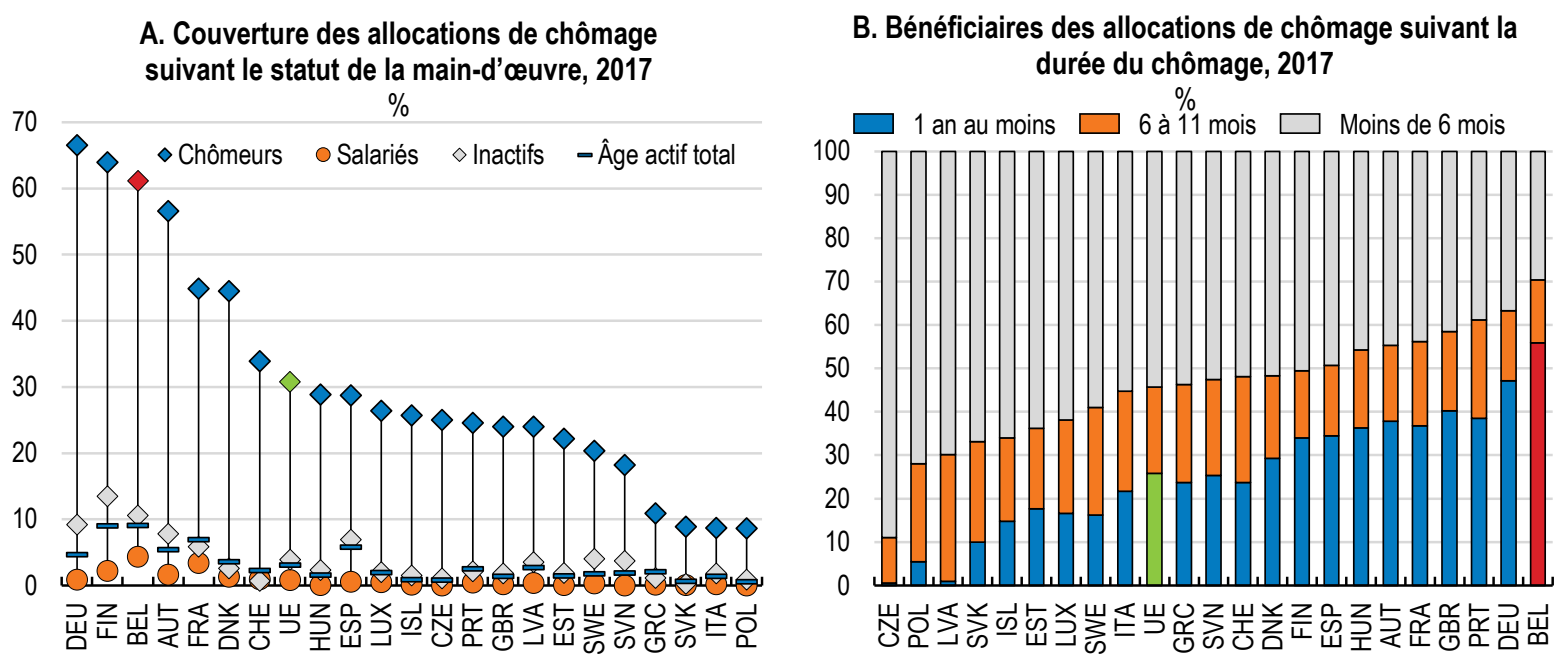

Source : Hijzen et Salvatori (2020), calculs de l'OCDE basés sur les données de l'EFT de l'UE.

\section{Graphique 23. Les taux de remplacement nets sont relativement élevés, en particulier pour}

Proportion du revenu antérieur d'un ménage actif conservée après une certaine période de chômage ${ }^{1}, 2018$

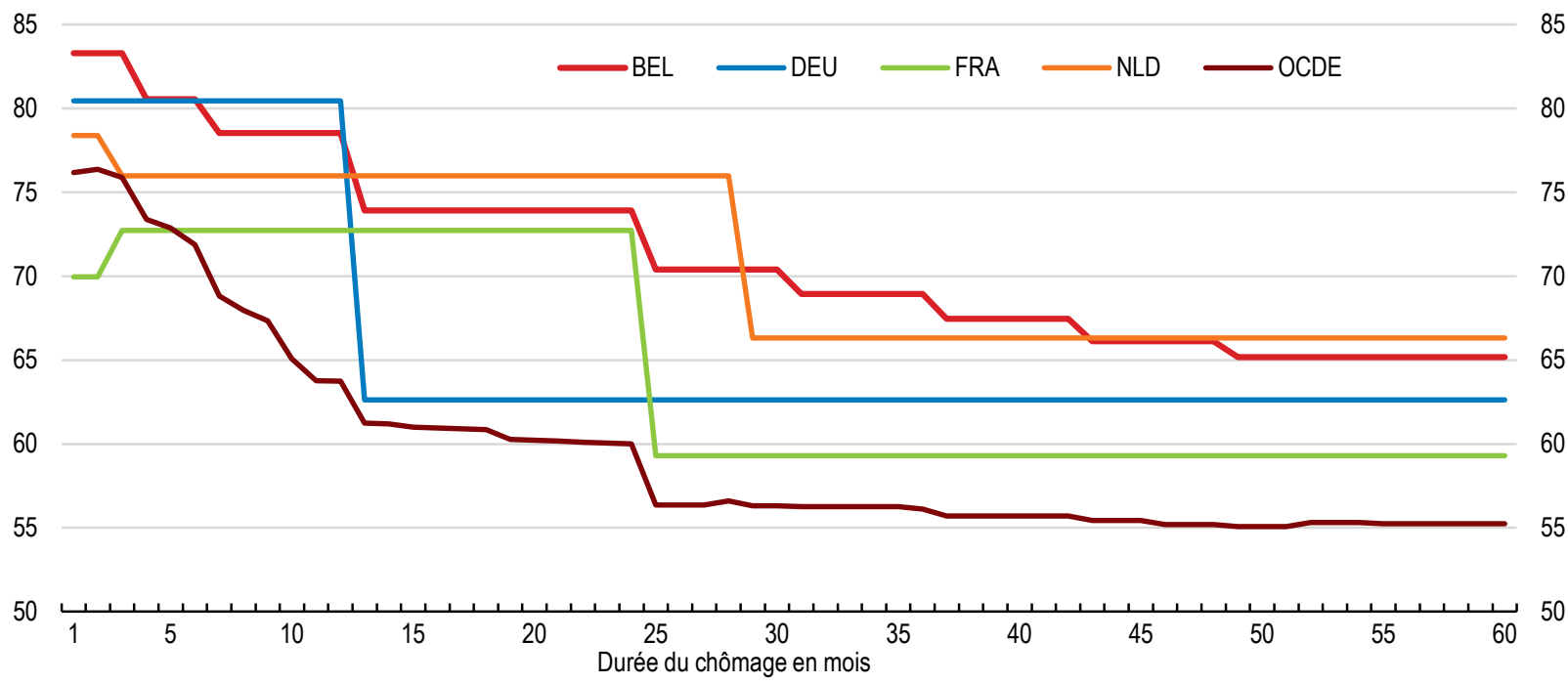

1. Les taux de remplacement nets correspondent au revenu net des ménages pendant le chômage exprimé en proportion du revenu net total des ménages avant le chômage. Le revenu des ménages pendant le chômage comprend l'assurance et l'assistance chômage, les allocations familiales, l'aide sociale et les allocations de logement. Les taux de remplacement nets sont calculés pour les ménages dans lesquels un adulte âgé de 41 ans n'ayant pas connu d'interruptions de carrière est réduit au chômage et dont le revenu d'activité antérieur représente $67 \%$ du salaire moyen. Ils correspondent à une moyenne pour six types de famille : les célibataires, les couples à revenu unique et les couples à deux revenus (tous avec et sans enfants).

Source : Hijzen et Salvatori (2020), calculs de l'OCDE basés sur le modèle impôts-prestations de l'OCDE.

Des taux de remplacement relativement élevés pour les chômeurs (et anciens travailleurs faiblement rémunérés) se traduisent par une adéquation des revenus relativement forte, laquelle correspond au revenu du ménage pendant le chômage en pourcentage du revenu disponible médian (graphique 24). C'est le cas pour toutes les durées de chômage et la plupart des types de ménages, à certaines 
exceptions notables près. Ainsi, le revenu net du ménage d'une personne faiblement rémunérée ayant un conjoint à charge et qui est au chômage depuis longtemps est bien en-deçà du seuil de pauvreté (soit $50 \%$ du revenu médian). Les profondes différences existant dans le revenu net des chômeurs de longue durée appartenant aux divers types de ménages, après prise en compte des différences de composition du ménage, sont difficiles à justifier et devraient être évitées. Cela tient en grande partie au fait que le niveau à long terme des prestations de chômage est constant et ne varie que selon trois grands types de ménages.

\section{Graphique 24. Une aide au revenu importante pour les travailleurs à bas salaire est généralement associée à des taux d'imposition de l'activité élevés}

Moyenne pour les six types de familles, $2018^{1}$
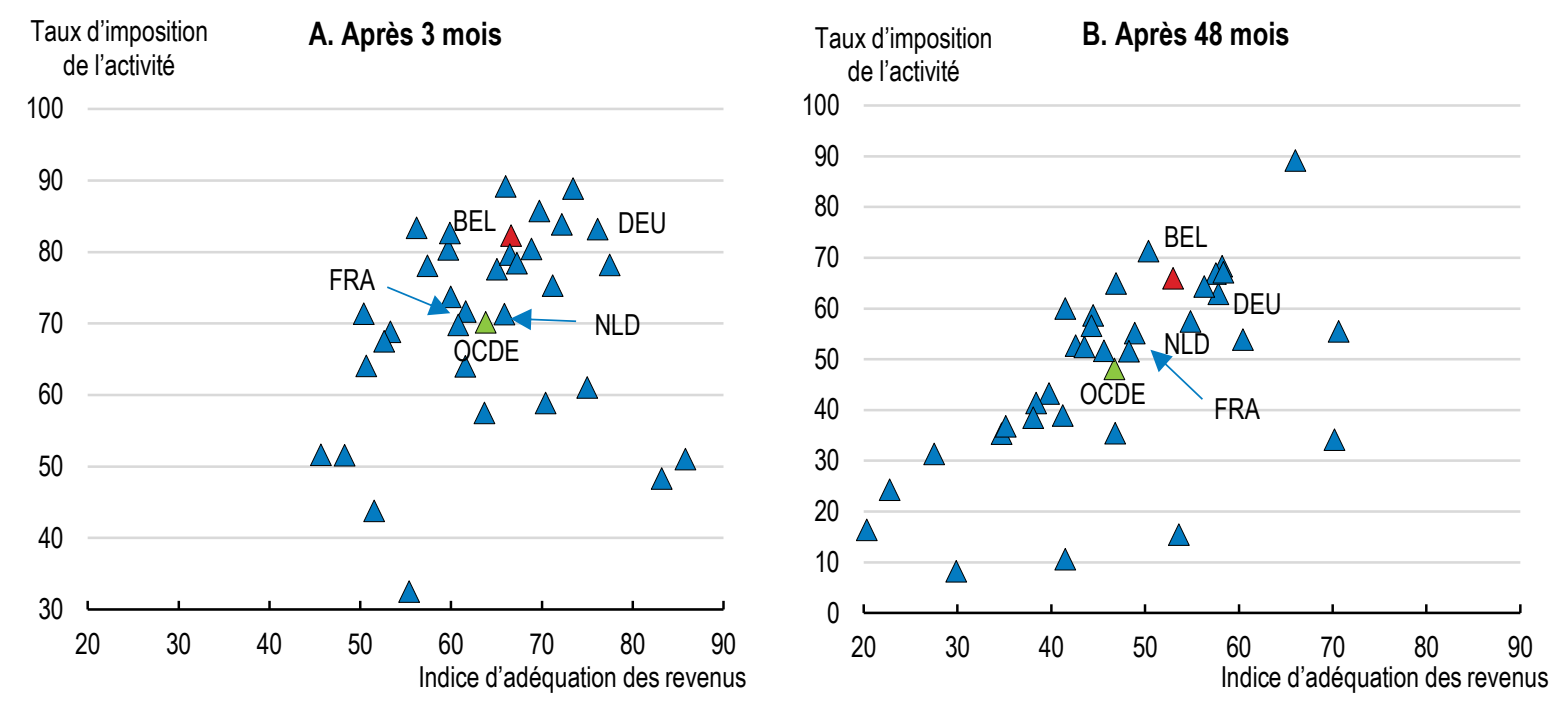

1. L'adéquation des revenus correspond aux revenus des ménages pendant le chômage, exprimés en pourcentage du revenu disponible médian. Les taux d'imposition de l'activité correspondent à la fraction du revenu d'activité brut supplémentaire qui est perdu en raison d'une hausse des impôts ou d'une baisse des allocations lorsqu'un chômeur reprend une activité. Les indices sont calculés pour les ménages dans lesquels un adulte âgé de 41 ans n'ayant pas connu d'interruptions de carrière est réduit au chômage et dont le revenu d'activité antérieur représente $67 \%$ du salaire moyen. Ils correspondent à une moyenne pour six types de famille : les célibataires, les couples à revenu unique et les couples à deux revenus (tous avec et sans enfants).

Source : Hijzen et Salvatori (2020), calculs de l'OCDE basés sur le modèle impôts prestations de l'OCDE.

Pour que l'aide à long terme apportée aux chômeurs corresponde davantage aux besoins des ménages, la plupart des pays de l'OCDE limitent la durée de versement des prestations de l'assurance chômage, tout en permettant aux chômeurs de bénéficier de programmes d'assistance chômage ou d'aide sociale soumise à conditions de ressources lorsqu'ils arrivent en fin de droits. De même, la Belgique devrait abandonner les allocations forfaitaires au profit de prestations soumises à conditions de ressources pour les chômeurs de longue durée, lesquelles pourraient être mises en œuvre grâce à l'un de ces programmes. Le principal avantage de l'introduction des conditions de ressources dans le système d'allocations de chômage actuel serait que les chômeurs pourraient continuer de bénéficier du dispositif d'activation qui accompagne le versement des allocations. Le pays pourrait aussi élargir les systèmes d'aide sociale, en réservant le même traitement à toutes les personnes vivant dans des ménages défavorisés - qu'il s'agisse de chômeurs de longue durée ou d'inactifs. II faudrait pour cela considérer l'aide au revenu octroyée aux chômeurs de longue durée appartenant aux ménages défavorisés comme une question relevant de la politique sociale, qui serait financée par les recettes fiscales générales et non par les cotisations de sécurité sociale. 
Quelle que soit la méthode choisie pour introduire les conditions de ressources, il importe de noter qu'une partie des bénéficiaires des allocations de chômage perdraient inévitablement l'aide au revenu qu'ils reçoivent. Ce sera probablement le cas des chômeurs qui vivent dans des ménages ayant d'autres sources de revenu, comme ceux dont le conjoint travaille, ou qui possèdent des actifs ou de l'épargne, comme certains travailleurs plus âgés ayant déjà effectué une longue carrière. De plus, les bureaux de l'Office national de l'emploi devraient rester en contact avec les personnes ayant besoin de mesures d'activation. Les économies en découlant pourraient être utilisées pour renforcer les incitations au travail en abaissant les cotisations de sécurité sociale à l'assurance chômage ou investir encore dans des mesures d'activation.

L'aide au revenu relativement généreuse dont bénéficient les chômeurs (dans la plupart des types de ménages) a tendance à réduire les incitations au travail. En janvier 2018, le taux d'imposition de l'activité, c'est-à-dire la part du revenu d'activité supplémentaire qui est perdue en raison de la baisse des allocations et de la hausse des impôts pour les travailleurs percevant un faible salaire (dans leur emploi antérieur et dans leur nouveau poste), s'élève à $82 \%$ après 3 mois et à $66 \%$ après 4 années de chômage, des chiffres plus élevés que les moyennes de l'OCDE qui ressortent à $70 \%$ et $48 \%$, respectivement. Le récent changement en matière de taxation (" tax shift ») aura fait diminuer encore le taux d'imposition de l'activité pour les travailleurs à faible revenu. D'après les calculs effectués par le gouvernement belge selon des hypothèses différentes sur les types de ménages et d'allocations de chômage, si l'on tient compte de tous les effets de la réforme fiscale, le taux d'imposition de l'activité aura été réduit de plus de $10 \%$ pour un chômeur de longue durée retrouvant un emploi faiblement rémunéré. Ces effets seront plus marqués pour les travailleurs qui pourraient toucher, en cas de retour à l'emploi, un salaire inférieur à leur salaire antérieur, ce qui est souvent le cas pour des raisons comme la dépréciation des compétences due à de longues périodes de chômage, à la discrimination exercée par les employeurs à l'encontre des chômeurs de longue durée ou à une détérioration du cycle économique (Jacobson et al., 1993 ; OCDE, 2013a).

La Belgique pourrait sensiblement réduire les contre-incitations à travailler, en particulier pour les chômeurs de longue durée, tout en maintenant ou même en relevant le niveau actuel de l'aide au revenu. Ainsi, après 48 mois de chômage, les Pays-Bas offrent approximativement le même niveau d'aide que la Belgique, mais pour des taux d'imposition de l'activité plus bas. En Allemagne, les taux d'imposition de l'activité sont globalement similaires, mais pour une aide au revenu plus élevée.

La Belgique a déjà pris depuis 2016, grâce à la réforme en matière de taxation (" tax shift »), des mesures destinées à accroître les incitations au travail pour les personnes à bas salaire qui sont entrées pleinement en vigueur en 2019. D'autres améliorations des incitations au travail pourraient être envisagées grâce à de nouvelles mesures permettant de faire en sorte que le travail soit attractif financièrement, conformément à l'évolution observée ces dernières années dans de nombreux pays de I'OCDE, qui ont mis l'accent sur l'aide aux personnes qui travaillent (Causa et Hermansen, 2017). Il est notamment possible de donner aux travailleurs à plein temps faiblement rémunérés la possibilité de cumuler des prestations des chômage et un revenu du travail, en s'appuyant sur le mécanisme qui existe pour les travailleurs à temps partiel (Allocation de Garantie de Revenus, AGR, ou Inkomensgrantieuitkering, IGU). La Belgique pourrait aussi envisager d'introduire des prestations liées à l'emploi, comme le crédit d'impôt sur les revenus du travail (Earned Income Tax Credit) mis en place de longue date aux États-Unis ou la « prime d'activité » en France (Carcillo et al., 2019).

Lors de l'adoption de ces réformes destinées à faire en sorte que le travail soit attractif financièrement, il est important de s'assurer que les mesures prises seront suffisamment bien ciblées sur les travailleurs à bas salaire, à la fois pour en limiter le coût budgétaire et pour réduire le risque qu'une partie de leurs avantages ne soient détournés par les employeurs. Dans la mesure où les minima salariaux, qu'il s'agisse d'un salaire minimum légal ou d'un minimum salarial sectoriel défini à la suite d'une négociation collective, sont contraignants pour les travailleurs faiblement rémunérés, le risque d'un détournement, 
par les entreprises, des avantages liés à des mesures visant à rendre le travail attrayant judicieusement conçues est limité en Belgique.

Un aspect de l'arsenal de réformes adopté en 2018, le " Jobs deal », qui comprend 28 mesures destinées à améliorer le fonctionnement du marché du travail et à stimuler l'emploi, a proposé une nouvelle réforme du dispositif d'allocations chômage, mais n'a pas été mis en œuvre. Cette proposition prévoyait notamment une nouvelle concentration des allocations de chômage en début de période, en les augmentant pendant les 6 premiers mois et en adaptant le rythme des diminutions par étapes ou le niveau correspondant des allocations. Néanmoins, le dernier montant des allocations, qui est atteint au plus tard après 48 mois de chômage, ne serait pas modifié.

L'expérience de la Hongrie porte à croire que les réformes qui concentrent les allocations de chômage en début de période peuvent faire baisser le chômage et être neutre en termes de recettes, même si les allocations augmentent à court terme (Lindner et al., 2016 ; DellaVigna et al., 2017 ; encadré 7). Toutefois, cela n'implique pas nécessairement qu'il est souhaitable, sur le plan social, d'accélérer la diminution des allocations de chômage, car une hausse du taux de sortie du chômage peut en partie dénoter une aggravation des difficultés financières des chômeurs.

\section{Encadré 7. Concentration des allocations de chômage en début de période : l'expérience de la Hongrie}

En 2005, la Hongrie a introduit une réforme ayant pour effet de concentrer les allocations de chômage en début de période. La somme versée les 90 premiers jours a été revue à la hausse, tandis que le montant payé les 180 jours suivants a été réduit et le niveau inférieur fixé au-delà de 270 jours est demeuré inchangé. La réforme a donc entraîné une nouvelle diminution après 90 jours, puis une baisse réduite après 270 jours.

L'évaluation de la réforme semble indiquer que l'accélération de la diminution des allocations de chômage dans le temps a fait reculer le chômage (Della Vigna et al., 2017) et n'a pas eu d'incidence sur les recettes en dépit de l'augmentation initiale des allocations (Lindner et al., 2016). Plus spécifiquement, Della Vigna et al. (2017) constatent qu'après la réforme, les sorties du chômage ont connu une forte hausse aux alentours du seuil des 90 jours, puis convergé, pendant les phases ultérieures, vers le niveau antérieur à la réforme. Ces observations pourraient s'expliquer par les préférences dépendant de la référence des travailleurs, qui s'ajustent dans le temps. Les travailleurs qui sont touchés par le chômage commencent par chercher activement un emploi pour retrouver le niveau de revenu et de consommation qu'ils avaient lorsqu'ils étaient en activité. Toutefois, à mesure qu'ils s'habituent à la diminution du niveau de revenu et de consommation due au chômage, ils réduisent peu à peu l'intensité de leur recherche d'emploi.

La question de savoir si la baisse des allocations de chômage sur la durée est souhaitable sur le plan social dépend de la possibilité de compenser ou non le coût induit en termes de perte de revenu (et de consommation) pour les chômeurs de longue durée par une augmentation du taux d'entrée sur le marché de l'emploi grâce à des incitations à travailler plus fortes. Cette possibilité dépend fondamentalement de la capacité des chômeurs à s'adapter, à différentes étapes du chômage, aux variations de leurs revenus et aux incitations financières. L'expérience récente de l'Espagne et de la Suède laisse supposer que les chômeurs sont moins réceptifs aux incitations financières que les chômeurs de courte durée, ce qui plaide en défaveur de la diminution des prestations (Campos, GarcíaPérez and Reggio, 2017 ; Kolsrud et al., 2018). Par conséquent, pour se faire une idée de la réceptivité des chômeurs aux variations du dispositif d'allocations de chômage en Belgique et contribuer à 
structurer le débat national sur cette question, il est nécessaire de procéder à une évaluation approfondie de la réforme de 2012 qui a accru la dégressivité des allocations dans le temps.

\section{Les retraites}

Lutter contre le risque de pauvreté des personnes âgées peut être particulièrement difficile pour les personnes qui occupent un emploi atypique ou les indépendants. Ces travailleurs peuvent ainsi verser des cotisations de retraite peu élevées au cours du temps ou même avoir des périodes prolongées pendant lesquelles ils ne payent pas de cotisations (OCDE, 2019b).

La Belgique a mis en place plusieurs retraites minimum, parmi lesquelles les pensions pour les travailleurs salariés et pour les indépendants, ainsi qu'un droit minimum par année d'activité pour les seuls salariés. Ceux qui en bénéficient perçoivent des prestations de retraite supérieures aux prestations de retraite classiques qui sont soumises à conditions de ressources. Pour le droit minimum par année de carrière, la durée de cotisation minimum requise correspond à 15 ans d'au moins un tiers d'une année de travail en équivalent temps plein. Dans le secteur public, il faut 20 années de service pour pouvoir prétendre à la retraite minimum. Pour ce qui est des retraites minimum, la durée de cotisation minimum exigée est relativement longue (graphique 25) et peut être difficilement atteignable pour certaines personnes, en particulier celles dont la carrière est en dents de scie. La Belgique sert des retraites non contributives relativement confortables, qui ne sont pas liées aux cotisations versées par chacun durant sa vie active (OCDE, 2019b). Toutefois, une diminution du nombre d'années de carrière requises pour avoir droit à une retraite minimum pourrait réduire encore le risque de pauvreté des personnes âgées pour les travailleurs atypiques.

\section{Graphique 25. La durée de cotisation requise pour les retraites minimum pourrait être difficile à} atteindre pour les travailleurs ayant une carrière en dents de scie

Durée de cotisation requise en années ${ }^{1}$

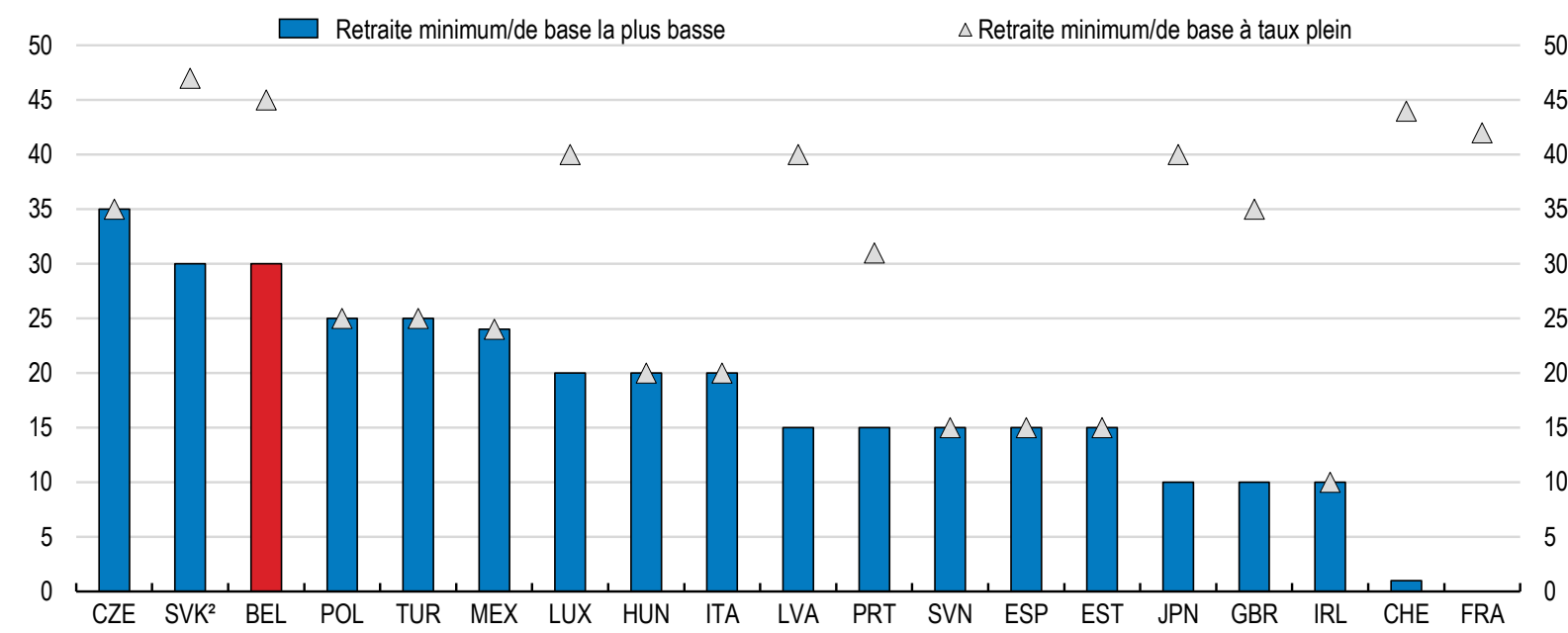

1. Les données correspondent aux régimes servant des retraites minimum, à l'exception de l'Estonie, de l'Irlande, du Japon et du RoyaumeUni, où les systèmes du premier pilier reposent sur des retraites de base. Des retraites minimum et de base sont versées par le Luxembourg et la République tchèque, où la durée de cotisation correspondante pour la retraite de base est de 10 ans et de 35 ans, respectivement. Voir OCDE (2015) pour plus de détails sur l'introduction, dans les systèmes de retraite, de crédits pour les périodes de chômage et d'éducation des enfants dans les différents pays.

2. En République slovaque, les retraites minimum ne sont pas plafonnées et augmentent pour chaque année de cotisation supplémentaire. Source : OCDE (2019b), Perspectives de l'emploi de l'OCDE 2019 : L'avenir du travail, Éditions OCDE, Paris. 
Malgré les réformes récentes de la protection sociale des indépendants, des différences de taille demeurent entre les salariés et les indépendants en termes d'accès aux retraites. Bien qu'ils soient tenus de cotiser, les indépendants sont soumis à des taux de cotisation plus bas et la retraite maximum à laquelle ils peuvent prétendre après une carrière complète est considérablement moins élevée que celle d'un salarié (soit quelque 1650 EUR par mois contre 2500 EUR, en 2018). De plus, cette retraite maximum pour les indépendants n'est que légèrement supérieure à la retraite minimum correspondante (autour de 1250 EUR par mois en 2018). Le montant de leur retraite au titre du premier pilier n'étant que peu lié à leurs revenus professionnels antérieurs en raison du niveau relativement bas des retraites maximum, les indépendants ne sont guère incités à déclarer des revenus élevés. Au lieu de quoi, l'épargne-retraite privée, par exemple, au moyen de produits fiscalement avantageux, peut être plus intéressante. Par rapport aux autres pays de l'OCDE dotés de systèmes de retraite facultatifs, toutefois, l'encours des actifs détenus dans des fonds de pension facultatifs en pourcentage du PIB est relativement faible (graphique 26 ; OCDE, 2018e).

\section{Graphique 26. Encours total des actifs des fonds de pension privés}

En \% du PIB, $2018^{1}$

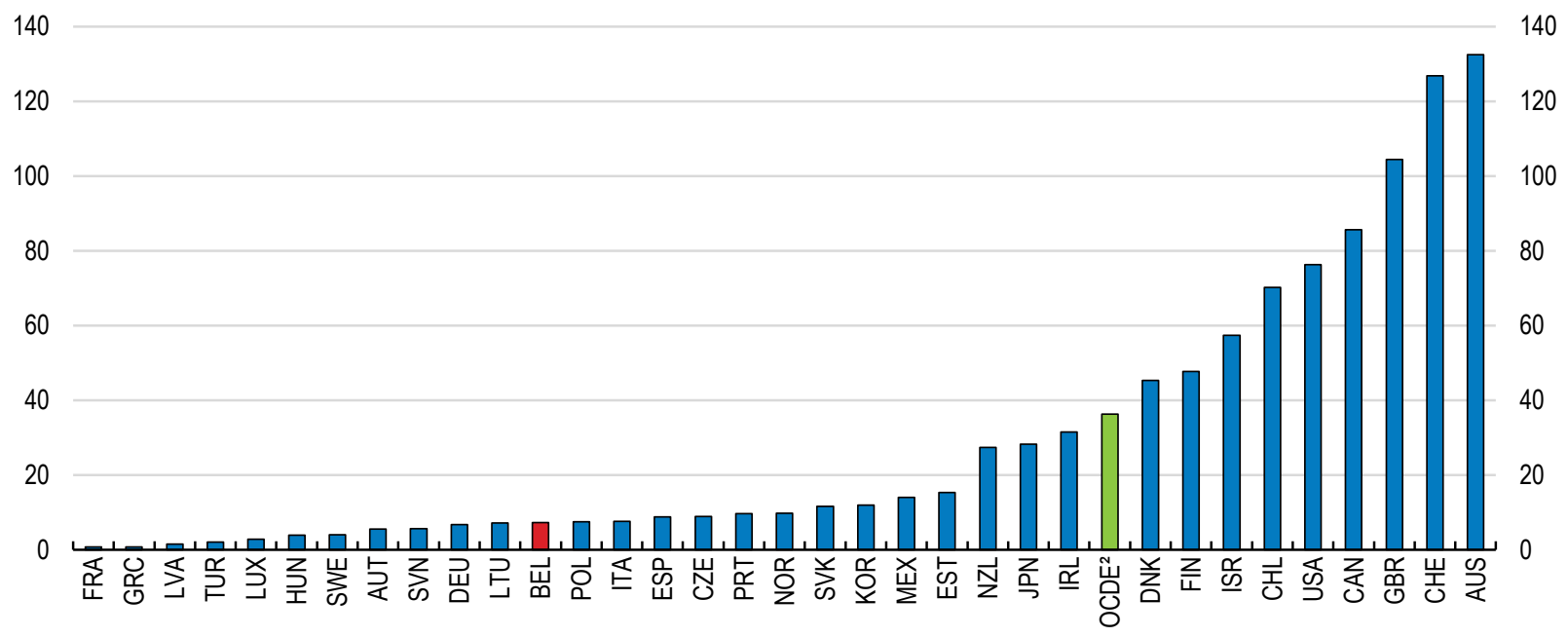

1. Les données concernent la totalité des plans par capitalisation (obligatoires ou facultatifs, professionnels ou individuels, pour les travailleurs du secteur public ou du secteur privé) susceptibles d'être financés par des fonds de pension, à l'exclusion toutefois des contrats d'assurance retraite, des réserves comptables des employeurs et des autres instruments de financement de la retraite. Données provisoires pour 2018

2. Moyenne non pondérée.

Source : OCDE (2019), Pension Market in Focus, sur la base de données recueillies auprès des autorités nationales en charge des retraites, dans le cadre du projet Statistiques de pensions de l'OCDE au niveau mondial.

Le système de retraite des indépendants devrait être davantage aligné sur celui des salariés, par exemple grâce à l'harmonisation des taux de cotisation et du mode de calcul des pensions. Le coefficient d'harmonisation actuellement utilisé a pour effet d'abaisser le revenu des travailleurs indépendants auxquels s'appliquent les calculs. Un alignement plus étroit du système des indépendants sur celui des salariés contribuerait à renforcer la protection sociale et à réduire les risques de pauvreté des personnes âgées dans cette catégorie. Pour faciliter le financement du système, les clients des indépendants pourraient être contraints de régler une partie des cotisations de retraite qui sont dues pour certains groupes de travailleurs indépendants, comme c'est le cas en Allemagne, en Autriche, en Italie et au Portugal (OCDE, 2019b). II pourrait aussi être utile de modifier le deuxième pilier des retraites pour les indépendants, dans la mesure où ses objectifs sont similaires à ceux du premier pilier. Ainsi, 
la plupart des retraites peuvent être retirées sous forme de capital, mais la conversion d'une partie du capital en rente pourrait présenter des avantages sous l'angle de la protection sociale. De plus, $50 \%$ environ des indépendants cotisant aux régimes de retraite du deuxième pilier, l'affiliation automatique assortie d'une possibilité de sortie, comme en Nouvelle-Zélande, pourrait accroître encore la participation.

\section{Les prestations maladie et invalidité}

Les systèmes d'indemnisation maladie et invalidité devraient trouver un équilibre entre la protection et les incitations à travailler afin d'assurer la réintégration des travailleurs malades, tout en restreignant les entrées injustifiées dans ces régimes. L'efficacité du système est essentielle, car selon une étude récemment menée par l'OCDE, les problèmes de santé constituent l'un des principaux obstacles à l'emploi en Belgique. (Hijzen et al., 2020). En effet, la proportion de bénéficiaires des prestations invalidité est relativement importante et a fortement progressé ces dernières années (graphique 27 , partie A). De plus, une part croissante de la population inactive invoque la maladie et l'invalidité pour expliquer son inactivité (graphique 27, partie B). Dans d'autres pays, les modifications apportées à d'autres régimes de prestations ont conduit à un recours aux prestations maladie et invalidité en raison de l'évolution de leur attractivité relative (Jousten et al., 2012). Cela pourrait expliquer en partie la situation observée en Belgique, où plusieurs réformes, dont la suppression progressive des régimes de retraite anticipée et du statut de " chômeur âgé » qui dispense les personnes concernées de chercher un emploi, ont durci les conditions applicables à d'autres régimes.

Les employeurs peuvent jouer un rôle important dans la prévention des congés maladie de longue durée et dans la réintégration des travailleurs malades au sein de l'entreprise à travers un processus clair de réinsertion et de retour au travail (OCDE, 2018a). Jusqu'à récemment, les employeurs, en Belgique, n'étaient pas tenus d'assurer la réintégration des salariés en congé maladie de longue durée. Toutefois, deux décrets royaux ont introduit en 2016 un " trajet de réintégration obligatoire " de ces salariés par les employeurs. Ils sont bienvenus, car pour réformer ces régimes avec succès, il est essentiel d'insister sur la capacité à travailler. II existe aussi quelque projets pilotes ayant pour objectif le retour à l'emploi de travailleurs en congé maladie ou percevant des prestations d'invalidité avec l'aide du service public de l'emploi, et ces initiatives devraient être développées.

S'il est encore difficile de mesurer pleinement les effets de ces réformes, il faudra contrôler et évaluer régulièrement les régimes existants pour s'assurer du maintien des incitations destinées aux personnes ayant une aptitude au travail partielle. Une première évaluation montre que $14 \%$ des personnes qui sont allées au bout de leur plan de réintégration ont trouvé un autre poste à temps plein, mais les plans sont souvent abandonnés en chemin, en particulier par les travailleurs âgés et les bénéficiaires des prestations invalidité (Saks, 2017). De plus, le succès de ces réformes implique une coordination entre l'employeur, le salarié et le médecin-conseil.

De plus, les parents célibataires et, dans une moindre mesure, les couples avec enfants ne sont pas incités, d'un point de vue financier, à reprendre le travail après un congé de maladie ou d'invalidité de longue durée ou (Hufkens et al., 2017). D'une manière générale, les incitations à travailler ont été améliorées par une réforme récente des prestations maladie. Par conséquent, une évaluation des régimes existants devrait s'intéresser en particulier aux effets produits sur les différents types de famille.

Les obligations légales liées à la prévention des risques psycho-sociaux constituent également un outil important pour empêcher les travailleurs d'entrer dans des régimes d'invalidité (OCDE, 2018a). En Belgique, la Loi relative au bien-être des travailleurs impose aux employeurs d'élaborer des plans de prévention sur cinq ans afin de régler les problèmes mis en évidence par les évaluations des risques psycho-sociaux, d'établir des plans d'action annuels et de nommer un conseiller en prévention psycho-social pour les aider à mettre en œuvre leur politique de prévention des risques. Néanmoins, les évaluations semblent indiquer que jusqu'à présent, la mise en œuvre de ces obligations a été 
restreinte, en raison de l'ignorance des employeurs et de ressources limitées pour les conseillers en prévention (SPF Emploi, Travail et Concertation Sociale, 2011 ; OCDE, 2013b).

\section{Graphique 27. Les entrées dans les régimes d'indemnisation maladie et invalidité devraient être contrôlées}
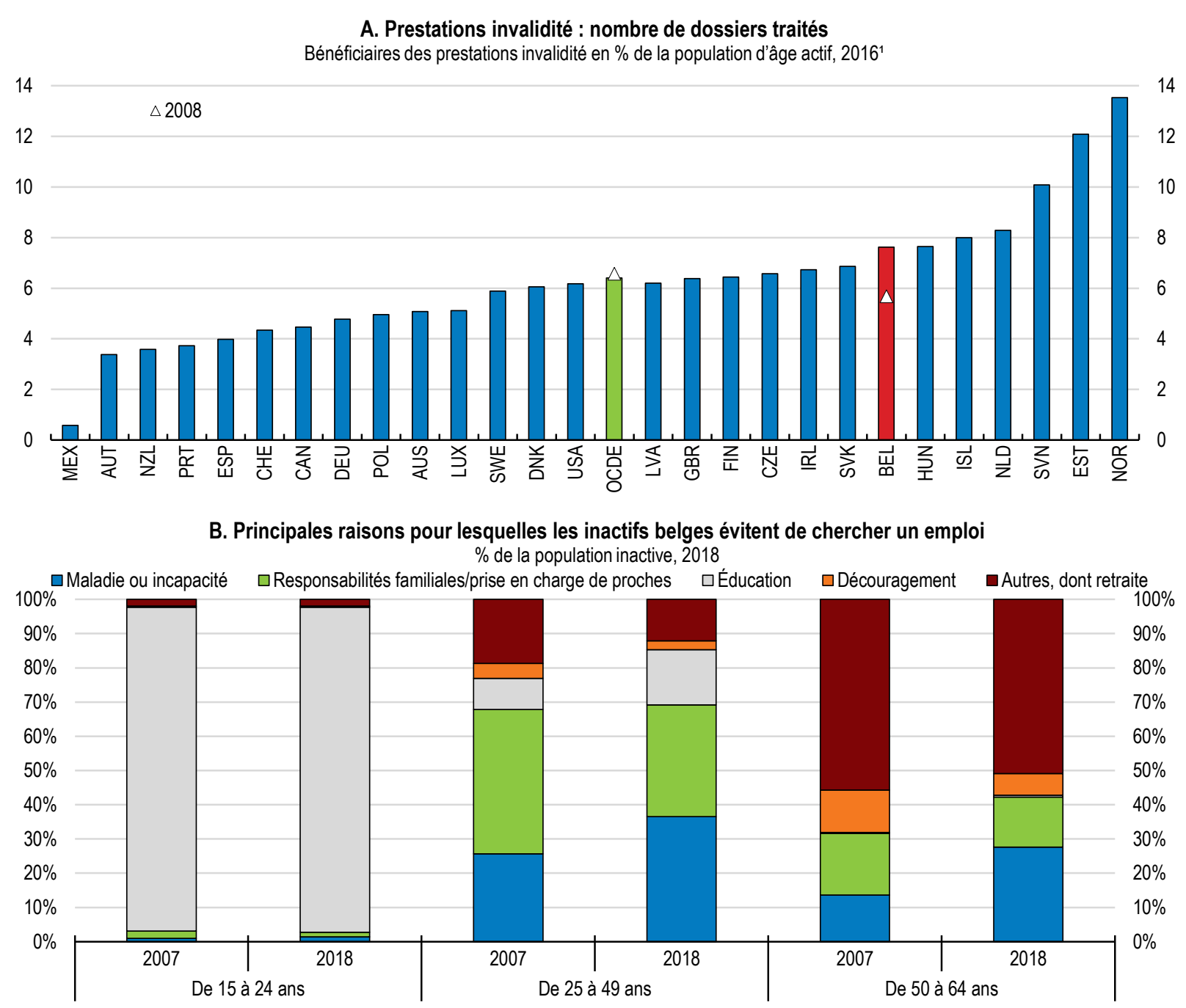

1. Ou dernière année disponible.

Sources : OCDE (2018), Des emplois de qualité pour tous dans un monde du travail en mutation, Éditions OCDE, Paris ; Eurostat (2019), «Population inactive ne recherchant pas d'emploi par sexe, âge et raison principale », base de données d'Eurostat.

\section{Une fiscalité équitable et efficiente}

La fiscalité du travail et l'existence de régimes fiscaux différents pour les formes de travail traditionnelles et atypiques peuvent sérieusement influer sur le niveau de l'emploi et sur la répartition du travail entre les divers types d'activité, en modifiant leurs prix relatifs (OCDE, 2019b). La charge fiscale supportée par les travailleurs belges était la plus élevée de l'OCDE en 2018 (graphique 28), et elle restera importante même après les allégements de la fiscalité du travail récents et à venir. Cette situation accentue le risque de répartition inefficiente des travailleurs entre des formes de travail diverses en raison de la différence de régime fiscal. 


\section{Graphique 28. La charge fiscale pesant sur les travailleurs belges est élevée}

Taux d'imposition moyen net pour un travailleur célibataire gagnant $100 \%$ du salaire moyen ${ }^{1}$, en $\%$ du coût du travail, 2018

60

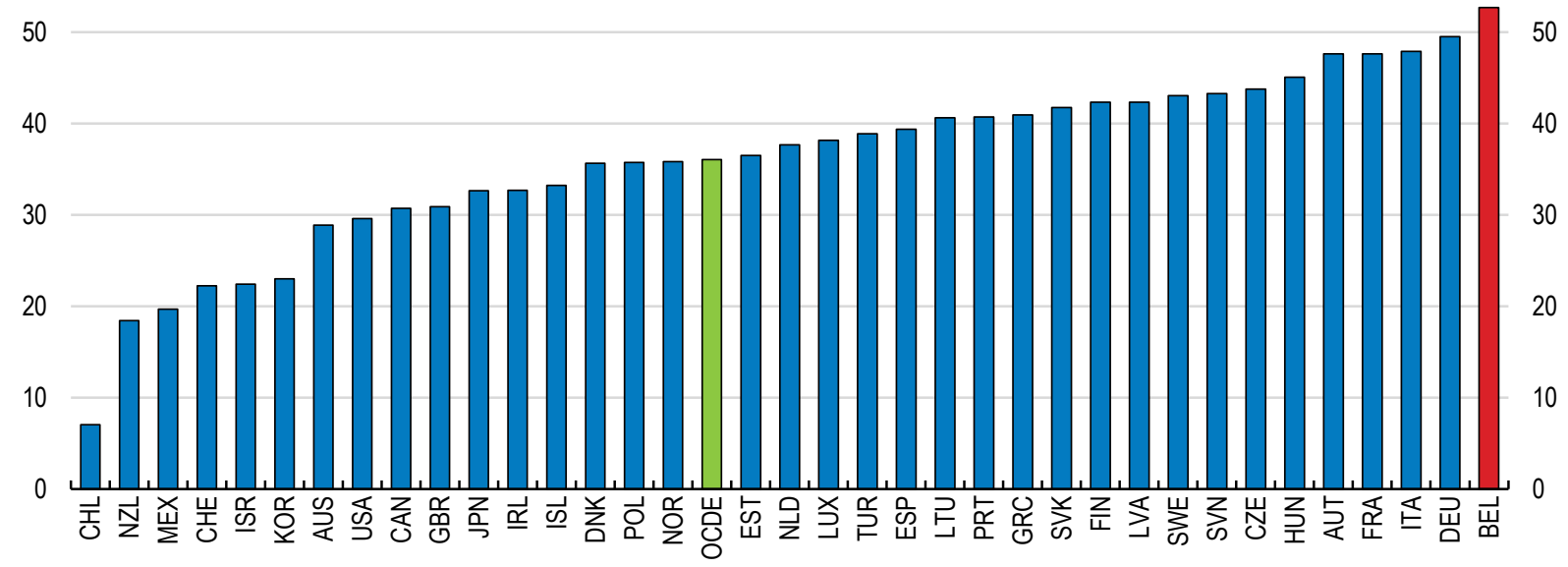

1. Cotisations de sécurité sociale salariales et patronales incluses, prestations en espèces exclues.

Source : OCDE (2019), Les impôts sur les salaires 2019, Éditions OCDE, Paris.

Comme on l'a vu, les cotisations de sécurité sociale sont obligatoires pour les travailleurs indépendants, mais à des taux quelque peu réduits, et des exonérations sont prévues. Les travailleurs atypiques ont d'autres possibilités de bénéficier de réductions d'impôts et de cotisations de sécurité sociale en Belgique. Le régime des «flexi-jobs » en fait partie. Introduit en 2015 dans le secteur de l'hôtellerie et de la restauration, il a depuis lors été étendu à d'autres secteurs et aux retraités, et une activité de type flexi-job a été enregistrée pour quelque 44000 personnes au total au premier trimestre 2019.

L'objectif du système des flexi-jobs est d'offrir une plus grande souplesse pendant les pics d'activité et de réduire les coûts salariaux de cette main-d'œuvre flexible. Ce dispositif est réservé aux personnes qui occupent déjà $4 / 5^{\mathrm{e}}$ au moins d'un emploi à temps plein. Les travailleurs ne peuvent pas exercer un flexi-job chez un employeur qui les a déjà recrutés à $4 / 5^{\mathrm{e}}$ au moins pour le même trimestre avec un autre type de contrat de travail. Dans le cadre des flexi-jobs, le salaire du travailleur est exonéré des cotisations de sécurité sociale et des impôts normalement appliqués, mais l'employeur est tenu de verser une cotisation spéciale correspondant à $25 \%$ de la rémunération. Le travail à temps partiel subi étant peu fréquent en Belgique et les bénéficiaires des flexi-jobs étant déjà présents dans une large mesure sur le marché du travail, ce dispositif pourrait n'avoir que peu d'incidence sur les taux d'activité ou d'emploi (CE, 2018).

Des réductions d'impôts ont aussi été introduites pour les travailleurs qui fournissent des services en-dessous d'un seuil d'exonération de 6000 EUR par an, y compris par l'intermédiaire de plateformes (collaboratives) en ligne (transactions réalisées via une application ou un site web mettant en relation clients et prestataires de services). Cette disposition s'applique aux travailleurs de plateforme, à condition qu'ils s'inscrivent sur une plateforme et enregistrent leurs activités. Pour que les travailleurs puissent bénéficier de l'exonération fiscale, la plateforme doit être officiellement reconnue par les autorités belges, et satisfaire ainsi à des conditions de transparence spécifiques, mais cela n'est pas obligatoire (Basellier et al., 2018). La plateforme doit communiquer le revenu des travailleurs à l'administration fiscale. Au-delà de 6000 EUR par an, les travailleurs doivent s'inscrire comme indépendants, ce qui implique qu'ils doivent aussi s'affilier au système de sécurité sociale obligatoire 
destiné aux indépendants. Cette dernière restriction s'applique également aux services fournis de manière informelle sans recourir à une plateforme.

Les flexi-jobs et les réformes concernant les travailleurs de plate-forme pourraient présenter des avantages importants, à savoir réduire le travail informel et élargir l'assiette d'imposition. La contribution de l'économie du partage progressant en Belgique, ces avantages pourraient être renforcés en rendant obligatoire l'enregistrement des plateformes auprès des autorités. En revanche, le régime des flexi-jobs pourrait être mis à profit par des sociétés apparentées cherchant à réduire au minimum les obligations fiscales des employeurs et des salariés. Cela pourrait entraîner une érosion de l'assiette d'imposition, de telle sorte qu'il faudrait contrôler le dispositif et pénaliser comme il convient tout comportement de ce type. II se pourrait aussi que ces travailleurs n'aient pas accès aux négociations collectives et à une partie des protections octroyées par le droit du travail, ce qui peut nuire au dialogue entre les partenaires sociaux. Pour limiter les distorsions entre les différentes formes de travail, il conviendrait d'aligner plus encore les régimes fiscaux qui leur sont appliqués, en supprimant progressivement les abattements fiscaux en faveur des travailleurs atypiques. 


\section{Tableau 3. Recommandations sur les défis liés au marché du travail}

\section{CONSTATATIONS (les principales sont en caractères gras) RECOMMANDATIONS (les principales sont en caractères gras)}

Renforcer les compétences pour faire face à l'évolution des besoins du marché du travail et à la transformation numérique

Les adultes âgés et ceux qui ont un faible niveau de qualification Instaurer des allocations de formation individuelles et, pour les participent peu aux programmes de formation continue. Les travailleurs désavantagés, prévoir des aides ciblées, par exemple sous la obligations de formation sont imposées au niveau des entreprises forme d'heures de formation plus nombreuses et/ou d'obligations de et non des travailleurs.

Les personnes moins instruites et à revenu plus bas ont des Cibler les formations numériques sur les personnes moins instruites et à faible compétences numériques relativement faibles. revenu, qui sont plus susceptibles de perdre leur emploi à cause de l'automatisation.

La proportion d'étudiants de l'EFP qui suivent une formation par Évaluer et, le cas échéant, renforcer les incitations financières en faveur de la alternance combinant formation scolaire et formation en milieu formation par alternance, comme les subventions directes, tant pour les professionnel est faible. entreprises que pour les élèves.

Instaurer une obligation d'accréditation (renouvelable) pour les entreprises qui proposent des formations professionnelles.

Réformer le marché du travail pour stimuler l'emploi et la productivité

Le taux du chômage de longue durée est élevé et plusieurs Élargir le recours à des outils statistiques pour repérer les demandeurs groupes se heurtent à de multiples obstacles à l'emploi.

d'emploi risquant de basculer dans le chômage de longue durée afin d'élaborer des programmes personnalisés de retour au marché du travail. Améliorer la coordination entre les politiques de l'emploi, de la santé et de l'éducation pour aider les personnes confrontées à de multiples obstacles à l'emploi.

Si les dépenses au titre des PAMT sont relativement élevées, leur Accroître les dépenses consacrées à la formation dans le cadre des PAMT. répartition pourrait être plus judicieuse.

Le marché du travail montre des signes de rigidités, peu de salariés quittant leur entreprise pour une autre et la durée d'occupation des emplois étant élevée.

Assouplir les licenciements collectifs, par exemple en adoptant une procédure de notification simplifiée, comprenant non plus deux étapes mais une seule. Permettre une négociation salariale plus décentralisée, dans le cadre des accords sectoriels, afin qu'il y ait une correspondance plus étroite entre les salaires et la productivité de l'entreprise.

Réformer la fiscalité et les prestations

Le système de prestations de chômage offre une garantie de ressources satisfaisante, mais ne favorise sans doute pas la recherche d'emploi.

Le système prévoit le versement de prestations uniformes à des chômeurs de longue durée qui, potentiellement, n'ont pas tous les mêmes besoins en fonction de leur situation familiale.

II existe une marge pour améliorer l'équité des allocations de chômage selon les niveaux de revenu.

La longueur des durées de cotisations requises pour pouvoir toucher les pensions minimales est difficile à atteindre pour les travailleurs indépendants et les travailleurs n'ayant pas eu une carrière complète.

Le système de retraite reste complexe et prévoit des régimes différents selon les catégories de travailleurs.

La proportion de bénéficiaires des prestations maladie et invalidité est relativement élevée et en progression.

Bien qu'elle puisse contribuer à stimuler l'emploi et à favoriser la flexibilité à court terme, l'existence de régimes fiscaux différents pour travailleurs traditionnels et atypiques peut fausser la répartition du travail à long terme.
Augmenter les incitations au travail pour les travailleurs faiblement rémunérés en instaurant des prestations liées à l'exercice d'un emploi. Sinon, étendre aux travailleurs à plein temps la possibilité de cumuler des prestations de chômage et un revenu du travail.

Évaluer la réforme des prestations de chômage opérée en 2012 pour voir comment il est possible d'améliorer la structure des prestations pendant toute la durée du chômage.

Pour les chômeurs de longue durée, prévoir des prestations sous condition de ressources plutôt que des prestations uniformes limitées dans le temps.

S'assurer que le taux de remplacement net n'augmente pas avec le niveau antérieur de revenu net.

Réduire le nombre d'années de carrière requis pour avoir droit à une retraite minimum.

Harmoniser les taux de cotisation obligatoires et le mode de calcul des pensions des travailleurs indépendants et des salariés.

Envisager, pour les indépendants, la conversion d'une partie du capital en rente pour les retraites du deuxième pilier.

Développer les projets pilotes ayant pour objectif le retour à l'emploi de personnes en congé maladie ou percevant des prestations d'invalidité avec l'aide du service public de l'emploi.

Améliorer l'efficacité des politiques d'évaluation et de prévention des risques psychosociaux.

Supprimer progressivement les abattements fiscaux qui favorisent les travailleurs atypiques. 


\section{Références}

Autor, D., L. Katz et M. Kearney (2006), « The polarisation of the U.S. labour market », American Economic Review, vol. 96, n² 2, http://dx.doi.org/10.1257/000282806777212620.

Bartelsman, E., P. Gautier et J. De Wind (2016), « Employment protection, technology choice, and worker allocation », International Economic Review, vol. 57, $n^{\circ} 3$, http://dx.doi.org/10.1111/iere.12176.

Basselier, R., G. Langenus et L. Walravens (2018), « L'essor de l'« économie du partage », Revue économique de la Banque nationale de Belgique, septembre, https://www.nbb.be/doc/ts/publications/economicreview/2018/revecoiii2018 h3.pdf.

Belloc, F. (2019), « Institutional complementarities between labour laws and innovation », Journal of Institutional Economics, vol. 15, n² 2, doi:10.1017/S1744137418000139.

Bratberg, E. et $\varnothing$. Nilsen (1998), « Transition from school to work: Search time and job duration », IZA Discussion Papers, $\mathrm{n}^{\circ}$ 27, http://ftp.iza.org/dp27.pdf.

Campos, R., J. García-Pérez et I. Reggio (2017), « Moral hazard versus liquidity and the optimal timing of unemployment benefits ", FEDEA Working Papers, $\mathrm{n}^{\circ} 10$, http://documentos.fedea.net/pubs/dt/2017/dt2017-10.pdf.

Carcillo, S. et al. (2019), « Assessing recent reforms and policy directions in France: Implementing the OECD Jobs Strategy », Documents de travail de l'OCDE sur les affaires sociales, l'emploi et les migrations, $\mathrm{n}^{\circ}$ 227, Éditions OCDE, Paris, https://dx.doi.org/10.1787/657a0b54-en.

Card, D., J. Kluve et A.Weber (2018), « What works? A meta-analysis of recent active labour market program evaluations », Journal of the European Economic Association, vol.16, $\mathrm{n}^{\circ} 3$, https://doi.org/10.1093/jeea/jvx028.

Causa, O. et M. Hermansen (2017), « Income redistribution through taxes and transfers across OECD countries ", Documents de travail du Département des affaires économiques, ${ }^{\circ} 1453$, Éditions OCDE, Paris, https://doi.org/10.1787/bc7569c6-en.

Commission européenne (2018), Rapport 2018 pour la Belgique, Bruxelles, https://ec.europa.eu/info/sites/info/files/2018-european-semester-country-report-belgium-fr.pdf.

Commission européenne/EACEA/Eurydice (2015), Éducation et formation des adultes en Europe : élargir l'accès aux possibilités d'apprentissage, Luxembourg, https://publications.europa.eu/fr/publication-detail/-/publication/aaeac7ed-7bad-11e5-9fae01aa75ed71a1/language-fr.

Conseil supérieur de l'emploi (CSE) (2016), Économie numérique et marché du travail, Bruxelles, juin, http://www.emploi.belgique.be/WorkArea/DownloadAsset.aspx?id=45081.

Conseil supérieur de l'emploi (CSE) (2018), Les immigrés nés en dehors de l'UE sur le marché du travail en Belgique, Bruxelles, octobre, http://www.emploi.belgique.be/rapportcseoctobre2018/.

Cournède, B., O. Denk et P. Garda (2016), « Effects of flexibility-enhancing reforms on employment transitions », Documents de travail du Département des affaires économiques, $n^{\circ} 1348$, Éditions OCDE, Paris, http://dx.doi.org/10.1787/bd8e4c1f-en.

De Sloover, F. et Y. Saks (2018), « La polarisation de l'emploi va-t-elle de pair avec celle des salaires ? ", Revue économique de la Banque nationale de Belgique , septembre, https://www.nbb.be/doc/ts/publications/economicreview/2018/revecoiii2018 h4.pdf.

DellaVigna, S. et al. (2017), "Reference-dependent job search: Evidence from Hungary », The Quarterly Journal of Economics, vol. 132, n 4, http://dx.doi.org/10.1093/qje/qjx015.

Deming, D. et L. Kahn (2018), « Skill requirements across firms and labour markets: Evidence from job postings for professionals », Journal of Labour Economics, vol. 36, $\mathrm{n}^{\circ} 1$, https://doi.org/10.1086/694106. 
Desiere, S., K. Langenbucher et L. Struyven (2019), « Statistical profiling in public employment services: An international comparison », OECD Social, Employment and Migration Working Papers, $\mathrm{n}^{\circ}$ 224, Éditions OCDE, Paris, https://dx.doi.org/10.1787/b5e5f16e-en.

Draca, M., R. Sadun et J. Van Reenen (2009), « Productivity and ICTs: A review of the evidence », in C. Avgerou, R. Mansell et D. Quah (dir. pub.), The Oxford Handbook of Information and Communication Technologies, Oxford University Press, http://dx.doi.org/10.1093/oxfordhb/9780199548798.003.0005.

Fernandez, R. et al. (2016), « Faces of joblessness: Characterising employment barriers to inform policy », Documents de travail de l'OCDE sur les affaires sociales, l'emploi et les migrations, $n^{\circ}$ 192, Éditions OCDE, Paris, https://dx.doi.org/10.1787/5j|wvz47xpti-en.

Gal, P. et al. (2019), « Digitalisation and productivity: In search of the holy grail: Firm-level empirical evidence from EU countries », Documents de travail du Département des affaires économiques, $n^{\circ}$ 1533, Éditions OCDE, Paris, https://dx.doi.org/10.1787/5080f4b6-en.

Garda, P. (2016), « The Ins and Outs of Employment in 25 OECD Countries », Documents de travail du Département des affaires économiques, $\mathrm{n}^{\circ} 1350$, Éditions OCDE, Paris, https://doi.org/10.1787/3f9fa009-en.

Goos, M. et A. Manning (2007), «Lousy and lovely jobs: The rising polarisation of work in Britain », The Review of Economics and Statistics, vol. 89, $\mathrm{n}^{\circ}$ 1, http://www.jstor.org/stable/40043079.

Goos, M. et al. (2013), « High-technology employment in the European Union », KU Leuven VIVES, Louvain, https://limo.libis.be/primoexplore/fulldisplay?docid=LIRIAS1826982\&context=L\&vid=Lirias\&search scope=Lirias\&tab=defaul $\mathrm{t}$ tab\&lang=en US\&fromSitemap $=1$.

Goos, M., A. Manning et A. Salomons (2009), « Job polarisation in Europe », American Economic Review, vol. 99, $\mathrm{n}^{\circ}$ 2, http://dx.doi.org/10.1257/aer.99.2.58.

Hijzen et al. (2020), « Lowering employment barriers in Belgium and Norway », Documents de travail de l'OCDE sur les affaires sociales, l'emploi et les migrations, à paraître.

Hijzen, A. et A. Salvatori (2020), « Designing fair and work-oriented unemployment benefits: The case of Belgium », OECD Social, Employment and Migration Working Papers, à paraître.

Hufkens, T. et al. (2017), « Fit for the labour market? An effort to reduce inactivity traps in the transition from benefit to work in the Belgian sickness and disability system », University of Antwerp, Herman Deleeck Centre for Social Policy Working Paper, $\mathrm{n}^{\circ} 11$, http://www.centrumvoorsociaalbeleid.be/sites/default/files/CSBWorkingPaper1711.pdf.

Jacobson, L., R. LaLonde et D. Sullivan (1993), « Earnings losses of displaced workers », American Economic Review, vol. 83, n 4, https://www.jstor.org/stable/2117574.

Jousten, A., M. Lefebvre et S. Perelman (2012), « Disability in Belgium: There is more than meets the eye ", in Wise, D. (dir. pub.), Social Security Programs and Retirement around the World: Historical Trends in Mortality and Health, Employment, and Disability Insurance Participation and Reforms, University of Chicago Press, Chicago, https://www.nber.org/papers/w17114.

Kleinknecht A., F. van Schaik and H. Zhou (2014), "Is flexible labour good for innovation? Evidence from firm-level data ", Cambridge Journal of Economics, vol. 38, Issue 5.

Kolsrud, J. et al. (2018), « The optimal timing of unemployment benefits: Theory and evidence from Sweden », American Economic Review, vol. 108, http://dx.doi.org/10.1257/aer.20160816.

Kuczera, M. (2017), "Striking the right balance: Costs and benefits of apprenticeship », Documents de travail de l'OCDE sur l'éducation, $\mathrm{n}^{\circ} 153$, Éditions OCDE, Paris, https://doi.org/10.1787/995fff01-en.

Lindner, A. et al. (2016), « Frontloading the unemployment benefit: An empirical assessment », IEHAS Discussion Papers, $\mathrm{n}^{\circ}$ 1627, http://econ.core.hu/file/download/mtdp/MTDP1627.pdf. 
Ministère autrichien de la Science, de la Recherche et de l'Économie(2014), Apprenticeship: Dual Vocational Education and Training in Austria Modern Training with a Future, Ministère autrichien de la Science, de la Recherche et de l'Economie, Vienne, https://www.en.bmdw.gv.at/Vocationaltraining/Apprenticeshipsandvocationaltraining/Docum.

Mühlemann, S. (2016), "The Cost and Benefits of Work-based Learning », Documents de travail de I'OCDE sur l'éducation, $n^{\circ}$ 143, Éditions OCDE, Paris, https://doi.org/10.1787/5jlpl4s6g0zv-en.

Nautet, M. et C. Piton (2019), "An analysis of non-standard forms of employment in Belgium », Revue économique de la Banque nationale de Belgique, juin, https://www.nbb.be/doc/ts/publications/economicreview/2019/ecorevi2019 h5.pdf.

OCDE (à paraître), "Labour market transitions in Belgium », document de référence technique.

OCDE (2019a), In-Depth Productivity Review of Belgium, Éditions OCDE, Paris, https://doi.org/10.1787/88aefcd5-en.

OCDE (2019b), Perspectives de l'emploi de l'OCDE 2019 : L'avenir du travail, Éditions OCDE, Paris, https://doi.org/10.1787/b7e9e205-fr.

OCDE (2019c), Perspectives économiques de l'OCDE, Volume 2019 Numéro 1, Éditions OCDE, Paris, https://doi.org/10.1787/0a0e3904-fr.

OCDE (2019d), Getting Skills Right: Future-Ready Adult Learning Systems, Éditions OCDE, Paris, https://doi.org/10.1787/9789264311756-en.

OCDE (2019e), OECD Skills Strategy Flanders: Assessment and Recommendations, Éditions OCDE, Paris, https://doi.org/10.1787/9789264309791-en.

OCDE (2019f), Études économiques de l'OCDE : France 2019, Éditions OCDE, Paris, https://doi.org/10.1787/10f0135f-fr.

OCDE (2019g), Getting Skills Right: Engaging Adults with Low Skills in Learning, Éditions OCDE, Paris, http://www.oecd.org/employment/emp/engaging-low-skilled-adults-2019.pdf/

OCDE (2018a), Des emplois de qualité pour tous dans un monde du travail en mutation : La stratégie de l'OCDE pour l'emploi, Éditions OCDE, Paris, https://doi.org/10.1787/4e6a92fa-fr.

OCDE (2018b), Perspectives de l'emploi de l'OCDE 2018, Éditions OCDE, Paris, https://doi.org/10.1787/g2g9ed68-fr.

OCDE (2018c), Education Policy Outlook 2018: Putting Student Learning at the Centre, Éditions OCDE, Paris, https://doi.org/10.1787/9789264301528-en.

OCDE (2018d), « OECD Skills for Jobs: Belgium Country Note », Éditions OCDE, Paris, https://www.oecdskillsforjobsdatabase.org/data/country notes/Belgium\%20country\%20note.pdf.

OCDE (2018e), OECD Pensions Outlook 2018, Éditions OCDE, Paris, https://doi.org/10.1787/pens outlook-2018-en.

OCDE (2017a), Perspectives de l'emploi de l'OCDE 2017, Éditions OCDE, Paris, https://doi.org/10.1787/empl outlook-2017-fr.

OCDE (2017b), Études économiques de l'OCDE : Belgique 2017, Éditions OCDE, Paris, https://doi.org/10.1787/eco surveys-bel-2017-fr.

OCDE (2015a), "Les compétences numériques : Un investissement vraiment rentable ? », Les compétences des adultes à la loupe, $\mathrm{n}^{\circ} 1$, Éditions OCDE, Paris, https://doi.org/10.1787/5js023qt18d5-fr.

OCDE (2015b), Perspectives de l'OCDE sur les compétences 2015, Éditions OCDE, Paris, https://doi.org/10.1787/9789264235465-fr.

OCDE (2015c), Perspectives de l'emploi de l'OCDE 2015, Éditions OCDE, Paris, https://doi.org/10.1787/empl outlook-2015-fr.

OCDE (2015d), Études économiques de l'OCDE : Belgique 2015, Éditions OCDE, Paris, 
$54 \mid$ ECO/WKP(2020)10

https://doi.org/10.1787/eco surveys-bel-2015-fr.

OCDE (2013a), Perspectives de l'emploi de l'OCDE 2013, Éditions OCDE, Paris, https://doi.org/10.1787/empl outlook-2013-fr.

OCDE (2013b), Santé mentale et emploi : Belgique, Santé mentale et emploi, Éditions OCDE, Paris, https://doi.org/10.1787/9789264187597-fr.

OCDE (2010), Formation et emploi : relever le défi de la réussite, Examens de l'OCDE sur l'éducation et la formation professionnelles, Éditions OCDE, Paris, https://doi.org/10.1787/9789264087491-fr.

Saks, Y. (2017), « Mieux comprendre l'évolution du nombre de bénéficiaires de l'assuranceinvalidité », Revue économique e la BNB, septembre, https://www.nbb.be/doc/ts/publications/economicreview/2017/ecorevii2017 h5.pdf.

Schwellnus, C. et al. (2018), « Labour share developments over the past two decades: The role of technological progress, globalisation and « winner-takes-most » dynamics », Documents de travail du Département des affaires économiques, $n^{\circ} 1503$, Éditions OCDE, Paris, https://doi.org/10.1787/3eb9f9ed-en.

Service Public Fédéral Emploi, Travail et Concertation Sociale (2011), Évaluation de la législation relative à la prévention de la charge psychosociale occasionnée par le travail, dont la violence et le harcèlement moral ou sexuel au travail, Bruxelles.

Service Public Fédéral Emploi, Travail et Concertation Sociale (2017), Rapport sur la Concertation Sociale Sectorielle 2017, Bruxelles.

Syntra Vlaanderen (2017), " Duaal Leren ", Werkplek Duaal website

Syverson, C. (2011), « What determines productivity? », Journal of Economic Literature, vol. 49, http://dx.doi.org/10.1257/jel.49.2.326.

Wulfgramm, M. et L. Fervers (2013), « Unemployment and subsequent employment stability: Does labour market policy matter? », IZA Discussion Paper, n 7193, http://ftp.iza.org/dp7193.pdf. 